\title{
HOUSEHOLD ENERGY USE IN NEW ZEALAND: THE CHANGING ROLE OF TELEVISIONS
}

\author{
By \\ Marion R Pahalawatta \\ Thesis \\ ENVIRONMENTAL STUDIES 593 \\ 2010
}

A 90 point thesis submitted to Victoria University of Wellington, as partial fulfilment for the degree of Master of Environmental Studies

School of Geography, Environmental and Earth Sciences

Victoria University of Wellington

December 2010 


\title{
HOUSEHOLD ENERGY USE IN NEW ZEALAND:THE CHANGING ROLE OF TELEVISIONS
}

\author{
Marion R Pahalawatta
}

\begin{abstract}
Energy efficiency plays a major role in policies to mitigate climate change and to secure future energy supply. Understanding energy use behaviour and appliance energy use is vital to policy design. The drivers of energy use in household sector are complex. Households use energy for comfort, health and entertainment in contrast to, the uses of energy for making a profit in industrial and commercial sectors. As a part of this study a model was developed identifying the major drivers of household energy use.

Household income and behaviour, house size, appliance technology and appliance energy efficiency are few factors that can influence household energy consumption patterns. Many OECD countries have managed to restrain traditional household energy end-uses such as space and water heating. However, IEA studies have indicated energy used by information, communication and entertainment appliances continue to increase. Television energy use was chosen for this study because it is widely used and operates together with many other associated appliances. This analysis draws from the New Zealand Television Energy Usage and Purchasing Survey to understand the current trends and patterns of television usage. The survey suggests television and associated appliance ownership and usage is increasing. Analysis draws from the survey to quantify TV energy use in New Zealand. This study illustrates how household behaviour, technology and size affects household energy use. The survey also demonstrate how households associate energy use with environmental impact. Some OECD data on household energy was used to analyse and contrast New Zealand's patterns in a wider context.
\end{abstract}

Key words: televisions, household energy use, household energy using behaviour, appliance energy efficiency, technology, OECD 


\section{Acknowledgements}

Firstly, I would like to express my deepest and sincere gratitude to my supervisor, Ralph Chapman for his guidance, advice, support, encouragement and patience. This thesis would not have been accomplished without the tremendous assistance and funding from Energy Efficiency and Conservation Authority and the commitment of the colleagues working there. In particular, I thank my manager, Robert Tromop, for encouraging and supporting me throughout the study. My thanks also go to Harbans Aulakh for sharing his wisdom, knowledge and experience on energy use and statistics. I am grateful to Sea Rothman for her generous allocation of time for critiquing my writings and providing reference materials. The New Zealand Energy Usage and Purchasing Survey, which generated original information for the study, would not have been possible without the invaluable assistance of Laura Christen and Terry Collins. I thank Hamish Trulove and Paul Halford for their assistance in various forms to complete the study. Thanks also go to our close friend Sunil Abeyratne for proofreading. I would also like to thank my parents and grandparents for fostering a value for learning. My heartfelt thanks go to my loving husband and daughter for their invaluable support and unending patience. 


\section{Contents}

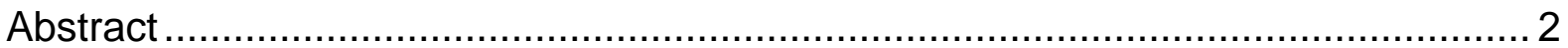

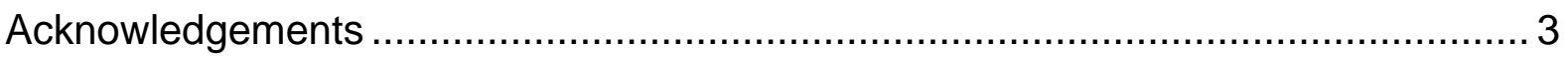

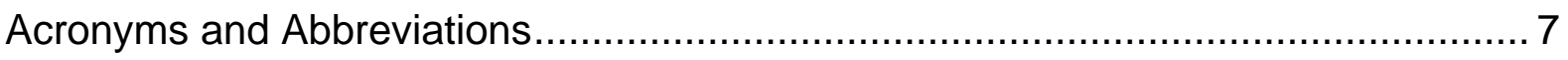

Chapter 1: Energy Demand in New Zealand, and the OECD Context ................... 8

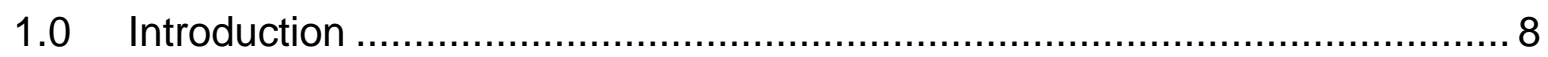

1.1 Where is energy used? Trends in energy consumption in the OECD and

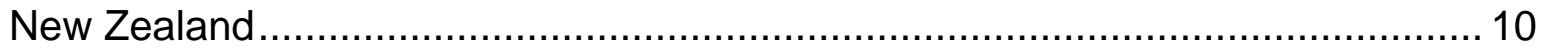

1.2 Household sector energy use ........................................................ 14

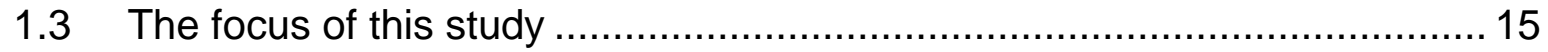

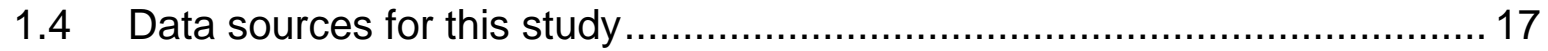

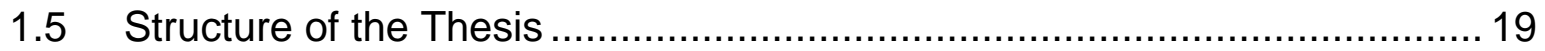

Chapter 2: Household Energy Use - Background Analysis and literature Survey ... 21

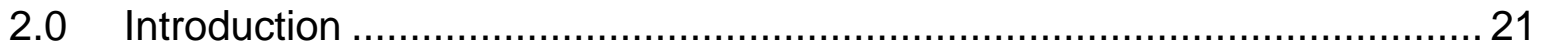

2.1 Factors Influencing Overall Energy Use ............................................. 21

2.1.1 Household choices, preferences and behaviour .............................23

2.1.2 Main energy end-use studies in NZ ....................................... 26

2.1.3 New Zealand residential sector energy end-use profile ...................... 26

2.1.4 Energy Affordability ......................................................... 28

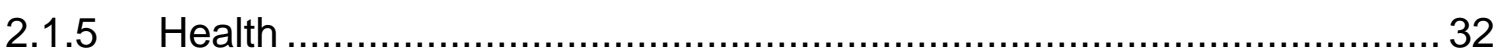

2.1.6 Housing Tenure .................................................................. 32

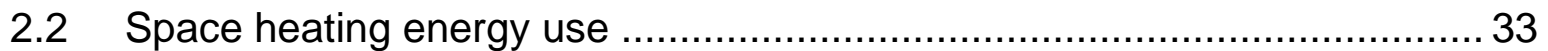

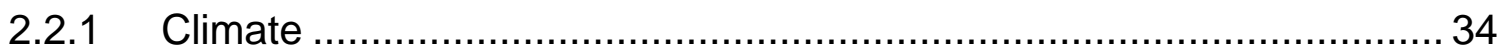

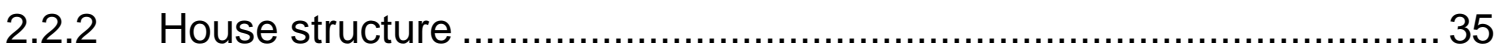

2.2.3 Fuels used for space heating ..................................................... 37 


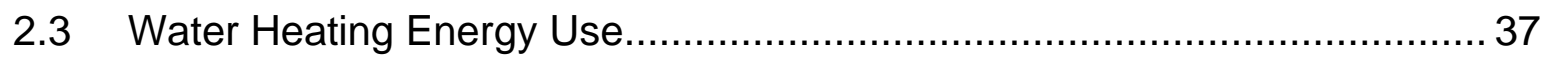

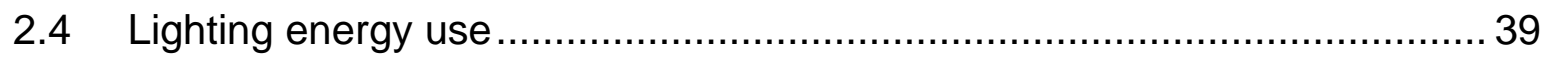

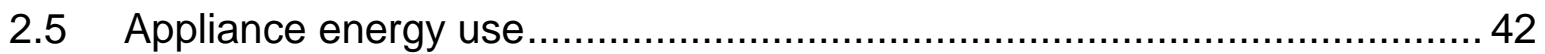

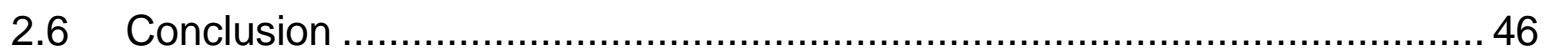

Chapter 3: Modelling the Drivers of Energy Use ............................................... 48

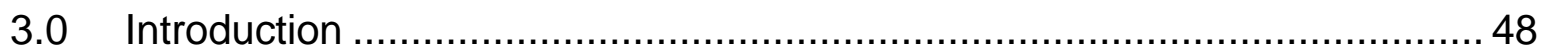

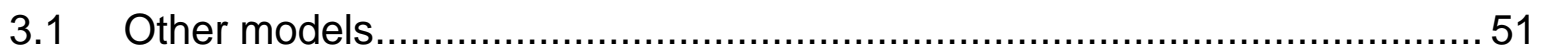

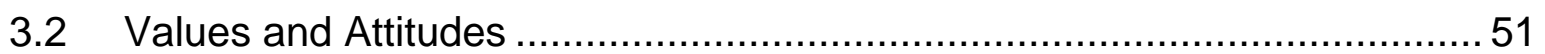

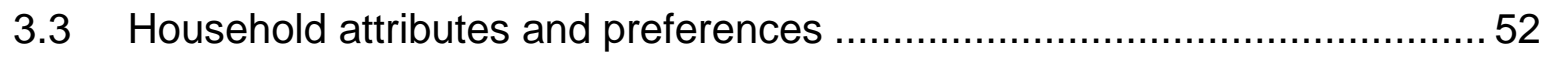

3.4 Household income, energy price, housing tenure and government income

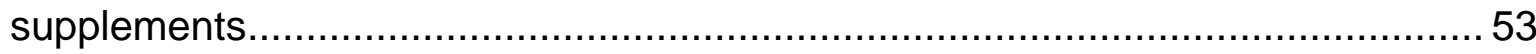

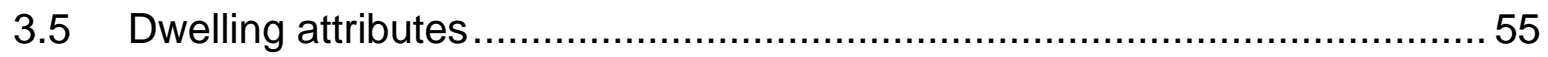

3.6 Government policies and information diffusion...................................... 58

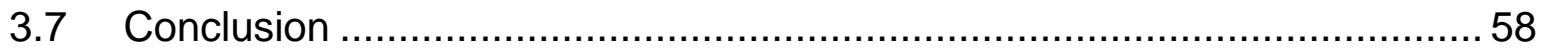

Chapter 4 - Benchmarking New Zealand's Energy Use against Similar Economies60

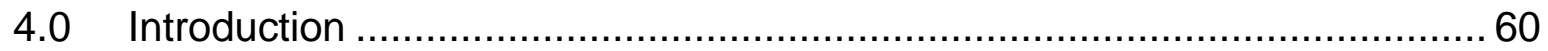

4.1 Criteria for Benchmarking Selection .................................................... 61

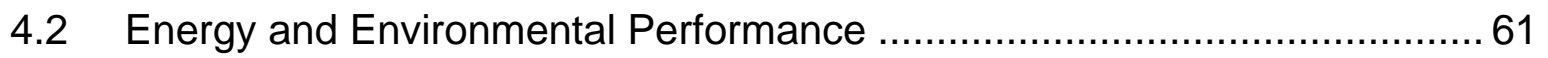

4.2.1 Proportion of renewable in Energy Supply and GDP ..........................62 62

4.2.2 Total Primary Energy Supply and GDP ...........................................63

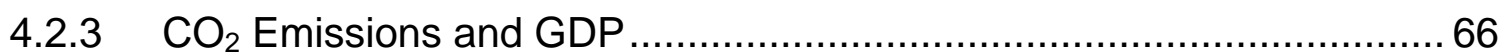

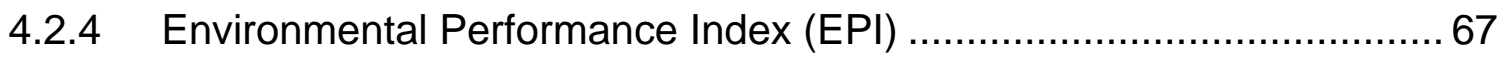

4.3 Overview of Countries selected for Benchmarking ....................................69

4.4 Changes in household sector end-use .............................................. 72

4.4.1 Changes in space heating energy use ……................................... 72

4.4.2 Changes in water heating energy use .......................................... 73

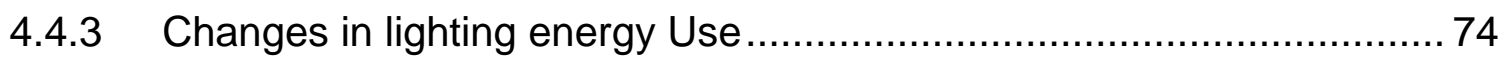

4.4.4 Changes in household appliances energy use ................................... 75 


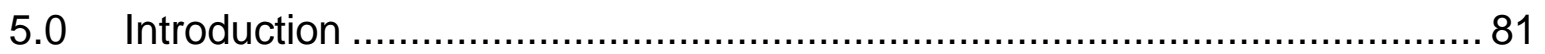

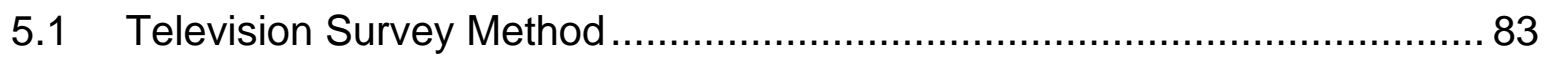

5.2 Survey Approach and Hypotheses.......................................... 84

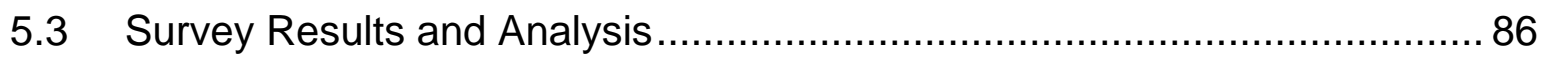

5.3.1 New Zealand TV Stock Profile ................................................ 86

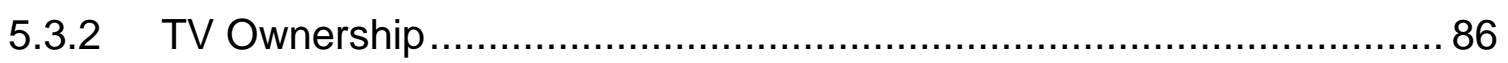

5.3.3 Size Distribution of Television Stock.......................................... 87

5.3.4 Technology Distribution of TV Stock........................................... 89

5.3.5 The Age Distribution of the TV stock .......................................... 91

5.3.6 Television use by type of activity ............................................... 92

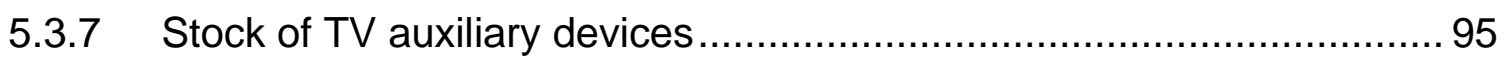

5.3.8 Energy Use of New Zealand TV stock ........................................ 98

5.3.9 Factors Influencing Purchasing Decisions ................................ 102

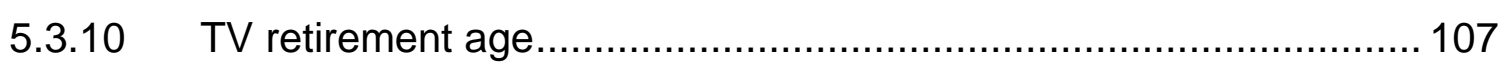

5.4 Comparisons of New Zealand survey results with International data on

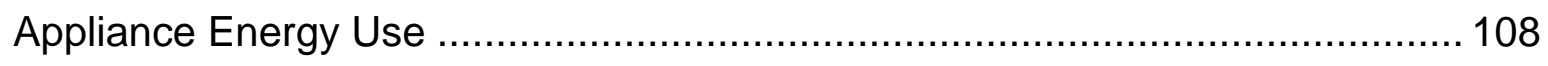

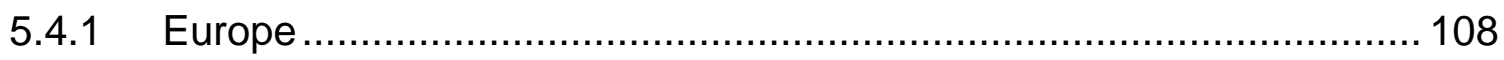

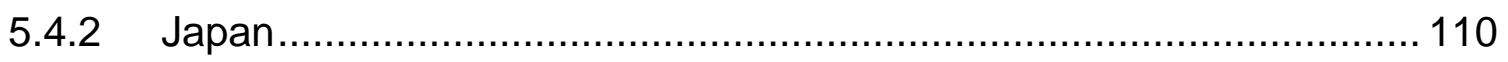

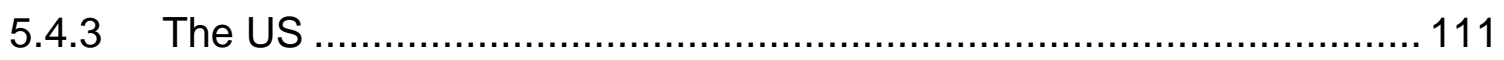

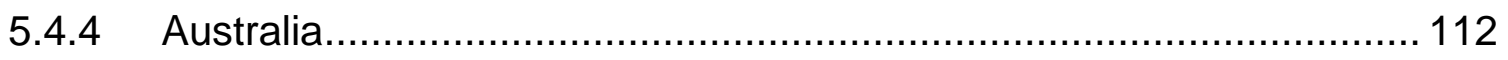

5.5 Implications for Future Household Sector Electricity Use..................... 113

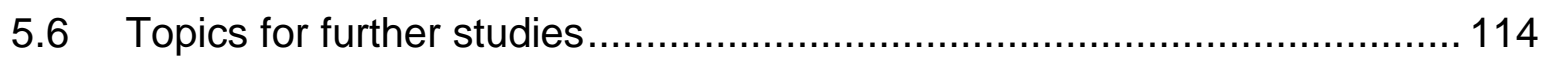

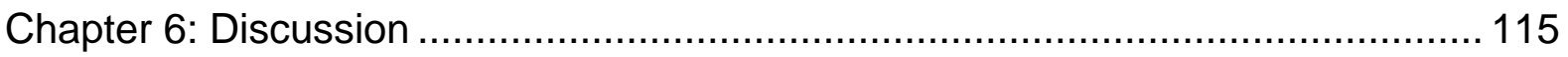

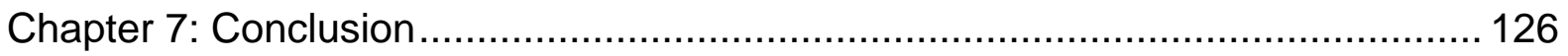

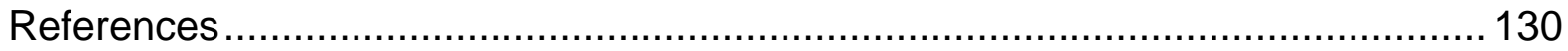




\section{Acronyms and Abbreviations}

CE

CRT

EDF

EECA

EEUDB

GDP

HEEP

HES

ICT

IEA

IPCC

MEPS/L

OECD

SNZ

TPES
Consumer Electronics

Cathode Ray Tube

Energy Data File

Energy Efficiency and Conservation Authority

Energy Efficiency and Conservation Authority's Energy End Use Database

Gross Domestic Product

Household Energy End-use Project

Household Economic Survey

Information and Communication Technology

International Energy Agency

Intergovernmental Panel for Climate Change

Minimum Energy Performance Standards and Labeling regulation

Organisation for Economic Co-ordination and Development

Statistics New Zealand

Total Primary Energy Supply 


\section{Chapter 1: Energy Demand in New Zealand, and the OECD Context}

\subsection{Introduction}

Many people in developed countries, including New Zealand, believe that accessibility to energy is a basic right and is fundamental to access many services provided in a modern society. Such beliefs are evident in the comments made by the general public in the media during or after a power failure (Blackwell,2009). Availability, accessibility and affordability of energy are usually closely associated with the level of development of a country.

All countries use fossil fuels for transport and to generate electricity and heat. They are also used as a back-up source of energy supply when there is a shortfall of energy from renewable energy sources. This is the case whether or not the country has its own fossil fuel resources. If a country depends on fossil fuels, it needs to consider several factors.

First and foremost, it is very likely that anthropogenic greenhouse gas emissions produced by burning fossil fuels are a major cause of climate change (Dincer and Rosen, 1999; Intergovernmental Panel on Climate Change,2007; Hansen, Sato et al.,2008). Greenhouse gas emissions increase the global average temperature, which is likely to have a wide range of effects, including significant altering of the services received from ecosystems (Rockström, Steffen et al.,2009). The Fourth Assessment Report of the IPCC suggests that, unless world greenhouse gas emissions are reduced by at least $60-85 \%$ by 2050 , it may not be possible to avoid a global temperature rise of $2^{\circ} \mathrm{C}$ above the pre-industrial level (Stern,2006). More recent work suggests that almost $2^{\circ} \mathrm{C}$ of warming (relative to the pre-industrial era) is already 'in the pipeline', i.e. close to unavoidable (Schellnhuber,2008). These projections imply that there will be intense pressure on all developed countries to reduce greenhouse emissions, including those from fossil fuels, in the next decade and beyond. 
In the year 2000, $74 \%$ of global greenhouse gas emissions were from energy (Mackay,2009). By comparison, in 2006, energy-sector greenhouse gas emissions in New Zealand were estimated to be responsible for only $44 \%$ of total greenhouse gas emissions (Ministry for the Environment,2008). There is clearly potential to reduce these emissions globally, including in New Zealand.

A second issue is the political instability of major oil-producing countries (Correlje \& van der Linde, 2006), together with the likelihood that liquid oil supplies will become gradually scarcer in coming decades (Hirsch,2005; Brecha 2008). Even New Zealand, with its ample renewable energy resources, is heavily dependent on energy imports, and uses diesel to generate electricity at Whirinaki to enhance the security of energy supply. New Zealand, like other countries, aims to develop indigenous primary sources of energy to reduce dependency on imported energy, which continues to put at risk its security of energy, supply (MED, 2007).

A related third issue is the environmental damage from coal use. Some $40 \%$ of world electricity is generated from coal (OECD, 2009). The coal fields are vast (Energy Information Agency,2008; Hansen, Sato et al.,2008) but development and on-going operation of these fields significantly damage the environment Kettering (2001) as well as presenting high future risks to the climate system, as mentioned above. Some have argued that, if coal use was not managed prudently, coal may become depleted before sufficient quantities of affordable alternatives become available, but this seems unlikely (Hansen, Sato et al.,2008).

A fourth issue is the impact of air quality on health, arising from fossil fuel use. The key air pollutants that affect health are particulates (mainly in the form of $\mathrm{PM}_{10}$ ), carbon monoxide, nitrogen dioxide and benzene. Emissions from internal combustion engines are regarded as a major cause of these emissions (Fisher et al, 2007). The study by Fisher et al shows $73 \%$ of New Zealand's population is affected by poor air quality.

Conversion of any primary energy source to a form that is useable produces adverse environmental effects. Because of this, and also because of the other risks and uncertainties around fossil fuel use outlined above, most countries promote demand 
side strategies such as energy conservation and efficiency measures in all sectors of the economy. These include incentives and subsidies for accelerated adoption of new technology, and information campaigns and rewards for behaviour change (Abrahamse, Steg et al.,2007).

The total of renewable and non-renewable energy available for a country constitutes the Total Primary Energy Supply (TPES). Even though renewable energy resources such as hydro, geothermal, wind, bioenergy and solar replenish naturally, there are limitations to the development of these resources. Wind and solar can be harvested without many adverse environmental effects if consideration is given to minimising environmental effects during the development phase. However, the availability of primary energy sources such as hydro, geothermal and bioenergy is finite and these sources must be developed in a sustainable manner ${ }^{1}$. Development of wind farms, hydro dams and geothermal sites can produce adverse environment effects including loss of landscape, habitat, and loss of biodiversity.

In summary, rising energy demand, energy supply difficulties and environmental constraints in New Zealand all point to the growing need to be prudent with the use of energy. Section 1.2 discusses energy demand in more detail.

\subsection{Where is energy used? Trends in energy consumption in the OECD and New Zealand}

Normally as a country develops, demand for energy increases. Between 1997 and 2007, gross domestic product (GDP) in OECD countries increased by 63\% (adjusted for 2007 prices). TPES in the OECD increased by 10\% from 1997 (213,284 PJ) to 2007 (234,067 PJ) (OECD,2009). Over this decade energy intensity in the OECD declined from 6.5 MJ/NZ $\$$ to $4.3 \mathrm{MJ} / \mathrm{NZ} \$^{2}$ (2007 prices) indicating improvements in energy efficiency and conservation measures. Even though energy use has increased it has risen significantly more slowly than the increase of GDP, indicating some weak decoupling of energy from GDP. During this period, net export of goods

\footnotetext{
${ }^{1}$ Such as balancing with water for crop cultivation and recreational activities or land subsidence if a large amount of steam is extracted from geothermal sites or loss of nutrients from forests if too much biomass residue is extracted

${ }^{2}$ Equivalent to 0.21 to 0.14 Mtoe/US billion $\$$
} 
declined and net exports of services increased in OECD countries OECD (2009). Even though this may suggest a shift from high energy intensive manufactured products to less energy intensive services, it may also indicate an increased consumption of imported goods.

By comparison to these general OECD trends, New Zealand's total primary energy supply, TPES (gross) increased from 722 PJ in 1997 to 752 PJ in 2007, which is an increase of $4 \%$. In that period New Zealand's GDP increased by $37 \%$. The energy intensity of the economy therefore declined from $3.4 \mathrm{MJ} / \mathrm{NZ} \$$ to $3 \mathrm{MJ} / \mathrm{NZ} \$$, indicating improvements in energy efficiency and conservation measures. It suggests energy use was weakly decoupled from GDP in the NZ economy over this period. In the same period, the net export of goods fell and net export of services increased showing a structural change in the New Zealand economy similar to other OECD countries.

During the same period, in OECD countries, energy obtained from fossil fuels increased from $67 \%$ to $69 \%$ of TPES and renewables decreased from $33 \%$ to $30 \%$. In contrast to many other OECD countries, New Zealand generates a high proportion of its electricity from renewable sources, mainly from hydro ${ }^{3}$. Hydro, geothermal, coal and natural gas are used both as primary energy sources in New Zealand to generate electricity and a backup source when other intermittent primary sources such as wind fail to satisfy the unmet demand.

The discovery of natural gas resources at the Maui field in 1969 meant that the NZ electricity generation industry did not have to keep developing new hydro electricity generation stations for a long period, although pressure to do so has now resumed, as the Maui field has been largely depleted.

Recently, electricity generation companies have been seeking resource consents to develop wind and geothermal resources as well as hydro. This interest was mainly driven by increasing electricity demand, increasing public concern for climate change, the depletion of the Maui gas field and increasing oil, electricity and gas prices. However, the public are becoming more aware of the adverse effects on the

\footnotetext{
${ }^{3}$ Only Norway and Iceland produce a higher proportion of their electricity from hydro than New Zealand, in the OECD.
} 
environment (and sometimes on local cultural values) caused by developing some renewable energy resources. Large-scale wind and hydro developments are often opposed by local communities (Barry and Chapman,2009).

Electricity generation stations need to be planned ahead to satisfy growing demand. Most projects have a long development lead time of several years, partly because of the complexity of the technology involved, and partly because the Resource Management Act 1991 requires that adverse effects on the environment are taken into account and avoided, remedied or mitigated.

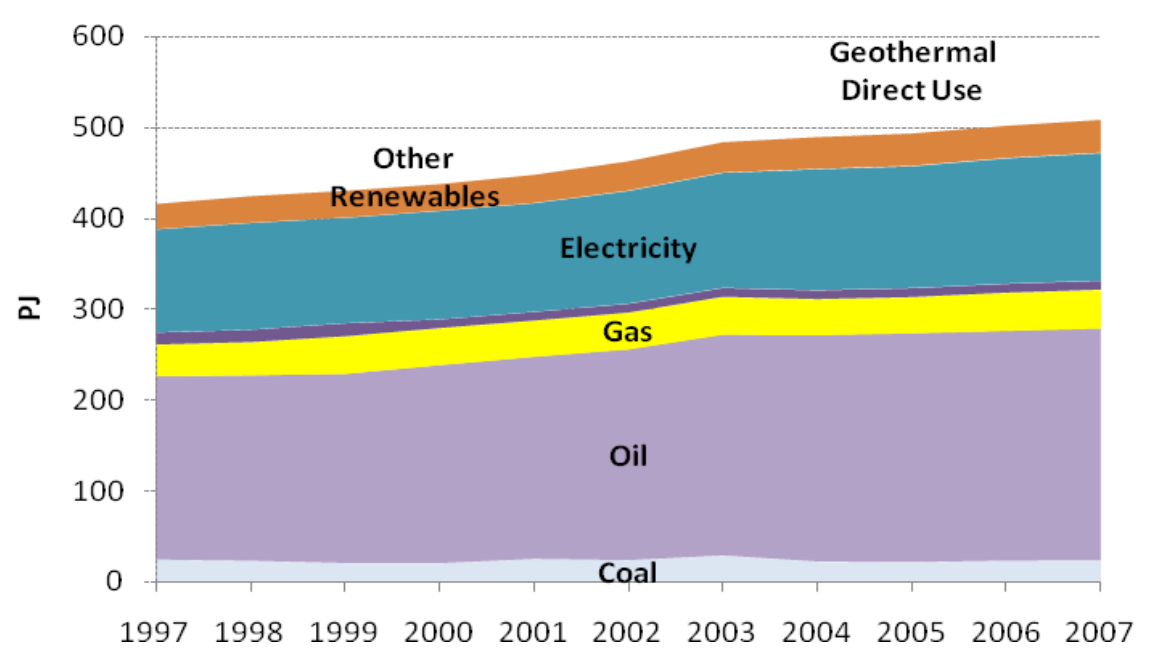

Figure 1: New Zealand's Total Consumer Energy Use by Fuel 1997 - 2007

Figure 1 shows the changes in New Zealand's consumer energy use (after losses in conversion and distribution) by fuel type between 1997 and 2007. Total consumer energy (TCE) increased by 22\% between 1997 (416 PJ) and 2007 (508 PJ). TPES increased at a slower rate than TCE, indicating an increase in efficiency of energy conversion and use.

Electricity use in New Zealand increased by 24\% from 1997 (114 PJ) to 2007 (141 PJ). This is slightly faster than total consumer energy use. Use of other renewable energy forms (including bio gas and wood) increased by $30 \%$. In the same period, oil and gas consumption increased by $27 \%$ and $22 \%$ respectively. Geothermal direct use and coal consumption decreased by $26 \%$ and $3 \%$ respectively. Solar energy is becoming more popular owing to a government grant scheme, public awareness of climate change and increasing energy prices. In the year 2008, (not shown in figure 
1) energy use from solar in the household sector was very close to energy produced from coal.

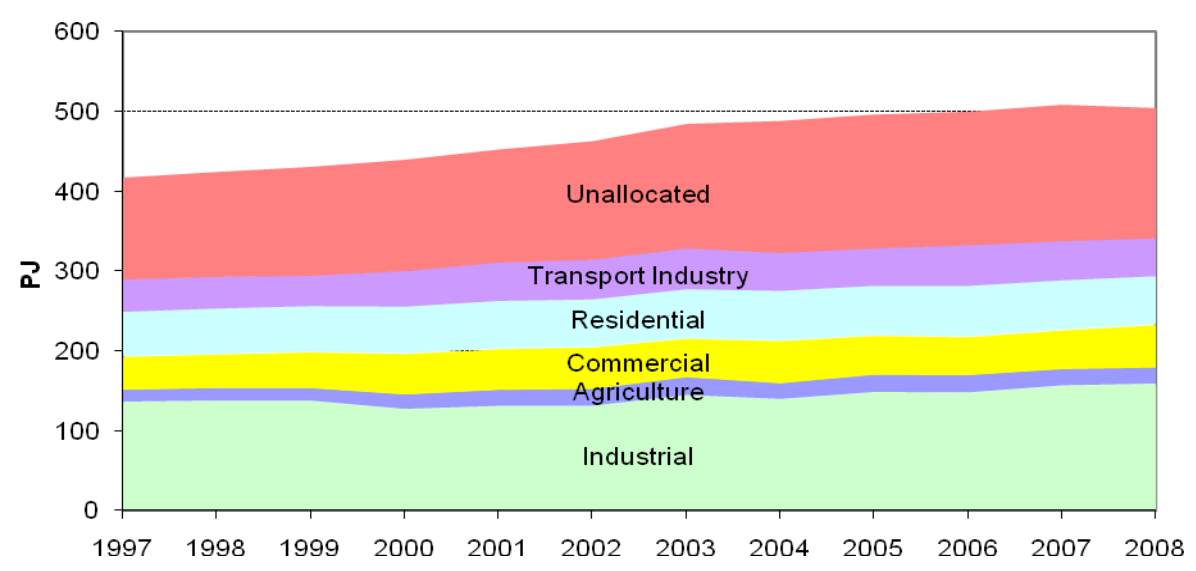

Figure 2: Changes in New Zealand's sectoral energy use between 1997 and 2008

Figure 2 shows sectoral energy consumption between 1997 and 2008. The agriculture sector had the highest increase of $36 \%$, off a small base. This was followed by the transport industry (21\%), commercial (18\%), industrial (15\%) and residential ${ }^{4}(11 \%)$.

Unallocated energy is fuel sold through all service stations and other delivery services. It includes sales to residential (domestic transport, lawn mowing, boats etc.), commercial (service vehicles, marina refuelling facilities etc.) and agriculture (farm delivery services). Unallocated energy use increased by $34 \%$ during the same period $^{5}$.

New Zealand generates electricity from renewables and non-renewables, with the proportion varying from wet years to dry years, and the renewable proportion falling over time. In 1997, 71\% of electricity was generated from renewable sources compared to $67 \%$ in $2007,67 \%$. The fuels used to generate electricity include hydro (55\%), gas (26\%), geothermal (8\%), coal (7\%) and the rest from wind, wood, biogas,

\footnotetext{
${ }^{4}$ Note: residential sector and household sector are interchangeable.

${ }^{5}$ It is currently difficult to disaggregate these sales to different sectors and therefore the Ministry of Economic Development has initiated a study to more accurately allocate energy use across sectors.
} 
oil and waste heat. Since almost all electricity generated is fed into same transmission and distribution networks, it is not possible to separate renewable and non-renewable portions of electricity use at sector level.

\subsection{Household sector energy use}

Between 1997 and 2007, household sector energy use in New Zealand increased from 55.7 to $61.9 \mathrm{PJ}$, or $11 \%$. Electricity use increased by $15 \%$; geothermal use was constant; coal use decreased by $3 \%$; gas use rose by $13 \%$; and wood use fell by $3 \%$. Data on wood use is less reliable, because of informal gathering of wood and poor estimation of wood use. Solar energy was not represented in 1997 but by 2007 it generated around one third of a PJ. ${ }^{6}$

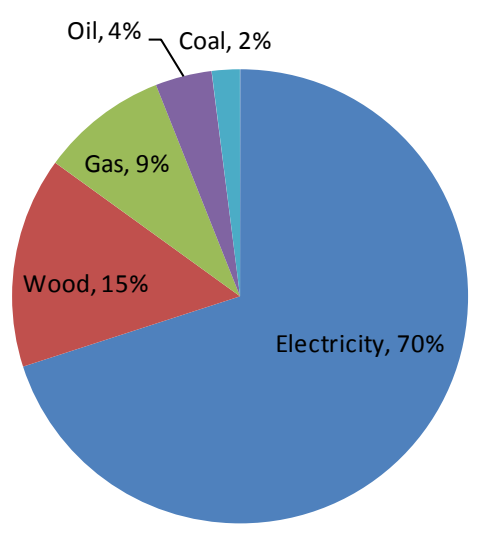

Figure 3: Fuel mix in New Zealand household sector energy use, 1997 Source: Ministry of Economic Development

Figure 3 shows the proportion of fuel types (percentages of total PJ) used in the household sector in 1997. Figure 4 shows the proportion of fuel types used in the household sector a decade later, in 2007. Even though absolute energy use in the household sector increased from 1997 to 2007, the proportions in the fuel mix remained steady for all fuels except for electricity, wood and coal. During the last ten years the proportion of electricity increased by $2 \%$ points, wood decreased by $2 \%$ points, and coal fell $1 \%$ point, indicating a shift from wood and coal to electricity.

\footnotetext{
${ }^{6} 1$ PetaJoule $=10^{15}$ Joules
} 
Possible reasons for this change are restricted use of open fires for some areas owing to air quality issues, and the increasing popularity of heat pumps.

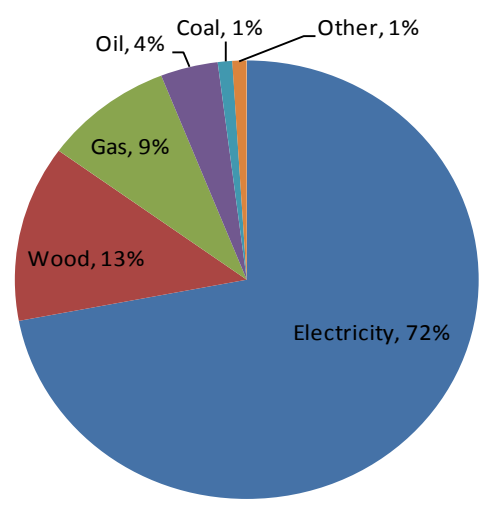

Figure 4: Fuel mix in New Zealand household sector energy use, 2007 Source: Ministry of Economic Development

The increase in household energy use was driven in part by the increasing number of households, with households on average becoming slightly smaller. From 1997 to 2007 , the number of households increased by $16 \%$ but the average household size decreased from 2.8 to 2.7. The number of permanent private occupied dwellings increased from 1.4 million to 1.6 million (or an increase of 14\%) compared to the increase of population from 3.8 million to 4.2 million (or an increase of $11 \%$ ). Household sector energy use per person was around $14.8 \mathrm{GJ}$ in 1997; it increased to 15.5 GJ in 2001 and declined to 14.7 GJ in 2007 ; essentially, then, it was stable over the decade. Household sector energy use per household was around $41.5 \mathrm{GJ}$ in 1997, increased to $42.3 \mathrm{GJ}$ in 2001 and declined to $39.7 \mathrm{GJ}$ in 2007 , apparently reflecting the shrinkage in number of people per household. Notwithstanding an effectively stable energy use per person in combination with a marginal reduction of energy use per household, the trend in overall household energy use is upward. Such an overall growth in household energy use was driven by the growth of population and the number of households.

\subsection{The focus of this study}

The energy consumption of a household depends on the ownership, efficiency and use of appliances that consume energy. However, each household's behaviour is 
unique and significantly influences the household's energy consumption. This uniqueness makes the estimation of future household sector energy use complex.

Overseas studies have identified that energy use in household small appliances is on the rise (International Energy Agency,2007). UK projections (Owen,2006; Owen,2007) show increasing trends for energy use in information, communication and entertainment devices.

New Zealand household sector energy use was unexplored for a long time until the Household Energy End-use Project (HEEP), begun in the mid-1990s provided an energy profile of an average New Zealand house. Even though the study was fairly comprehensive for owner-occupier households, it did not capture the energy profile of rental households, heat pump energy use, trends in consumer electronics and the impact of behaviour on climate change.

A metered energy use study on heat pump and entertainment devices in households is being currently developed and conducted by the Building Research Association of New Zealand (BRANZ) to address these gaps. The study is still in its initial stages and the results will not be available in time to be considered in this thesis.

The central focus of this study is to address gaps in understanding of household appliance demand and associated household energy use in New Zealand. I focus on one appliance, televisions, because TVs are regularly used appliances (on average, households leave their TVs switched on for about 50 hours a week) and because TV ownership has been growing in New Zealand (details are set out in chapter 5).

To collect richer data on television use, including the energy needs of television use, a television ownership and purchasing survey was conducted in New Zealand. Furthermore, this data collection enabled the investigation of trends in television and TV auxiliary device ownership and their use in New Zealand, to determine whether such trends align with, lead or lag behind other countries. TV auxiliary devices are defined as devices that use a television set to function. Findings from this survey are used in this thesis to estimate the proportion of energy consumed by televisions 
in the household sector. It also provides data to compare the changing patterns and trends of household energy use with countries similar to New Zealand.

At a later stage, these findings of the survey and the results of a planned BRANZ study are likely to feed into a model, developed by the New Zealand Energy Efficiency Conservation Authority (EECA), of the drivers and impacts of household behaviour in respect of entertainment device energy use. The survey will also provide information for EECA's household energy efficiency potential model and support a review of the Minimum Energy Performance Standards and Labelling (MEPS/L) regulations.

\subsection{Data sources for this study}

The main background data source for this thesis study was the New Zealand Energy Data File (EDF). The EDF continually changes with international reporting requirements, improvements in data collection, new sectoral surveys and other improvements. Data are reviewed and updated continuously and may change from year to year. EECA's Energy End-Use database (EEUDB) was used to examine the changes in sectoral energy end use. The EEUDB was created using a top-down allocation applied to energy statistics in the EDF. The most recent version (year ending March 2007) of the EEUDB uses findings from the Household Energy Enduse Project (HEEP) to allocate household energy end-use.

Statistics New Zealand ${ }^{7}$ provides economic performance and demographic data for New Zealand. The dwelling and population statistics estimated by Statistics New Zealand were used for the analysis (census statistics are not considered appropriate as they do not include households that are temporarily absent within New Zealand or moved overseas on census night). Household sector permanent private occupied dwellings and corresponding populations were approximated using the 2006 Census. Household and commercial sector dwellings are separated to align with household and commercial sector energy use in the EDF.

\footnotetext{
${ }^{7}$ http://www.stats.govt.nz/
} 
Statistics from the Organisation for Economic Co-ordination and Development (OECD) were used to understand international demographic, economic and energy trends. Detailed energy performance data from OECD countries were available from the International Energy Agency (IEA) ${ }^{8}$ and its energy indicator studies.

Standardised OECD country statistics were utilised for comparisons of countries.

Data from the HEEP mentioned above (Isaacs, Camilleri et al.,2006) were used to examine changes in the proportion of household energy end-uses over time. The HEEP data identified gaps in fuel use and corrected for the understatement of space energy sourced from free firewood and coal in households, to correct the EDF data. However, heat pump space heating technology was under represented in the HEEP house sample especially with the rapid recent increase of heat pump use in New Zealand (French ,2008) ${ }^{9}$. The HEEP survey is also not fully representative of the range of dwelling tenures in New Zealand, and under-represents rental housing.

Most of the large appliances such as refrigerators, freezers, dishwashers, clothes washing machines and clothes dryers are regarded as essential items in modern developed societies. Large appliance data were collected by EECA under Minimum Energy Performance Standards and Labelling (MEPS/L) regulation.

Although Statistics New Zealand has collected ownership details on large appliances in the past, it is not clear whether these appliances were in working order, nor was information collected on the frequency of their use. Access to this data was discontinued after the 2004 Household Economic Survey (HES). There is almost no data on information, communication and entertainment devices, especially on the way they are used ${ }^{10}$.

As a part of this thesis, a survey was initiated to understand the way televisions are used in households and the way this impacts on households' energy use. The survey was funded by EECA and the findings will be used to develop mechanisms to

\footnotetext{
${ }^{8} \mathrm{http}: / /$ www.iea.org/stats/index.asp

${ }^{9}$ A new HEEP is underway as of late 2009 , with a focus on heat pump to close this data gap.

${ }^{10}$ To bridge this gap, a new HEEP survey will be gathering data on the way households use home entertainment devices through an end use metering survey.
} 
reduce television and associated appliance energy use in households ${ }^{11}$. Even though other communication and entertainment devices were not studied, this survey shows the major trends in new appliance technology adoption and penetration in NZ households and the implications for future energy use.

\subsection{Structure of the Thesis}

Figure 5 shows the structure and the interrelationship of different chapters in the thesis.

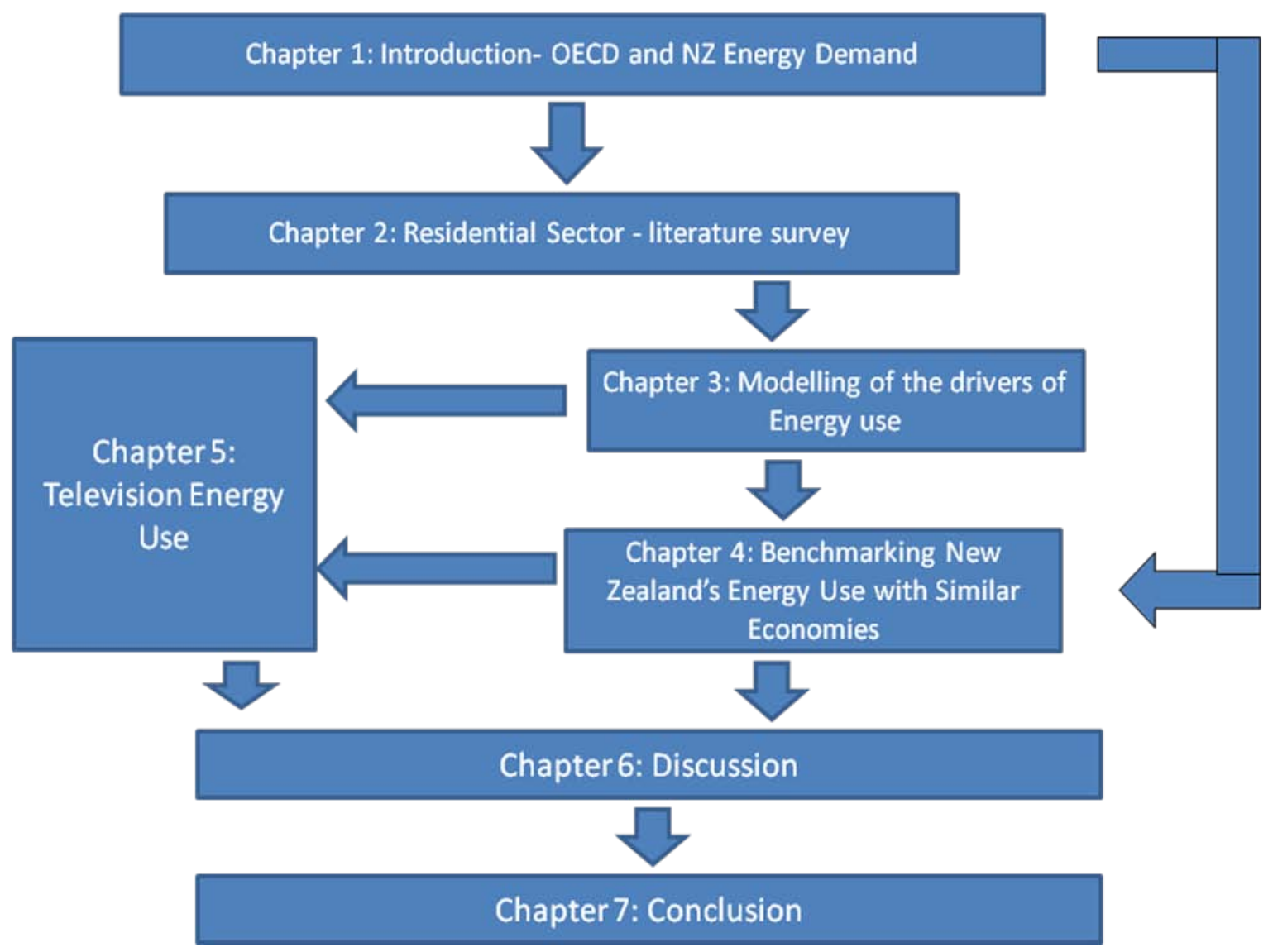

Figure 5: Chapter overview of the thesis

Chapter 1 has discussed the economy-wide picture of escalating energy use, highlighting key trends and patterns. It has also provided an introductory overview of household sector energy use in OECD and New Zealand. A comprehensive literature survey of household sector energy use is provided in chapter 2. A detailed

\footnotetext{
${ }^{11}$ At that time the author was working for Energy Efficiency and Conservation Authority (EECA) and led the team in designing and developing the TV Usage and Purchasing Survey.
} 
model is developed in Chapter 3 to explain the interaction between different drivers of household energy use. In Chapter 4, New Zealand is benchmarked against comparable countries in the OECD, in terms of household energy use. Chapter 5 examines the energy use trends of televisions (TVs) and TV auxiliary devices, using available data as well as data from a TV purchase and usage survey conducted by the author and EECA. The results from chapters 2, 3, 4 and 5 are consolidated and discussed in Chapter 6. Chapter 7 concludes the study by identifying trends and potential for growth in household sector energy consumption. 


\section{Chapter 2: Household Energy Use - Background Analysis and literature Survey}

\subsection{Introduction}

Energy is used by households to provide a comfortable and healthy indoor living environment, to reduce the effort required to perform everyday tasks and for communication and entertainment. In this respect the major end-uses are heating and cooling of space, water heating, lighting and powering appliances. Household energy use depends on ownership of dwellings and appliances, their efficiency, frequency of operation, characteristics of households, and occupants' preferences and behaviours.

This study focuses only on direct household stationary energy use. It excludes indirect energy consumption (e.g. embedded energy) as well as energy use for domestic transport. Stationary energy accounts for approximately half of total household energy consumption, whereas indirect energy consumption accounts for the rest (Reinders, Vringer et al.,2003). A study of household energy dynamics in relation to end-uses is critical for clearly understanding the emerging household energy use trends and drivers.

This chapter examines the literature and data previously published on household energy use and its drivers. It first identifies the factors which influence overall household energy use. Then each end use category is discussed in detail and current drivers and future trends are identified from national and international studies. Where possible, conclusions are drawn about the potential for energy savings.

\subsection{Factors Influencing Overall Energy Use}

Household decision making is influenced by values, beliefs, attitudes and norms, i.e. social and psychological drivers (Stern,2005) as well as physical, financial, and regulatory factors. These closely interwoven factors affect present and future energy 
use, separately as well as collectively. Attitudes are largely based on the beliefs and values of households. They are further refined by the norms of their communities, and knowledge and awareness of issues such as climate change and security of energy supply.

Physical factors include the nature of existing dwelling structures and are highly influential on the level of present and future energy use. The literature suggests most households are reluctant to invest in energy efficiency measures that require a considerable capital outlay for changing the existing physical structure. Many households cannot afford to alter house structure without third party incentives or subsidies (Wilson and Dowlatabadi,2007).

Household financial management balances disposable income and expenditure. For many households, energy expenditure amounts to a significant proportion of household disposable income and provides some incentive for households to invest in energy efficiency measures. In 2007, a typical household in New Zealand and Ireland spent $3.7 \%{ }^{12}$ and $3.3 \%{ }^{13}$ of its household expenditure on household fuel and power (electricity, gas and coal) respectively.

The regulatory framework in developed countries consists of statutes and regulations, such as building codes and government directives that govern energy used by buildings and energy using devices. To a certain extent households' transactions costs are also reduced by these mechanisms. For example, regulation removes inefficient energy using devices from the market, reducing costs to consumers in analysing information on available options.

As noted earlier, household sector behaviour is complex (Wilson and Dowlatabadi,2007). The complexity arises from interactions among the components that influence energy use in households, and these factors change over time, with social trends, changing information and technological innovation (Abrahamse, Steg et al.,2005).

\footnotetext{
12 http://www.med.govt.nz/upload/68020/New\%20Zealand\%20Energy\%20Indicators\%202009.pdf

${ }^{13}$ http://www.bordgais.ie/files/corporate/library/20081113115533_CPA_Energy_Affordability_Repor.pdf
} 


\subsubsection{Household choices, preferences and behaviour}

Household choices, preferences and behaviour are the most complex of the drivers of energy use. They rest first on socio demographic factors, such as employment status and the life stages of occupants (Carlsson-Kanyama and Lindén ,2007; Roberts ,2008; Yohanis, Mondol et al.,2008).

For most households, economic constraints set by household income and wealth limit household energy demand. Household wealth rests upon the level of the country's economic development (as proxied by gross domestic product, GDP) and the employment opportunities in a country Firth, Lomas et al. (2008).

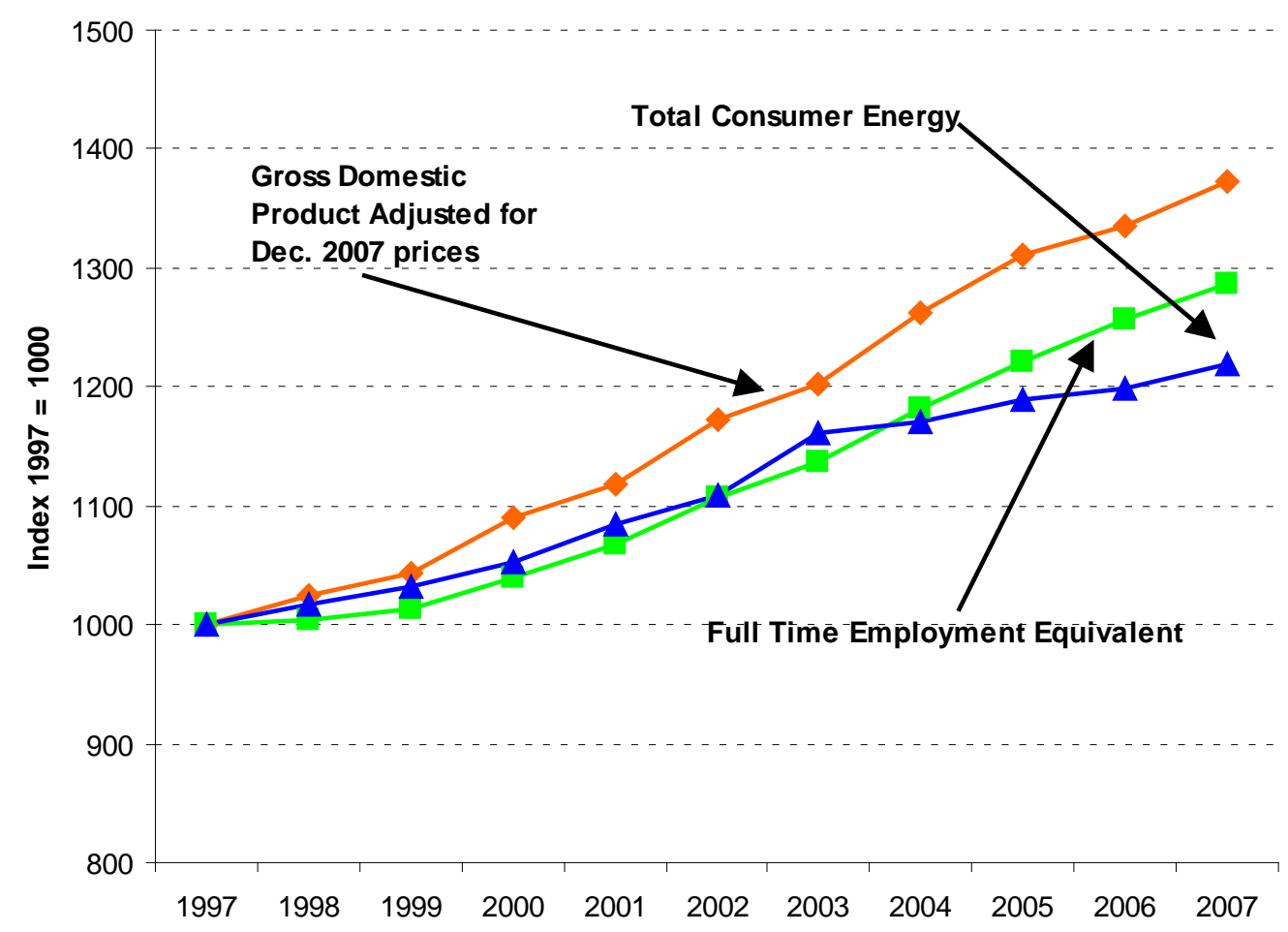

Figure 2.1: New Zealand Gross Domestic Product, Full Time Employment and Total Consumer Energy from 1997 to 2007 (Source: MED, 2007)

Over time, rising incomes allow households to spend more on energy, as noted in the previous chapter. 1980s studies suggested household energy use growth has decreased and was likely to plateau (Schipper and Ketoff,1989). However, small appliances growth has managed to resist this trend (Anker-Nilssen,2003). Figure 2.1 shows the association between New Zealand's GDP (a proxy for total income) and labour force, and total consumer energy use. GDP and the labour force increased at 
a faster pace than total consumer energy use. However the rate of increase in consumer energy use has fallen since the early 2000s. Since 2004, energy consumed for each unit of GDP, i.e. consumer energy intensity, has decreased. Furthermore, the figure shows that labour force employment increased at a faster rate than energy use. A higher ratio of employment to total consumer energy use means a reduction in total consumer energy per worker since 2004.

As well as income, household size affects energy use in the house (Wilhite, Nakagami et al.,1996). Electricity consumption per occupant generally increases as the number of occupants in the household falls (Roberts,2008; Yohanis, Mondol et al.,2008). In New Zealand, the number of people per household has been falling slightly, and floor area per person has been increasing over the last decade. Average floor area in New Zealand is similar to rich countries such as Canada, Denmark and Norway (IEA, 2007).

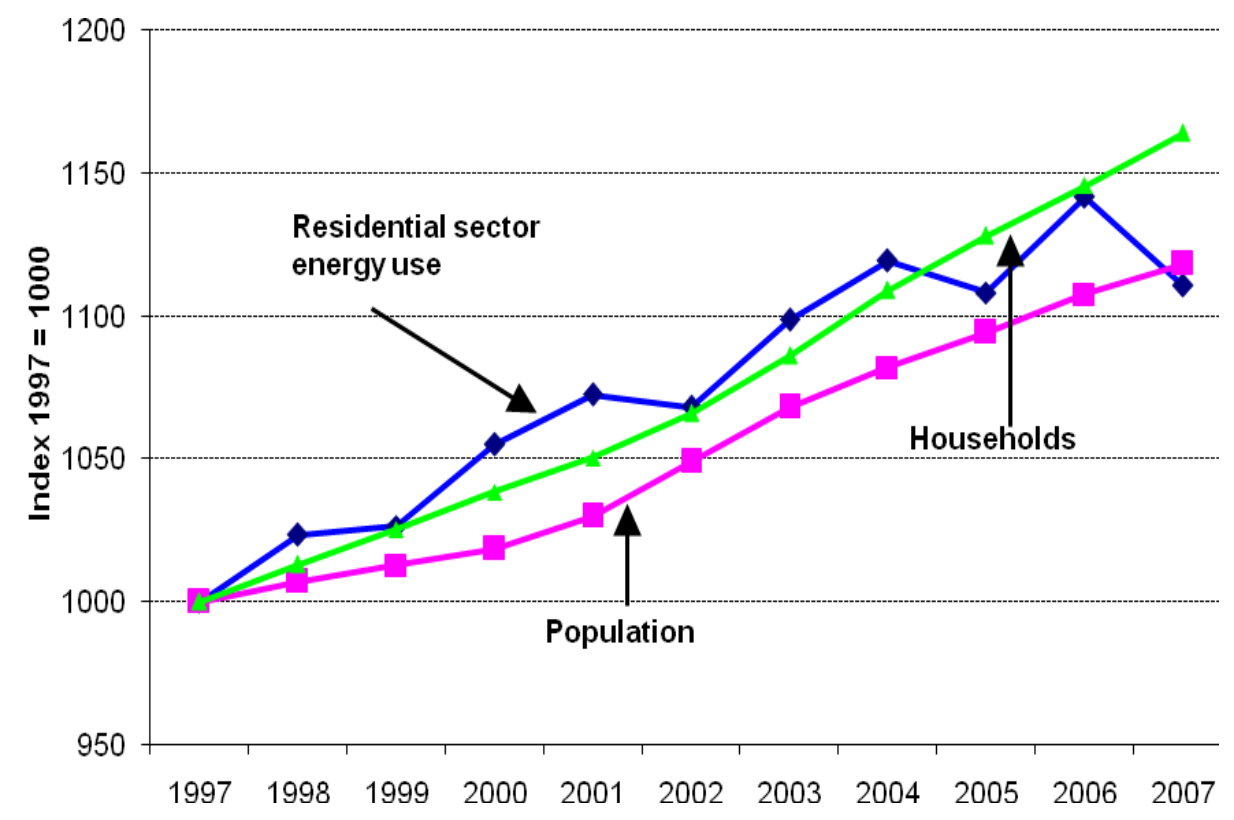

Figure 2.2: New Zealand residential ${ }^{14}$ sector energy use, population and households from 1997 to 2007 (Source: MED, 2007)

Figure 2.2 shows that residential sector energy use is cyclical as well as having an increasing trend. Economic fluctuations and dry year energy saving campaigns

\footnotetext{
${ }^{14}$ Note: residential and household sectors are interchangeable
} 
(Blackwell,2009) are likely to be the cause of these cyclical variations. The average rates of growth in population and residential sector energy use are very similar. However, residential energy use increased at a slower rate than the number of households, very likely because households are shrinking in size, resulting in falling residential energy use per household. As noted in the last chapter, from 1997 to 2007 residential sector energy use per person and per household fluctuated within a range of $1 \mathrm{GJ}$ and $2 \mathrm{GJ}$ respectively. However, it did not show a clear pattern of change, either an increase or a decrease within this period.

The market choices available include the opportunity to select and use the most appropriate, economic and available fuel type for a given end use, although for some households, these choices are constrained by income.

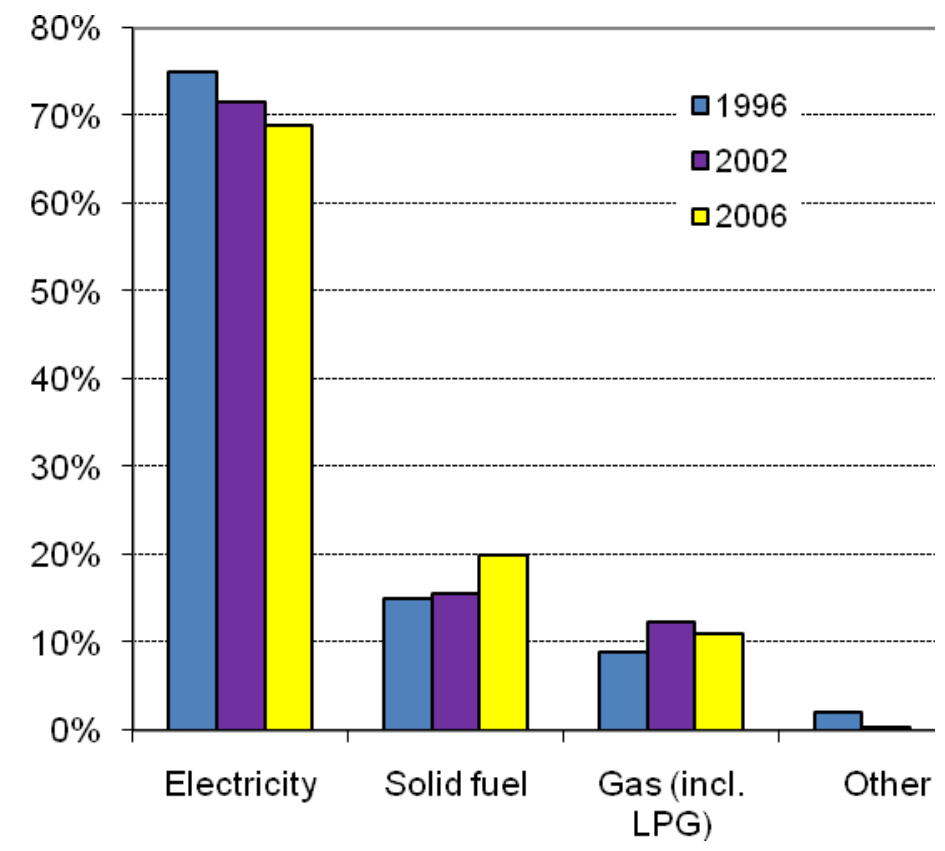

Figure 2.3: Residential sector fuel uses in 1996, 2002 and 2006 proportion of total residential fuel use

Figure 2.3 shows changes in fuel use over time, estimated from a number of sources and surveys conducted during the period 1995 - 2006 (1996; (2002; Isaacs, Camilleri et al.,2006). However, the variations are more likely to come from improvements in data collection and measurement techniques rather than actual shifts in fuel use or consumption behaviour changes. Energy contributed by solid 
fuels (wood and coal) was underestimated in previous studies. Free firewood was used by many New Zealand households. However, energy balances in MED's Energy Data File did not record free firewood because the quantity and the energy content of firewood were unknown. Similarly many households in coal producing regions have been using coal that was not recorded in the Energy Data File.

Furthermore, the HEEP (2006) sample did not have any houses on the West Coast, where coal use was reported to be high (MfE, 2005). The decrease in gas use from 2002-06 may be due to gas price increases owing to depletion of the Maui gas field. Figure 2.3 shows electricity use is a high percentage of total energy use in the New Zealand residential sector. It is possible that electricity use has been falling in the five years 2001-06, as residential electricity prices increased over that period (discussed below).

\subsubsection{Main energy end-use studies in NZ}

There have been two major studies of note on New Zealand residential energy use. The first metered study of electricity end-use was the 1971/1972 insulation/temperature study by the predecessor of Statistics New Zealand (Department of Statistics,1976). Secondly, BRANZ conducted the HEEP study over ten years from 1996 - 2006 with a view to capturing all fuel use, end-uses and technologies (Isaacs, Camilleri et al.,2006). The first study, unlike HEEP (2006), examined electricity end-use only. Although the HEEP study considered all energy forms, it was not able to capture the increasing popularity of heat pumps ${ }^{15}$.

\subsubsection{New Zealand residential sector energy end-use profile}

Figure 2.4 shows that in 2006 the highest share of residential energy use was for space heating (34\%), followed by water heating (29\%), appliances (29\%) and lighting (8\%). The amount of energy required to heat houses depends on the outdoor temperature, air tightness and thermal envelope of the building shell, the size of the house, the efficiency of the heating system and household behaviour.

\footnotetext{
${ }^{15}$ A new study by BRANZ will meter energy use by heat pumps as well as entertainment devices to fill the gaps in knowledge from the previous HEEP study.
} 
With an average outdoor annual temperature of $12.9^{\circ} \mathrm{C}$, New Zealand households need to heat their houses to keep warm. This need is exacerbated by the poor thermal performance of the housing stock.

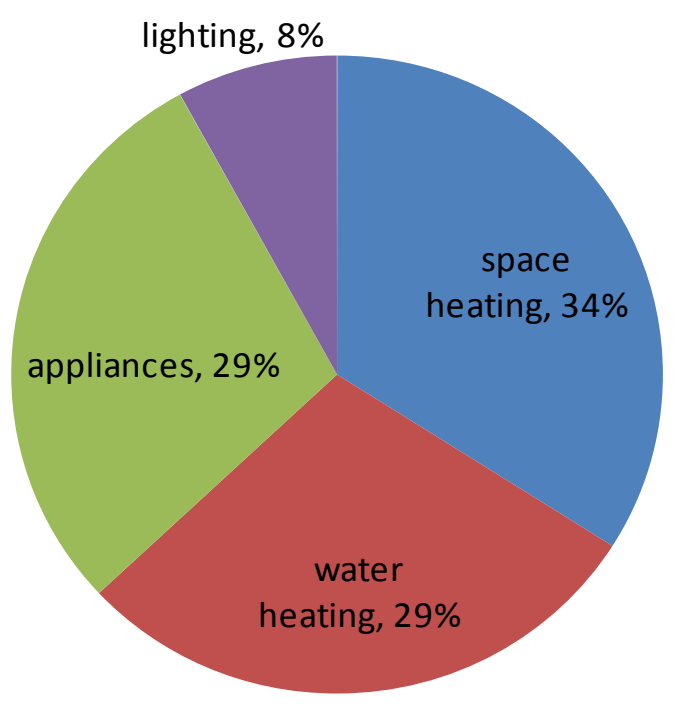

Figure 2.4: Major household energy end-uses by proportion (Isaacs, 2006)

Figure 2.5 shows household energy end-use in the last decade, based on data collected in the HEEP study. As previously discussed, energy use from free firewood was not considered and therefore space heating is under-represented in 1996 and 2002. This problem was, to a certain extent, corrected in the 2006 HEEP study. Figure 2.6 also shows a sharp increase in New Zealand's appliance and lighting energy use, and decline in water heating use.

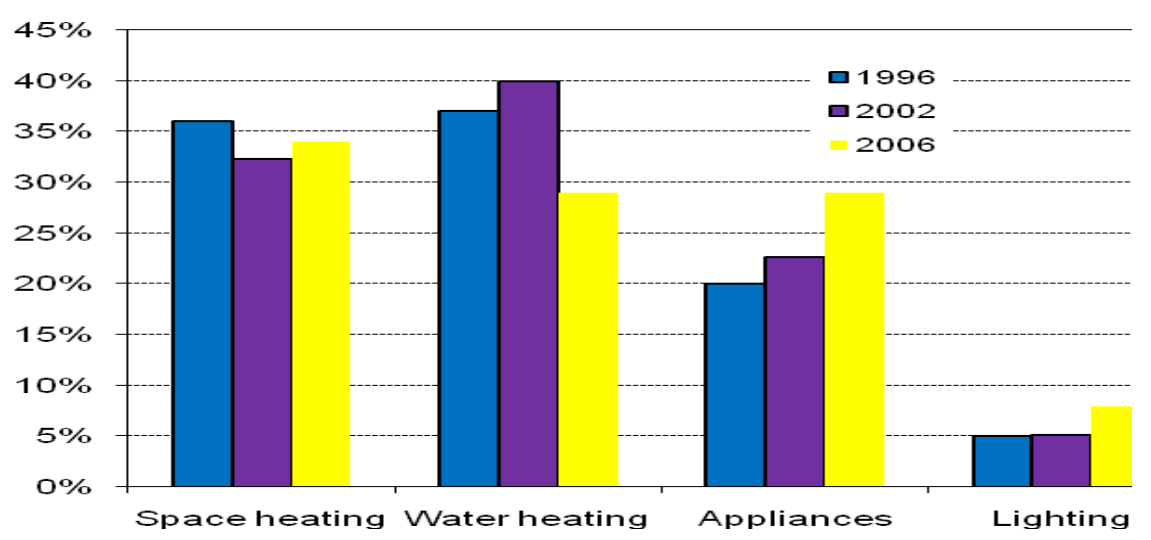

Figure 2.5: Household sector energy end-use 1996 - 2006 


\subsubsection{Energy Affordability}

Household income, the price of energy and unavoidable energy use determine energy affordability for a household (Wilhite, Nakagami et al.,1996). Retired, unemployed, and disabled people and invalids with reduced income streams and less discretion over energy use are more affected by energy affordability (HowdenChapman, Signal et al.,1999; Tonn and Eisenberg,2007; Howden-Chapman, Viggers et al.,2009). A UK study shows a link between low income and high energy consumption as well as related carbon emissions (Roberts,2008). According to Roberts a basic principle of sustainable energy is that every household should be able to afford "a warm and adequately-lit home", "together with access to energy saving appliances ranging from a fridge to a TV". If a house is uninsulated, it may be impossible to heat a home adequately for some low-income households (Davie 2007; Howden-Chapman et al 2009; Bob Lloyd, 2009). This is a common situation for households in fuel poverty, defined formally as a condition where $10 \%$ or more of household income is required to be spent across all fuels used in the household, in order for adequate indoor temperatures to be attained (Boardman,1991).

Most households evaluate their actions to reach an 'optimum' set of outcomes based on their budgets, knowledge and household circumstances. They balance their incoming and out-going finances at least heuristically if not in terms of detailed accounts. It allows them to decide their purchasing choices including the amount of energy consumed at a particular point in time (Abrahamse and Steg,2007; Wilson and Dowlatabadi,2007). Household circumstances include the physical structure of a dwelling, household income, housing tenure, household requirements and relevant regulatory requirements such as the Building Code. A change in energy use can occur under different circumstances such as moving to a new home, change in occupant life style or work status, adoption of new technology, and increased knowledge and awareness. As income increases households purchase more energy-using devices but energy prices are likely to constrain energy use. Therefore household energy use is likely to rise with increasing household income and decreases with increasing energy price (Sanne,2000; O'Doherty, Lyons et al.,2008). 
Households who own energy efficient houses and appliances tend to use more energy as household income increases. A study of Norway, Sweden and Denmark illustrates an increase of energy use with household income and a decrease over time with installation of energy efficiency measures in houses (Greening, Greene et al.,2000; Unander, Ettestøl et al.,2004; Lindenberg and Steg,2007).

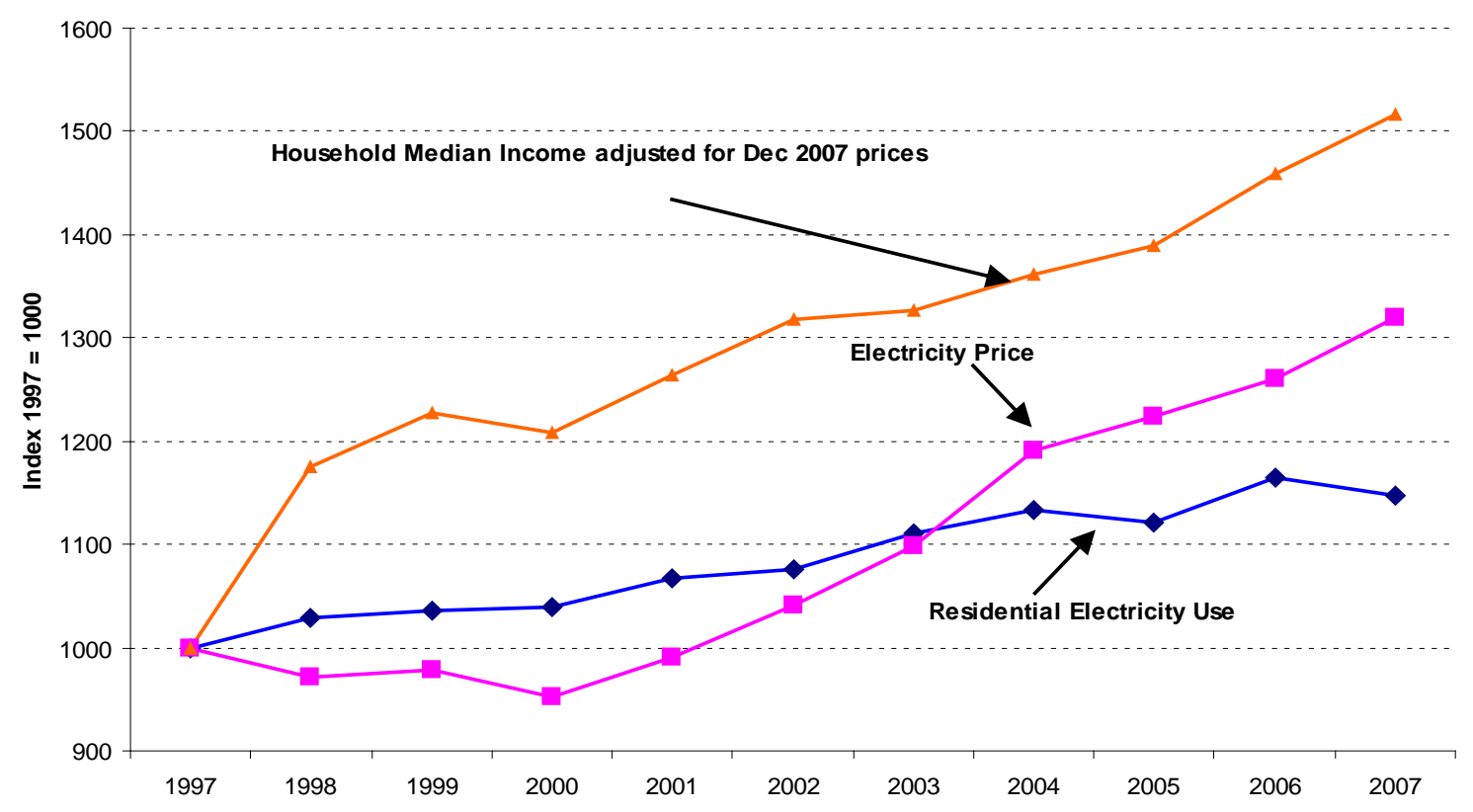

Figure 2.6: New Zealand household median income (adjusted for Dec. 2007 prices); household real electricity prices, and household electricity use from 1997 to 2007 (Source: MED, 2007)

Figure 2.6 shows the association between household median income, real household ${ }^{16}$ electricity price and household electricity use in New Zealand. Household income and the electricity price (an average across the country) increased at faster rates than household electricity use. Since 2000 electricity prices have been increasing at a fast rate. Not surprisingly, given rising prices, electricity use increased at a slower rate than median household income. While the increase in floor area per dwelling and more use of appliances would have driven up energy use, increasing energy efficiency and rising energy prices would have exerted a balancing downward pressure on energy use. Figure 2.7 shows household sector electricity

\footnotetext{
${ }^{16}$ Note: residential and household words are interchangeable.
} 
use has increased at about the same rate as floor area for an average household but not nearly as fast as household median income.

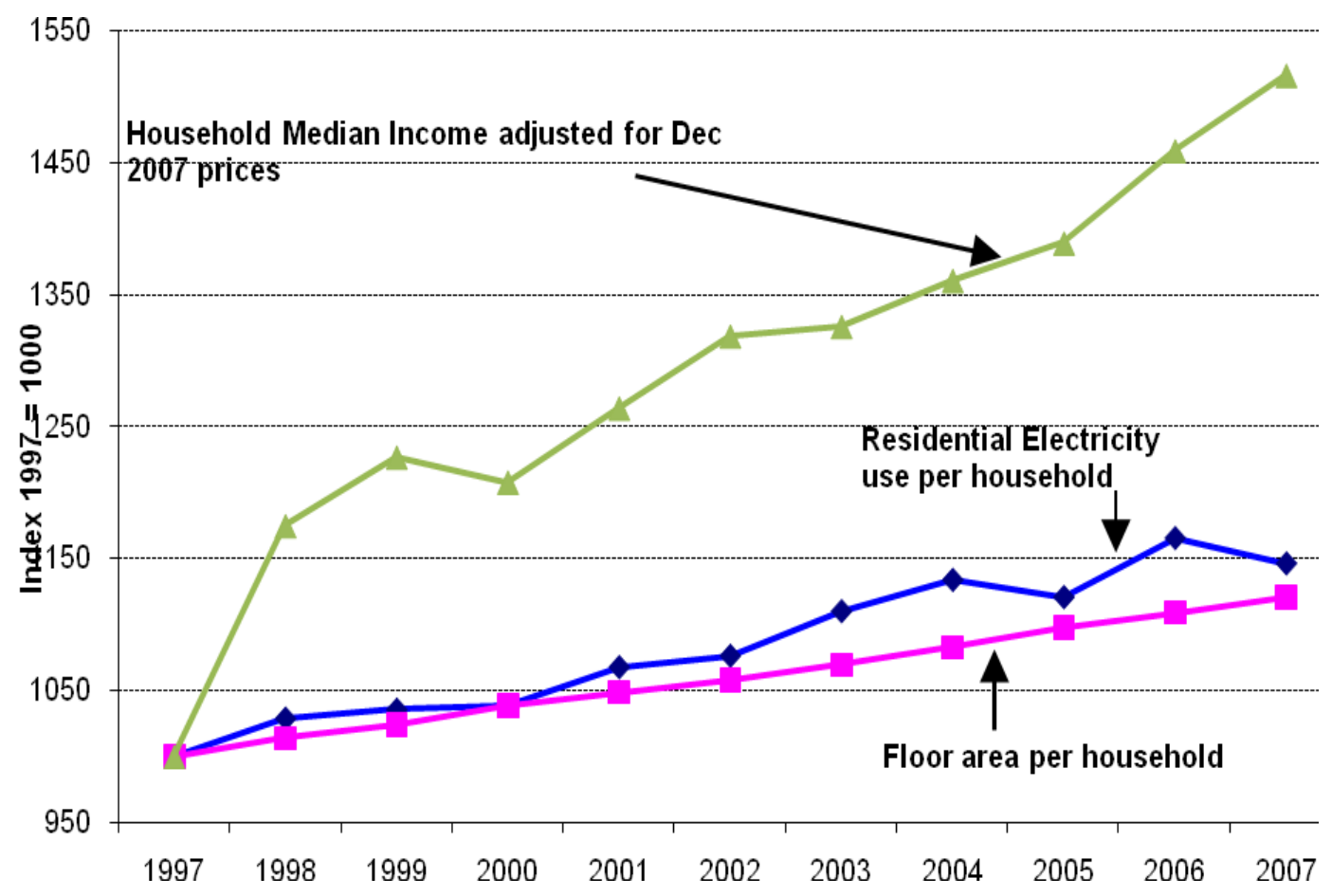

Figure 2.7: New Zealand household median income, floor area and residential electricity use for an average household from 1997 to 2007 (Source: MED, 2007)

Energy prices influence energy affordability. Insufficient household income may force residents to heat their houses to a temperature level less than comfortable and healthy (Shannon, Lloyd et al.,2003; Lloyd,2006; Lloyd, Bishop et al.,2007). Owneroccupier houses are more energy efficient than rental houses and can be heated at a lower cost (International Energy Agency,2007); the combination of lower incomes among tenants (in general) and lower levels of energy efficiency leads to significantly lower levels of heating in rental dwellings (Howden-Chapman et al, 2009).

Employment status and life stages of households impact on energy affordability. British studies have found households with invalids, the disabled, unemployed, retired and young children experience higher energy use (Healy and Clinch,2004; Howden-Chapman, Viggers et al.,2009). US studies indicate that some elderly forgo medicine to pay their utility bills (Tonn and Eisenberg,2007). In contrast households with professional couples, who have been living in their own apartment in a city for 
more than 10 years, use less residential energy (O'Doherty, Lyons et al.,2008; Yohanis, Mondol et al.,2008).

According to environmental psychologists such as Abrahamse, households are unaware of, or have only a vague idea of, the amount of energy use across different end-uses (Abrahamse, Steg et al.,2005). Household energy bills do not provide sufficient information to illuminate for households the amount of energy use broken down by end-use. This prevents them from identifying the most effective end-use or household behaviour change to implement energy efficiency measures in their homes for reducing the energy bill.

International studies suggest that countries which generate a major proportion of their electricity from renewables have low electricity prices compared to countries that generate electricity with fossil fuels. Electricity prices are low in Norway and Sweden, for example, where a high proportion of electricity is generated from hydro compared to Austria and UK, where electricity is generated from fossil fuels. The ostensible reason for this is that running costs associated with hydroelectric generation are low (Sanne,2000; Sartori, Wachenfeldt et al.,2009). That is, fuel used for hydroelectricity is often essentially free while fossil fuel costs are escalating. However, other factors could include underestimation of capital and environmental costs of hydro. As a consequence of low electricity prices, households tend to use more electricity because it is affordable.

For many years, following the post-war hydro investment boom, New Zealand had spare capacity to generate electricity. Therefore high priority was not given to curbing residential energy demand and to improving electricity efficiency or developing new generation projects until supply constraints began to emerge due to high electricity demand. In contrast, countries in the European Union (EU) which rely on fossil fuels to generate electricity have given high priority to increasing electricity efficiency, in order to reduce greenhouse gas emissions and improve energy supply security. These countries have managed to curb their electricity demand more effectively than their counterparts which generate most of their electricity from water (Hargreaves, Johnstone et al.,1998). 


\subsubsection{Health}

Studies of retrofitting insulation have found that health benefits gained from maintaining indoor temperatures at a level required by human physiology far outweigh any benefits received through reducing energy use (Barnard, Baker, Hales, \& Howden-Chapman, 2007; Howden-Chapman, et al., 2005; Howden-Chapman, et al., 2008). Houses not heated to the required temperature may result in increased hospital admissions, GP visits, absence from work and school, and even mortality (Chapman, Howden-Chapman, O'dea, Viggers, \& Kennedy, 2009; Davie, Baker, Hales, \& Carlin, 2007; Hajat \& Haines, 2002; Howden-Chapman, et al., 2009). Indoor temperatures below $16^{\circ} \mathrm{C}$ adversely affect health through such effects. The World Health Organisation (WHO) recommends to set indoor temperature between $18^{\circ} \mathrm{C}$ and $21^{\circ} \mathrm{C}$ (World Health Organisation, 2003). The prevailing culture of cold houses in New Zealand may curb the growth in demand for energy to heat houses in spite of health gains that can be achieved from adequate heating of houses (Howden-Chapman, et al., 2009). However, public interest, the introduction of an insulation and heating subsidy programme by the New Zealand government, and the demand for such subsidies to upgrade energy performance in houses illustrates that public awareness has been increased (including by the studies mentioned) and that gradual changes in behaviour patterns are likely.

Households with vulnerable groups have higher energy need than others if they are to maintain health. Vulnerable groups are infants, young children, and older people, the disabled and invalids. Infants and small children need high indoor temperature than healthy adults (Howden-Chapman, et al., 2008). Furthermore the sick and those with disability who are sedentary and people who stay at home for longer periods, such as the unemployed, retired and carers will consume more energy (Easterlow, Smith, \& Mallinson, 2000). As householders age their bodies require higher temperatures for optimal performance (Rudge \& Gilchrist, 2005).

\subsubsection{Housing Tenure}

Housing tenure influences occupants in deciding whether to install energy efficiency measures. Owner-occupiers are likely to live long periods in the same house and often are willing to upgrade their own houses to reduce household energy use 
(International Energy Agency, 2007b; Spees \& Lave, 2007) and install more energy efficient appliances. In economic terms, they accept a longer payback period for recovering their investments. On the other hand, for landlords and tenants there is a split incentives problem. Tenants are not interested in installing insulation or efficient heating system in a house they do not own. Since landlords do not pay the energy bills they have less incentive to install insulation or efficient heating systems. Households in tenanted houses may have no choice but to reside in uninsulated houses and use more energy than otherwise necessary to heat their houses (International Energy Agency, 2007b). However, their consumption is constrained by income and affordability. Because their houses are uninsulated, they may perceive it not to be worthwhile to heat their dwellings, except for the room they are in. Yohanis et al. indicate that owner-occupiers consume almost double the amount of energy that a low income social housing tenant consumes (Yohanis, et al., 2008).

\subsection{Space heating energy use}

Space heating energy requirements are influenced by climate (Fong, Matsumoto, Lun, \& Kimura, 2007; International Energy Agency, 2007a), age of the house (French, Camilleri, Isaacs, \& Pollard, 2007), solar gain (Greening, et al., 2000), house orientation (Farahbakhsh, Ugursal, \& Fung, 1998), house size (Roberts, 2008c; Yohanis, et al., 2008) and design and building material quality (CarlssonKanyama \& Lindén, 2007).

International experience shows that energy efficiency improvements to houses, space heating technology and government policies have made a considerable difference to space heating energy use (Geller, Harrington, Rosenfeld, Tanishima, \& Unander, 2006; L Schipper, Unander, Marie-Lilliu, Walker, \& Murtishaw, 2000; Unander, et al., 2004). EU countries introduced measures to improve the housing stock to restrain growth in household energy use after the first oil shock in 1973 (Geller, et al., 2006). Studies suggest these early interventions have resulted in space heating in many countries reaching saturation levels (International Energy Agency, 2007a). Saturation level is achieved when the thermal envelope of the housing stock is improved to minimise the heat loss, and any gain in temperature in 
the house will result in discomfort. After reaching the saturation level any other energy efficiency measure will reduce overall energy use (Hong, Gilbertson, Oreszczyn, Green, \& Ridley, 2009). Norway, Sweden and Denmark are prime examples of this effect (Unander, et al., 2004). Furthermore, some countries have shown a reduction in the proportion of energy use going to household space heating even with an increase in floor area (International Energy Agency, 2007a). In contrast, New Zealand households are under-heated (Lloyd, 2006; L Schipper, et al., 2000). Improvements to the housing stock and heating to WHO recommended temperatures therefore indicate that energy use for space heating is likely to be increased in the future (Amitrano, 2004; Barnard, et al., 2007; Howden-Chapman, et al., 2009).

\subsubsection{Climate}

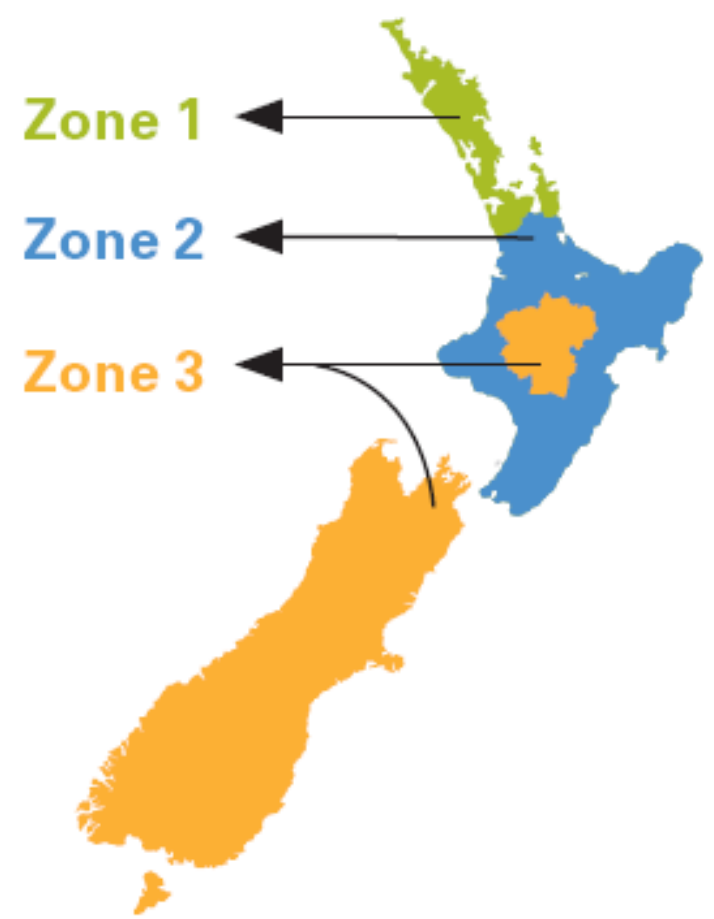

Figure 2.8: Map of New Zealand Climate Zones (Department of Building and Housing, 2008)

The climate of a country strongly influences demands for heating and cooling (Wilhite, et al., 1996). For many OECD countries with cold climates, reducing space heating demand without decreasing space heating benefits has been a priority. As discussed above, Nordic countries have achieved the objective successfully. 
International studies indicate New Zealand households' energy use is the lowest within OECD countries (L Schipper, et al., 2000). Likely reasons for this, as well as the socially accepted norms of low space heating in NZ houses just mentioned, include the mild temperatures in New Zealand in comparison to extreme cold temperatures in the Nordics, and high room temperature settings in other OECD countries. Another factor, as mentioned earlier, is likely to be the underestimation of energy from free solid fuel; this has traditionally been more important in the colder parts of New Zealand (climate zone 3 in Figure 2.9).

In 2008, New Zealand annual average temperature was $12.9^{\circ} \mathrm{C}$ (National Institute of Water \& Atmospheric Research, 2009). The three NZ climate zones defined in the NZ building code are shown in Figure 2.9. Temperatures in Zone 3 are the coldest followed by Zone 2 and Zone 1 . On average the number of heating degree days ${ }^{17}$ in Zone 1, Zone 2 and Zone 3 are 1200, 1200 to 1800 and over 1800 respectively (McChesney, et al., 2008). New Zealand's National Institute of Water and Atmospheric Research temperature maps shows cooling degree days in the three zones are very few. These measures indicate that NZ requires much more space heating than space cooling.

Despite NZ's relatively temperate climate, New Zealand houses clearly do require winter heating and the high incidence of excess winter deaths strongly indicates this. Many New Zealand studies have shown the relationships between housing age, socio-economic status, winter hospitalisation and inadequate home heating (Barnard, et al., 2007; Howden-Chapman, et al., 2009; Lloyd, et al., 2007).

\subsubsection{House structure}

The efficiency of a dwelling's thermal envelope influences energy use for space heating. The thermal envelope separates indoor and outdoor air. It can be improved by increasing the thermal resistance of the envelope and the air tightness of a house. Thermal resistance can be improved by better insulating a house, helping to retain heat inside the house by reducing loss through conduction and

\footnotetext{
${ }^{17}$ Heating degree days are defined as (number of days) * (difference in degrees $\mathrm{C}$ between the mean daily temperature and a base temperature) (McChesney, Cox-Smith, \& Amitrano, 2008). The base temperature for this calculation is $18^{\circ} \mathrm{C}$.
} 
convection. Minimising air leakages from the building fabric further reduces space heating requirements (Hong, et al., 2009; Hong, Oreszczyn, \& Ridley, 2006).

Every five years, BRANZ conducts a sample-based House Condition Survey for houses occupied by the owners. The House Condition Survey 2005 provided a general overview of NZ housing conditions (Clark, Jones, \& Page, 2005), but was focused on Auckland, Wellington and Christchurch regions. From an energy point of view, it covers insulation levels, and space and water heating systems. It highlights major house quality concerns for NZ houses. The 2005 Survey, generalising to the whole housing stock, estimates that only $70 \%$ of the stock has sufficient ceiling insulation, $55 \%$ of the stock has no wall insulation and only $20 \%$ of the stock has fully insulated floors.

House insulation became mandatory in 1978. NZ houses built before 1978 have high heat loss because they have little or no insulation. About $70 \%$ of households in New Zealand were built prior to 1978 (EECA, 2008). According to the HEEP Report (2006) a simple retrofit (ceiling and floor insulation) of a pre-1978 house will reduce heat loss but the house will still lose more heat than a house built after 1978, due largely to the absence of wall insulation (Clark, et al., 2005; Lloyd, 2006).

In 2007 the Building Code was revised, requiring improved thermal performance in new houses ${ }^{18}$. The New Zealand Building Code 2007 requires roof/ceiling, walls, floor $^{19}$, skylights and windows to be insulated at a higher level than the previous building code. The Building Code states that R-values, measuring thermal resistance, should be higher for Zone 3 than Zones 2 and 1. A systematic insulation upgrade of the housing stock has the potential to decrease space heating energy use (Lloyd, 2006). Furthermore, using building materials that have the ability to capture and maintain heat will reduce energy use (Howden-Chapman, et al., 2009).

A government sponsored program has been in place for some years to fund low income households to insulate houses (Lloyd, 2006). This initiative is designed to improve the thermal performance of part of the New Zealand housing stock, improve

\footnotetext{
${ }^{18}$ In other countries building code has been gradually strengthened to reduce heat loss.

19 It also includes provisions for heated floors.
} 
social equity and reduce residential energy demand. It has also long been clear that some of these energy savings may be taken back through increased used of energy for space heating (Page, 2006); a question is how much. Howden-Chapman et al (2009) suggest that takeback varies a great deal: for some households it could be greater than $100 \%$ (i.e. they spend more on heating after insulation is installed) but for many it is considerably lower - around $40 \%$ of households split greater thermal efficiency between comfort and heating cost savings. That study found that on average retrofitting insulation led to metered energy savings of around $13 \%$.

\subsubsection{Fuels used for space heating}

According to the HEEP study the houses with solid fuel burners were the warmest. Use of solid fuel burners needs to be balanced with air quality considerations (Fisher, Kjellstrom, Kingham, Hales, \& Shrestha, 2007). Coal burning pollutes air locally and accelerates climate change. Solid fuel burners in cities such as Christchurch are required to shift from coal and other inefficient fuel to more efficient wooden pellets and chips. Even though wood is the fuel mainly used to heat space, heat pumps are gaining popularity in New Zealand (French, 2008). EECA sales data suggests the most efficient heat pump sold in New Zealand in year ending March 2008 had an efficiency of more than $500 \%$. It means that such a heat pump is capable of providing 5 units of heat energy for each unit of electricity consumed. Typical efficiencies are likely to be lower, perhaps around 300\%, and heat pumps are often not installed or operated according to specifications (Nimmo \& McChesney, 2007). Studies suggest older people prefer heat pumps to other forms of heating because of their affordability and convenience.

\subsection{Water Heating Energy Use}

HEEP (2006) studies found water heating consumed $29 \%$ of household energy use (Isaacs, et al., 2006). Demand for hot water energy use depends on climate, hot water system efficiency, heat loss from cylinders and pipes, life stage of occupants, number of occupants and behaviour and choices of households (Wright, 2008). According to HEEP findings, NZ household hot water use ranges from no hot water in dwellings to heating large swimming pools; households commonly use hot water 
for bathing or showering, food preparation, washing hands, clothes and dishes. Energy used for water heating is higher in winter compared to summer. Reasons include lower water base temperature, higher pipe losses, higher heat losses from storage cylinders and from clothes washing. Furthermore, behavioural aspects such as longer showers or baths to compensate for lower indoor temperatures were also considered a contributing factor. The report also found that households with gas instantaneous hot water systems use more hot water than households with other systems (Hart \& de Dear, 2004).

The House Condition Survey 2005 reports about 75\% of hot water systems were heated by electricity. It further states that in 2005 over $35 \%$ of cylinders were C grade cylinders with high energy losses. In 2005, more houses had more efficient hot water cylinders which were less than ten years old and more cylinders and pipes wrapped to reduce heat losses, compared to 1999. Hot water delivery capabilities and cylinder sizes were regarded as inadequate and some households have set the thermostat at a higher temperature level to compensate, leading to water temperature beyond the NZ Building Code recommendations as well as inefficient energy use. In $17 \%$ of houses the shower flow rate is too low for adequate service levels and in about $21 \%$ of houses the shower flow rate is too high, resulting in inefficient energy and water use (Clark, et al., 2005).

Recent NZ government policies have been promoting solar water heating in NZ by providing grants to install solar water heating systems in households. Solar water heating systems can only store hot water up to the capacity of the cylinder. The additional hot water requirement will be supplemented by other types of heating systems. Installation of an efficient solar water heating system can reduce conventional energy use for hot water. The drivers of hot water system energy use include efficiency of the system, the ability to reduce heat losses in cylinders as well as the losses from the pipe, life stage of occupants, number of occupants in the household, climate zone and behaviour / choices of the household .

A Swedish study found that government information campaigns to reduce energy for household water heating have been effective (Lindén, Carlsson-Kanyama, \& Eriksson, 2006). However, Greening et al suggest there will be a $10-40 \%$ rebound 
effect for energy use in water heating with implementation of energy efficiency measures. A UK study shows that, after energy efficiency measures have been taken, in most cases energy used for water heating remains around the same (Owen, 2006). Efficient water heating systems are likely to reduce energy use for water heating (Willis, Stewart, Panuwatwanich, Jones, \& Kyriakides, 2010)

Taken together, these space heating and water heating studies suggest even though there is potential to save energy the technologies and practices have penetrated to main stream practice for these two end-uses. Governments need to design policies to accelerate adoption of these practices and technologies. Helping households with insufficient disposable income, to upgrade their houses is likely to result in less expenditure on health and other social welfare policies.

\subsection{Lighting energy use}

Lighting consumes about $12 \%$ of average household electricity or $8 \%$ of average household energy (Isaacs, et al., 2006). The main drivers of lighting energy consumption are the number of occupants, floor area of household, income (Wall \& Crosbie, 2009), efficiency of light bulbs, number of light fixtures life stage and lifestyles of occupants, knowledge and awareness of energy efficiency lighting technologies, household behaviour and choices, local practices and norms (Wall \& Crosbie, 2009), and government policies (Stokes, Rylatt, \& Lomas, 2004; Wright, 2008).

For most households, lighting provides internal ambience (Crosbie \& Guy, 2008). Lighting practices and norms differ from country to country (Waide, 2006). For example, Norwegians prefer incandescent lighting for a cosy and warm feeling, whereas Japanese prefer compact fluorescent lighting for brightness. Furthermore an average house in Norway has 9.6 light bulbs per living room compared to 2.5 in Japan (Wilhite, et al., 1996). 
As the number of households increases over the years, lighting energy requirements of a country as a whole will increase. If housing costs increase, the number of occupants per household is likely to increase. Therefore occupants may share household appliances (including lights) and this may result in lower aggregate lighting energy use (Richardson, Thomson, Infield, \& Delahunty, 2009; Roberts, $2008 b)$. On the other hand, as incomes rise, the average number of occupants per house is likely to fall, offsetting this trend.

More daylight hours in the summer season reduces energy use for lighting (Isaacs, et al., 2006; Richardson, et al., 2009). A significant reason for adjusting clocks to extend daylight hours is to reduce lighting electricity use. A NZ electricity market study confirms that New Zealand households reduced energy use with commencement of daylight savings (Aries \& Newsham, 2008).

According to Richardson, lighting in houses depends on natural lighting in the house, levels of lighting required by occupants and the activities of household occupants (Richardson, et al., 2009). As people age, their eyesight deteriorates and they prefer more lighting (Tonn \& Eisenberg, 2007; Wall \& Crosbie, 2009; Wright, 2008). Roberts states that an adequately lit home is a basic right of all people (Roberts, 2008c).

Lighting is an end-use with a high potential for energy saving (Aries \& Newsham, 2008; Crosbie \& Guy, 2008; Waide, 2006). Compact fluorescent lighting (CFL) consumes about $80 \%$ less energy to provide the same amount lighting as incandescent lighting (Aries \& Newsham, 2008). The uptake rate of CFL is low because it can require not only changing light bulbs but changing light fittings (Owen, 2006). Another UK survey found that 'cold' light, unattractive shape, taking too long to achieve full brightness, unsuitability for many fittings, incompatibility with dimmers, cost and unreliability were reasons for a slow uptake rate of CFL (Wall \& Crosbie, 2009).

Even though households often do not realise it, energy used by lighting is considerable. A 2002 European study claims that by replacing existing appliances and lighting with the most energy efficient appliances and lighting, a household can 
save about 1800 kWh of energy per year (Hart \& de Dear, 2004). Energy used by an incandescent bulb can light four energy efficient bulbs and the latter last 12 times longer. A UK energy saving trust claims that if each household were to install three CFLs, this would save enough energy to pay for all the street lighting in the UK (Owen, 2006).

There are several reasons for households not implementing lighting energy saving measures. Mostly it is lack of awareness and lack of knowledge of energy saving potential. Secondly, inaction results from the split incentives of builders, owners and tenants (International Energy Agency, 2007b). House builders tend to minimise the cost of lighting because they wish to minimise the capital costs of a building, in accordance with house buyers' preferences, and are not responsible for paying the ongoing energy bills. Once a house is built and light fixtures are fitted, an additional cost needs to be borne by the owner-occupiers to install energy saving light fittings. On the other hand, tenants in rented houses have short-term interests and are unlikely to install efficient lighting, while landlords assume that they are unlikely to recover the cost of more efficient lighting through higher rents or capital values. Other reasons for not implementing energy efficient lighting include that installing light bulbs are a low priority because savings are small; there are no energy efficiency standards or labelling, and unavailability of energy efficient light bulbs that aligns with existing fittings (Owen, 2006). Environmental and, interestingly, financial reasons emerged as the main reasons for implementing lighting energy saving measures (Wall \& Crosbie, 2009).

A Swedish study by Lindén et al (2006) found that by improving household habits, energy used for lighting can be reduced. Linden et al claim that most householders in Sweden do not use energy efficient lighting or switch lights off when leaving a room. Lights are left on in houses for cosiness, safety and to facilitate moving around the houses. Lifestyles, number of occupants, norms and behaviours of households are major drivers for lighting electricity use. 
Emerging technologies have the potential to reduce lighting energy demand ${ }^{2021}$ (Parliamentary Office of Science and Technology, 2005). Current studies expect Light Emitting Diodes (LEDs) to be more versatile than fluorescent lighting. LEDs can emit different colours and have the flexibility to be used either as a line or as a screen of lighting (Wright, 2008). There are claims that with new developments, LEDs can be three times more efficient than CFL. Halogen lights are more efficient than incandescent lights but the tendency to use multiple bulbs in one fitting cancels the energy efficiency gains (Owen, 2006).

Literature suggests that a house designed to maximise daylight is not only energy efficient but it can also increase the productivity, health and well-being of its occupants (Webb, 2006). Sensor controls, LEDs and the correct placement of lighting fixtures are likely to improve household energy savings. Setting up a standard of energy use in building codes may to some extent control energy use for lighting (Waide, 2006), but ultimately, household behaviour will be the largest influence on savings.

\subsection{Appliance energy use}

In New Zealand, appliances (defined as excluding light bulbs) consume $29 \%$ of average household energy, including $42 \%$ of average household electricity (Isaacs, et al., 2006). There are no comprehensive studies on consumer electronic energy use available for New Zealand. A UK study projects that consumer electronics and information, communication and technological equipment will consume $45 \%$ of household electricity by 2020 (Owen, 2007) compared with 30\% in 2006 (Department of Energy and Climate Change, 2010).

Most appliances are operated by electricity. Major drivers of appliance energy use ${ }^{22}$ in households are similar to other energy end uses. Growth of appliance ownership and appliance energy use have been identified as drivers of the increase in direct

\footnotetext{
${ }^{20}$ http://physicsworld.com/cws/article/news/18616

${ }^{21} \mathrm{http}$ ://www.envirovaluation.org/index.php/2010/03/01/doe-report-estimates-energy-savings-potential-of-ssl

${ }^{22}$ Appliance energy use include operation or "on" mode as well as "standby" mode (Hart \& de Dear, 2004).
} 
household energy use (Firth, et al., 2008; International Energy Agency, 2007a; O'Doherty, et al., 2008; Roberts, 2008b). Another factor is that labour saving appliances have reduced the time spent on housework, providing more time for entertainment and communication (Owen, 2007). A significant proportion of energy consumed by household appliances is used for keeping the appliances in a ready-touse standby mode. The Australian Greenhouse Office claims that in Australia and New Zealand ${ }^{23}$ use of appliance standby energy accounts for $8 \%$ of residential energy use.

Household appliances can be categorised as either small or large. Large appliances include refrigerators, freezers, dish washers, clothes washers and driers. Small appliances $^{24}$ include kitchen appliances, consumer electronics and information, communication and technological (ICT) equipment. Most appliances' energy use (except refrigerators) tends to vary with household preferences and choices. Since refrigerators are continuously operated, energy efficiency can be translated into energy savings (Greening, et al., 2000; Sorrel, Dimitropoulos, \& Sommerville, 2009). However, new refrigerators and freezers trend towards larger capacities and extra door features and energy savings are taken back to power the additional features (Young, 2008). New Zealand experience (EECA) suggests that, despite larger capacities and extra features, refrigerator/freezer energy savings are increasing. New appliances tend to be more energy-efficient and provide better services than older appliances. Therefore appliance upgrades may likely reduce energy consumption in households (Wood \& Newborough, 2003) unless other energy consuming devices are added.

However, even with relevant standards or regulations, energy use by consumer electronic and ICT devices is likely to rise. Some studies (International Energy Agency, 2007a) include televisions as a large appliance because they can consume as much energy as a refrigerator. According to Owen (2007) the running cost of a large (65 inch) plasma television can be about three times as much as a small cathode ray tube (CRT) television and another UK study claims some models of plasma TVs consume over five times the energy of a conventional CRT television

\footnotetext{
${ }^{23}$ Derived from HEEP Year 10 Study

${ }^{24}$ Most of the appliances in homes are infrequently used and consumes small amounts of power (Owen, 2006).
} 
(Parliamentary Office of Science and Technology, 2005). Most of the other appliances in homes are infrequently used and consume small amounts of power (Owen, 2006). IEA indicators show large appliance energy efficiency has been improving owing to Minimum Energy Efficiency Performance Standards and Labelling (MEPS/L) (Firth, et al., 2008; Wright, 2008).

An Australian study found that households' decision making processes for whiteware appliances are markedly different from those applying to television and ICT and other electronic devices. The main reason for this stems from the fact that households feel confident in selecting whiteware appliances with more established technology, in contrast to rapidly developing consumer electronics. Another reason is relative life spans. For example, refrigerators are regarded as having a longer life span and consumer electronics, such televisions are regarded as a product with a short life span. Furthermore most households seem to believe the energy consumption across different models and technologies is about the same for similar size devices (Winton Sustainable Research Strategies, 2008).

Most countries are aware of the energy saving potential with large whiteware appliances and have introduced regulations to remove the most inefficient appliances from the market. However, the increasing size of appliances and penetration of unregulated consumer electronics has increased energy use, partly because most OECD countries do not have regulations for consumer electronics (CE) and information and communication technologies (ICT). There was little urgency to curb the energy use by these devices until Owen's UK study (2007). Afterwards increased awareness has prompted other major studies on CE and ICT to be undertaken (International Energy Agency, 2009). However, there is criticism that Owen's study did not adequately consider the influence of drivers and behaviour of households in their purchasing decisions (Crosbie, 2008). The European Union has adopted a directive to take into account the environment in energy using appliance design.

Furthermore, consumer electronic device use differs across different age groups. For example, most households in Sweden have computers. Most young households seem to be confident in using energy efficient low-power modes with their consumer 
electronic devices, while older households prefer to operate devices on only one mode (Lindén, et al., 2006). Furthermore, a study found that televisions were often used by single occupant households for comfort (Owen, 2007).

As well as age, UK studies indicate household income is a major factor in appliance energy use. It determines the range of appliance ownership and the ability to pay electricity bills (Roberts, 2008b; Yohanis, et al., 2008). High income households can afford to invest in energy-efficient appliances with long payback periods whereas low income households tend to invest in appliances with short payback periods. Roberts suggests that appliances' real prices, even with mandatory energy efficiency measures, have come down over the years (International Energy Agency, 2009; Owen, 2007; Roberts, 2008b). A small sample survey conducted by EECA confirms this trend for New Zealand. In most cases, households consider appliances' upfront (capital) cost. However, once households invest in appliances, the energy consumption of that appliance will continue until the end of its lifetime, and upfront price savings can be more than the ongoing higher energy costs. Therefore access to readily available information before purchasing an appliance will help to reduce household energy use (Wood \& Newborough, 2003).

Appliance ownership in houses is increasing (Owen, 2006). In a 2003 Irish study, an average household (in the study sample) owned 2.7 TV sets, 1.5 video recorders, 1.4 DVD sets, 1 stereo system, 1 computer and 0.8 game consoles. It also indicated that households tend to have late nights and intense entertainment device use (Yohanis, et al., 2008). According to Roberts, household appliance ownership has shifted from labour-saving appliances to entertainment devices.

Studies reveal that a mix of technological advances, changes in lifestyles, embedded energy efficiency measures in appliances, energy use feedback mechanisms and increased public awareness can lead to reductions in appliance energy use. According to an IEA study, $40 \%$ of appliance energy savings can be achieved by using existing technologies. Further development of appliance technologies have the potential to save more energy (International Energy Agency, 2009). Many studies suggest the need for embedding energy efficiency measures in new innovative energy using devices before they reach the market place . 
A Swedish study states that when recent trends in lifestyles, comfort and the latest fashions merge with energy efficient new technologies, households will automatically reduce household energy use (Lindén, et al., 2006). Another study found that when households were provided with feedback via computers, they reduced energy more than did other households. Furthermore, after feedback, respondents who were aware of environmental issues tended to reduce energy consumption even more (Abrahamse \& Steg; Abrahamse, Steg, Vlek, \& Rothengatter, 2007; Brandon \& Lewis, 1999).

\subsection{Conclusion}

Energy use around the world seems to be escalating unsustainably. Though there are economic reasons for reducing energy use in commercial and industrial sectors, household sector energy use seems to be more driven by social and psychological as well as physiological factors. This mix means that there is potential for the lack of energy in poor households to harm health, at the same time as energy is squandered on entertainment (and leaving unneeded lights on) in other households. In some cases the inability to purchase the required amount of energy to keep warm exacerbates poor health, and precipitates winter deaths.

Households in New Zealand mainly use energy to heat water and space, light their homes and operate appliances. Energy use for space and water heating is influenced by climate, choice of fuels and efficiency of heating systems, among other factors. There is evidence that New Zealand houses are cold but increased public knowledge, new energy efficient technologies (e.g. heat pumps) and government policies are likely to improve this situation gradually.

Less emphasis has been given in research to lighting and appliance energy use because, at face value, these items individually seem to consume relatively little energy. However, collectively these devices may consume a significant proportion of electricity generated nationally. 
Detailed studies have revealed that, in both rich countries and developing countries, energy consumption for lighting and operating appliances is increasing (Jollands, et al., 2010; Rosas-Flores \& Gálvez, 2010). Current government policies address this issue by encouraging the use of energy efficient devices. There has been relatively little attention paid by governments to reducing energy use by changing appliance related behaviour, perhaps because of a view that this might intrude into the private domain of the household. According to research studies, however, influencing household behaviour, preferences and purchasing patterns can further reduce energy use in households. Furthermore information and statistics on appliance ownership and energy use may offer unique opportunities to reduce energy use without decreasing the utility value of the service provided by a particular device.

Overseas studies indicate that the proportion of household energy used by consumer electronics and ICT devices is increasing. Rising energy use by these devices, especially televisions and computers, which seem to be operated for longer periods and left on standby mode, is of particular concern.

However, any energy-related policy consideration requires good quality baseline information on appliance use. At present, lack of relevant information may hinder the realisation of energy reductions that are likely to benefit New Zealand. 


\section{Chapter 3: Modelling the Drivers of Energy Use}

\subsection{Introduction}

The underlying premise behind this study is that household energy demand needs to be contained to successfully manage the global and national issues of climate change, energy supply security and energy affordability as outlined in Chapter 1. Moreover, according to a recent opinion survey, ${ }^{25}$ many New Zealanders believe prudent management of energy is an important issue (ShapeNZ, 2007). This chapter illustrates the complexity of household energy consumption using the findings from a literature survey, and integrates these ideas into a framework which will be used in subsequent parts of this research.

Household energy demand depends on a large number of complex factors, including population, dwelling size, number of dwellings, occupancy rate, quality of housing stock, types and number of appliances used, types of fuel used, and household occupant behaviour. Energy efficiency measures can be viewed as ways of reducing energy demand for given service levels. However, in practice, household sector behaviour is such that some savings from energy efficiency measures are 'taken back' through improvements in service levels. For example, as energy efficiency in heating systems improves, households may heat more rooms or increase indoor temperatures. The common belief is that 'take back' (Greening, Greene, \& Difiglio, 2000) and split incentives (International Energy Agency, 2007) are responsible for the gap between estimated potential energy savings from energy efficiency measures and actual energy savings. Therefore, modelling of household energy demand should recognise not only the drivers of demand but also the subtleties of household behaviour and their interdependencies.

\footnotetext{
${ }^{25}$ A ShapeNZ survey $(n=960)$ found that $86 \%$ of respondents felt that 'the management of New Zealand's energy needs and where we get our energy from' represented an issue. Responses included 'A problem now' (39\%) and 'An urgent and immediate problem' (47\%). Other responses included 'Not really a problem at all' (2\%), 'A problem for the future' (11\%); and Don't know (1\%). This poll was conducted between April 4-7, 2007, by ShapeNZ, a national public online survey panel run by the New Zealand Business Council for Sustainable Development (www.nzbcsd.org.nz).
} 
An inter-disciplinary approach seems the best way to explain household energy use. The household energy use model shown in Figure 1 was developed by the author, drawing on the literature reviewed in the previous chapter. It indicates, among other things, how values and attitudes of households influence their decision-making process, underpinned by household attributes and preferences (Government Social Research Unit, 2010). In turn, these attributes and preferences are influenced by factors such as national economic growth, household income, energy prices, government policies, information diffusion and dwelling tenure.

Household energy use is driven by household attributes, preferences and income, energy prices and dwelling attributes. Dwelling attributes include parameters such as location, orientation and local climate, the age, design and size of dwelling, quality of building materials and workmanship, and the efficiencies of energy using equipment in the household. The rest of this chapter discusses interactions between the elements of this model. 


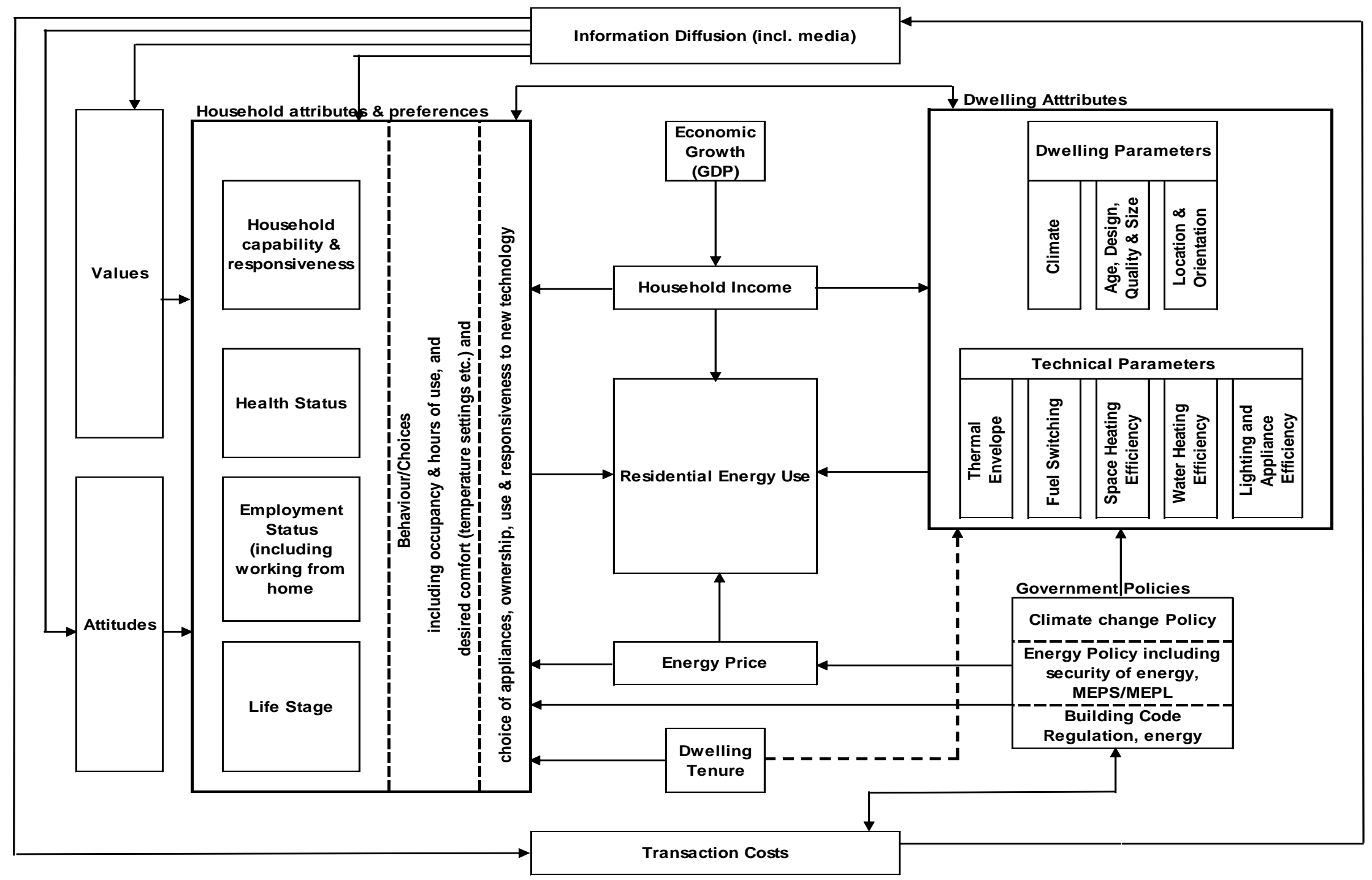

Figure 1: Major drivers of household energy use 


\subsection{Other models}

Many models of household energy use have been developed within different disciplines. In most cases they observe and model a few elements, setting aside the other elements to reduce the complexity of the model. Econometric models examine energy use from a household income and energy price point of view, whereas engineering models attempt to identify drivers of efficiency of household energy-using appliances. Abrahamse and Steg (2009) proposed a socio-demographic and psychological model. Other models explain the interaction between health and socio-economic characteristics of households (Barnard, Baker, Hales, \& Howden-Chapman, 2007; Chapman, 2004; Howden-Chapman, et al., 2005; Howden-Chapman, et al., 2008) and temperature and energy use (Schweiker \& Shukuya, 2009). CarlssonKanyama and Lindén (2007) proposed a model that takes into account differences between countries as well as within countries and the energy consumption habits between different generations. Frequently, behavioural factors are omitted, e.g. an Australian model developed to estimate household energy use does not take into account household behaviour (Department of the Environment Water Heritage and the Arts, 2008). Furthermore, there are models developed to assist electricity demand forecasts, taking into account behavioural aspects and government policies, such as increased awareness of issues relating to energy supply security, energy prices and incentives $\mathrm{Xu}$, Hu et al. (2008)(Xu, Hu, Wu, \& Zhou, 2008). Recent literature suggests the need to understand the drivers of household energy use from an interdisciplinary perspective (Wilson \& Dowlatabadi, 2007; Xu, et al., 2008).

\subsection{Values and Attitudes}

Values, attitudes, principles, norms or world views provide a basic value framework for energy use behaviour within households. Although occupants with different upbringing negotiate on the basis of their values, attitudes and norms, to settle on an energy consumption pattern in a household, they 
balance their actions within their value framework (Hall, et al., 2009). ${ }^{26}$ Studies also suggest there are barriers, such as limited disposable income and house design, that hinder households from acting on their value framework (Hall, et al., 2009). Attitudes and world views can range widely, e.g. from "NZ greenhouse gas emissions in comparison to world greenhouse gas emissions are negligible" to "NZ has plenty of primary energy sources to generate electricity". These attitudes can be maintained until a catalyst or evolving social norms convinces individuals to change their attitudes, personal norms or world views. However, values of people are very difficult to change because they are linked to people's core beliefs, principles and motivations (Stern, 2000). Values are also strongly influenced by people's upbringing and own past experiences. Research suggests continuous information campaigns can increase awareness and after some time people slowly change their decision making process to incorporate these messages into their lifestyles (Abrahamse \& Steg; Abrahamse, Steg, Vlek, \& Rothengatter, 2005; Steg, Dreijerink, \& Abrahamse, 2005). Therefore, there is a relationship, albeit a complex one, between households' values frameworks and household choices and behaviours.

\subsection{Household attributes and preferences}

Energy use, related to household attributes and preferences, is mainly driven by health, comfort and leisure activities, each of which contributes to a household's well-being and productivity. For example, physiological needs of the homebound -- that is the disabled, the elderly, very young and the sick --are different to the general population. Households with homebound groups and the unemployed spend more time at home compared to employed housing occupants and students. Health status is likely to be a factor influencing some homebound people's energy use. Even though people

\footnotetext{
${ }^{26}$ These finding are from an EECA funded survey report to understand the motivations and barriers for New Zealand households to use energy wisely. The survey $(n=803)$ found that $47 \%$ of respondents felt that 'Not enough money' was the major barrier to using energy wisely and $43 \%$ of respondents believed that 'things outside my control' was a barrier for not using energy wisely. Responses for barriers for not using energy wisely included 'Finding good information' (29\%), 'My own knowledge' (29\%) and 'Conflicting Information' (31\%). This poll was conducted late June 2009 by Synovate New Zealand, Research Now online survey panel run by Synovate New Zealand and weighted to represent New Zealand population.
} 
spending more time at home are likely to spend more on energy, they also seem to be more committed to reduce their energy use (Hall, et al., 2009). Their motivations to reduce energy may be influenced by world views such as care for the environment but are likely to be more heavily influenced by financial constraints, such as the household's ability to afford the purchase of energy. The ability to purchase energy depends on household income and employment status, energy prices and government energy subsidies.

Capable and responsive households have the ability to absorb relevant information to implement energy efficiency measures and change household behaviour to increase energy affordability. They can utilise government incentives and subsidies, and evaluate their choices with available information when purchasing energy consuming equipment to reduce household energy use. However, many households remain uninformed about government programmes and incentives, or place household energy use low on their household management priority list. An EECA study (Hall, et al., 2009) suggests households who are willing to invest in energy efficiency measures often lack money and information. Most of the solutions they are aware of require considerable funds to implement. For example, investing in solar water heating or zero energy housing initially require a large investment. Households also often felt that the payback was insufficient for the investment involved (Hall, et al., 2009).

\subsection{Household income, energy price, housing tenure and government income supplements}

Economic considerations are the basis of household energy affordability and hence strongly influence household energy demand. Energy affordability is a balance of household income and energy prices, and is strongly influenced by housing tenure. Employment opportunities tend to increase with a country's ability to generate income. As household income increases, since energy is a normal good, demand for household energy will increase. An increasing number of households, due to new household formation or increased 
immigration, will further intensify household energy demand. New Zealand's past experience suggests that energy prices are likely to continue to rise, especially if energy supply does not increase with energy demand (Ministry of Economic Development, 2009).

Governments are becoming aware of energy affordability issues with increasing household energy prices. Low-income, vulnerable groups are likely to be the most affected and long-term solutions to this issue are needed (Melhuish, 2006) Many governments around the world redistribute income received from taxation to upgrade the housing stock, in order to provide a minimum level of energy use to sustain population well-being (Ashina \& Nakata, 2008; Audenaert, Cleyn, \& Vankerckhove, 2008). Rising energy prices will shrink real (inflation-adjusted) household disposable income and create energy poverty.

Real (price-adjusted) household disposable income strongly influences the ability to save to purchase a house, and that essentially determines housing tenure as well as energy use. As population increases, demand for housing increases, lifting house prices as accessible available land is used, even if an increased supply of houses on the land that is available is forthcoming. This lift in prices may contribute to the reduction observed in New Zealand's home ownership rate this fell from $73.7 \%$ in 1986 to $66.7 \%$ in 2006 (Department of the Prime Minister and Cabinet, 2008). With increased rental housing, split incentives become important as discussed in the previous chapter. Split incentives tend to increase household energy use or reduce the energy services a household receives from a single unit of energy (International Energy Agency, 2007). Conversely, home owners can more readily implement energy efficiency measures, thereby increasing the service received from a single unit of energy. Therefore, it is likely that energy service distribution and energy affordability for homeowners and tenants are unevenly distributed in society. 


\subsection{Dwelling attributes}

Dwelling attributes also affect household energy use. Many dwelling parameters affecting thermal efficiency are hard to change once the dwelling is built. For an existing dwelling, the Building Code at the time of construction, dwelling design (reflecting the value the owner or developer places on energy efficiency or on smart design), the workmanship of the builder and quality of building materials determine the efficiency of its thermal envelope. Dwelling attributes consist of permanent, medium-term and short-term characteristics.

Permanent characteristics include climate, location or orientation, building materials, design and size. Climate determines space conditioning requirements. Changing the orientation, design and size may be feasible in the long run. However, it will likely require a large investment, inconvenience and considerable transaction costs. Such changes are unlikely to be costeffective to improve energy efficiency because the payback period is likely to be long. Houses designed to maximise passive energy and to meet zero energy standards consume less energy. Such house design includes optimising solar energy by locating windows to facilitate heating in winter and cooling in summer. Some gardens are designed for solar exposure in winter and to provide shelter in summer. Ideally, houses should be sized to meet the requirements of their occupants, although these vary over time, and the transaction costs and social dislocation of moving deter people from doing so. Government building codes also ensure houses meet mandated minimum energy efficiency standards; while in the past these have been inadequate and poorly enforced, they are nevertheless an important policy area in which further gains can be made.

Technical parameters deal with systems that have a technical potential to improve dwelling energy consumption. These include thermal envelope, space conditioning, water heating, lighting and appliances. The thermal envelope largely depends on the age of a dwelling. Most dwellings built before mandatory energy efficiency measures were introduced are likely to consume more energy than recently built dwellings. Reducing heat loss from 
the thermal envelope is a cost-effective energy efficiency measure with a short payback period. The thermal envelope includes ceiling, floor and wall insulation and draught stopping. Extra thickness of insulation is required to reduce heating energy requirement for cooler climates. Double glazing windows will save energy but the payback period will depend on the climate zone of the dwelling. Most technical parameters are medium-term characteristics.

Energy using appliances and systems (such as heating and cooling) do not last as long as the dwelling. Their life spans and payback periods are likely to vary, depending on the households' choices and preferences. Other measures with short payback periods are resealing of refrigeration appliances, energy-efficient lighting, stopping leakages from dripping water pipes, wrapping hot water cylinders, low-flow shower heads and thermal curtains.

As occupancy of a house increases, i.e. the number of occupants rise, energy use per capita decreases. This is because the common areas that need heating and lighting, and the number of some appliances (e.g. a refrigerator) tend to be constant regardless of the number of occupants.

Efficient heating systems reduce energy use for heating in households. Since heating consumes the highest proportion of energy in households in colder climates, replacing an inefficient heating system with an efficient heating system can reduce energy use significantly (Schipper, Unander, Marie-Lilliu, Walker, \& Murtishaw, 2000; Unander, Ettestøl, Ting, \& Schipper, 2004). Studies suggest that replacing wood burners with efficient heat pumps is likely to increase electricity consumption in winter (French, 2008). Moreover, it has also made space cooling more popular in summer and is thus blamed for increased electricity use. Heat pumps may meet a previously unsatisfied demand for cooling in a more efficient way.

There is also potential for reduce household energy consumption by improving the efficiency of lighting and appliances. Since modern households have a considerable number of appliances this reduction may be significant. 
Lighting, heating and appliances are considered medium-term investments. They do not last as long as houses do and are normally replaced several times during the lifetime of a house. However, efficient lighting requires installation of lighting fixtures, which may require considerable investment. At the end of their lives, lighting fixtures and appliances are often replaced with more efficient substitutes. The level of efficiency gain that could be obtained through the replacement process is significantly influenced by government regulations and information diffusion. Energy efficiency and service improvements are enhanced by government regulations, standards and accessibility to readily available information at points of purchase. The take up of improvements is also influenced by how responsive architects and builders are to new information on changing technologies and approaches.

House and technical parameters are interlinked with household income as well as household attributes and preferences. Household attributes and preferences can influence improvements to house attributes but without sufficient disposable income or government support, households are less likely to implement energy efficiency measures requiring capital investment.

Shifting from one fuel to another impacts on household energy use. For example, shifting from wood to electricity for space heating is likely to increase electricity network congestion as well as electricity generation shortages, resulting in an increase in electricity prices. As electricity prices increase, demand for alternative energy forms will increase. This demand increase will result in an increase in prices for other forms of energy. Life stage and employment status also influence type of fuels used by households. The literature suggests that as people age, the likelihood of using electricity increases, especially for heating (French, 2008). Older households tend to replace wood heating systems, which are inconvenient and sometimes impractical for older people to manage compared to electricity operated heating systems. 


\subsection{Government policies and information diffusion}

Governments increase awareness of energy efficiency and conservation among the general public through regulation, incentives, information campaigns and advice. Information campaigns and advice also include ways to eliminate energy wastage as well as smart use of energy. Governments, through regulations and standards, remove inefficient products from the marketplace and use endorsement labels to promote the most efficient products. This reduces households' time and effort needed to spend on searching for relevant information on more energy efficient products. Information and technology diffusion theories suggest that even with the best information and marketing campaigns, household energy efficiency implementation rate is slow (Wilson \& Dowlatabadi, 2007). In New Zealand, the diffusion of information about improved dwelling energy efficiency has been slow, partly because of a lack of reliable research until recently; partly because of complacency among New Zealanders about the need to heat houses adequately; and partly because of slow government policy change, compared with more activist countries such as Germany (Lah, 2009).

\subsection{Conclusion}

As the recent literature suggests, it is important to understand the drivers of household energy use from an inter-disciplinary perspective (Wilson \& Dowlatabadi, 2007; Xu, et al., 2008). The approach outlined in this chapter incorporates a wide range of influences. It identifies the potential to save energy, as well as barriers to reduce energy and improve energy affordability in dwellings. New Zealand houses are comparatively cold (Lloyd, 2006). Upgrades to housing quality alone are unlikely to substantially increase the indoor temperature in New Zealand dwellings; however, Howden-Chapman et al have shown that even small increases in low indoor temperatures have a demonstrable impact in improving household health. Arguably, from the perspective of improving health and well-being, households' energy use for space heating should be increased, but a preliminary step is for cost-effective 
steps to improve dwelling efficiency, especially by improved insulation, to be taken. As households do increase indoor temperatures, total energy used for household heating is likely to rise. Potential energy saving opportunities from water heating targeted by government policies has been implemented to exploit such opportunities. The policies include grants for solar water heating, low flow shower heads and information campaigns. Further opportunities seem limited. However, at present, most households are not aware that energy use can be reduced by energy efficient lighting and small appliances including entertainment devices. Therefore, understanding household preferences, behaviour and choices in relation to lighting and small appliance use, including entertainment devices, are important and likely to provide another opportunity for achieving energy reduction in the household sector. In summary, the diagram in figure 1 can be used to understand and illustrate potential energy savings in the household sector, and the various drivers at work. It can also be used to identify energy efficiency potential for a household. Implementation of energy efficiency measures can be a highreturn and sustainable means of reducing energy demand. 


\section{Chapter 4 - Benchmarking New Zealand's Energy Use against Similar Economies}

\subsection{Introduction}

Benchmarking is one of the techniques used to identify countries with best practices (Helgason, 1997). This chapter explores the benchmarking of household energy use to identify countries that were successful in reducing energy used in the household sector and to understand the underlying policies and measures such countries adopted, which may have led to this reduction.

New Zealand household space heating, water heating, lighting and appliance energy used per person was benchmarked against similar energy end uses of selected OECD countries. The reasons for selecting specific countries from the OECD to be compared against New Zealand were availability of data, similarities in economic and social structure; using information from OECD countries based on such reasons is a common practice. Such comparisons are made notwithstanding the likelihood that several OECD countries (Statistics New Zealand, 2005) that have similar economic and social profiles to New Zealand, also have considerable climate and cultural differences that can impact on household behaviour, as discussed in previous chapters. For this reason, even if countries appear ostensibly similar to New Zealand, household energy behaviour may in fact diverge significantly from New Zealand's.

The purpose of this chapter is to select and examine countries with good practices in relevant areas in order to obtain insights and learnings from their policies which can in principle be translated into the New Zealand context, with the primary goal of improving energy savings in residential dwellings. This translation process requires an understanding of similarities to and differences from New Zealand. 


\subsection{Criteria for Benchmarking Selection}

An initial criterion for country selection was that the pool of countries should include countries that are culturally similar and influence our way of life. Australia and New Zealand share a common social and historical heritage and now a common market, and normally the highest flow of migration to New Zealand is from the UK (Immigration New Zealand, 2009). Thus Australia and the UK are clear candidates for benchmarking. Even though the US and Canada have Anglo-Saxon origins, their energy use profiles are very different to New Zealand. Norway, Denmark and Sweden were selected because of their highly effective integrated environmental and economic policies, which New Zealanders (or at least some) aspire to emulate.

Important potential similarities were also considered in terms of per person energy supply, per person gross domestic product (GDP), per person $\mathrm{CO}_{2}$ emissions, proportion of renewables in the fuel mix, and a similar Environmental Performance Index (EPI) (Yale University \& Columbia University, 2008). Data were obtained from the OECD Fact File 2009 based on 2007 OECD country statistics. Standardised OECD data were preferred over data sourced from individual countries.

Data sources were checked to ensure the availability of data on household energy end-use per person for two points in time over the last two decades so that an assessment of the success in reducing energy use could be made. Data were obtained from an IEA publication, which compares energy end-use for 1990 and 2004 (International Energy Agency, 2007). The space heating data in this publication was corrected to reflect yearly climate variation.

\subsection{Energy and Environmental Performance}

In this section the energy and environmental performance of the selected countries are discussed and compared focusing on points of similarity but points of differences are also acknowledged. In summary, the reasons for this 
filtering are as follows. Culturally, Australia and the UK are very similar to New Zealand, as described above. Norway, Sweden and Denmark are environmentally conscious as New Zealand aspires to be. Denmark and New Zealand are similar in having agriculture based economies whose brand relies significantly on being 'clean and green' (Amine, 2003; Gabzdylova, 2009). Additionally, Denmark has been successful in reducing $\mathrm{CO}_{2}$ emissions and maintaining stable energy consumption (Ministry of Environment (Denmark), 2007) despite GDP growth, unlike New Zealand. Even though Ireland and New Zealand have similar characteristics, Ireland was not selected because of the unavailability of household energy end-use data.

In the figures and diagrams included in this chapter, selected benchmark countries are circled green, and red squares show countries that have dissimilar characteristics.

\subsubsection{Proportion of Renewables in Energy Supply and GDP}

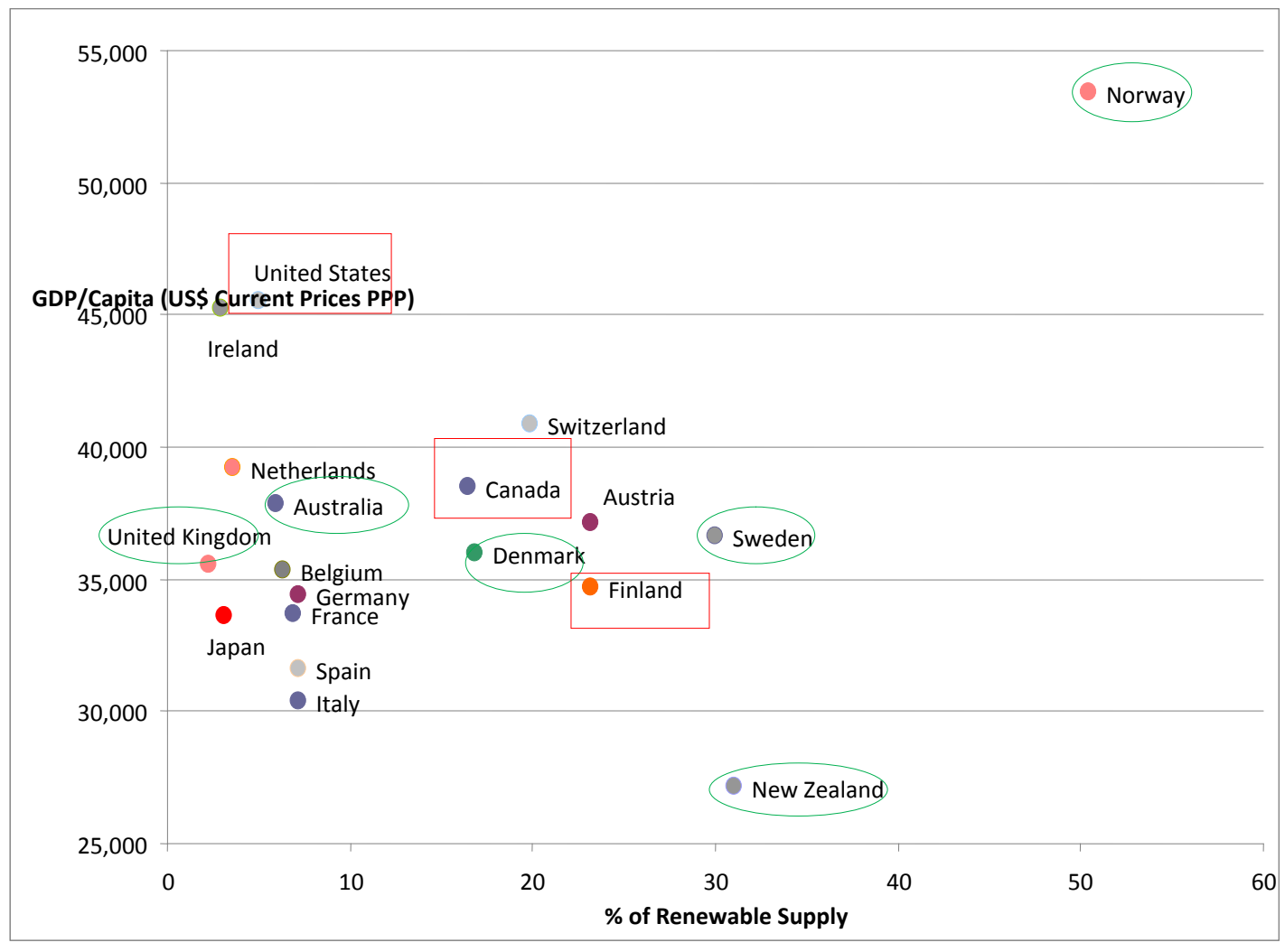

Figure 4.1: Gross domestic product per person and percentage of Renewables in Energy Supply 
Figure 4.1 shows the association between proportion of renewables in energy supply and gross domestic product. Norway, New Zealand and Sweden have a high proportion (more than 30\%) of renewables in their energy supply, which is basically hydro electricity. At the other extreme, the percentages of renewable energy of UK (2.3\%), Ireland (2.9\%), Japan (3.1\%), the Netherlands (3.6\%), the United States (5\%), Australia (6\%), Belgium (6.3\%), France (6.9\%), Germany (7.2\%), Spain (7.2\%) and Italy (7.2\%) are less than $10 \%$ of their total primary energy supply.

Many countries in Figure 4.1 generate electricity from nuclear power. The proportion of nuclear power in their total electricity generation is as follows: the Netherlands (4\%), Canada (14.7\%), the UK (15.7\%), Spain (17.8\%), the US (19.4\%), Germany (23.2\%), Japan (25.6\%), Finland (29\%), Switzerland (39.9\%), Sweden (47.4\%), Belgium (54.1\%) and France (76.8\%). These figures ignore imports and exports of nuclear electricity from nearby countries.

Norway and Denmark do not generate electricity from nuclear power. Even though Sweden generates electricity from nuclear power, it has a high proportion of renewables in its fuel mix like New Zealand and has also curbed its $\mathrm{CO}_{2}$ emissions. The Nuclear Power Referendum 1980 (Holm, 2001) showed that, like New Zealand, residents of Sweden do not want nuclear energy in their fuel mix. However, in the beginning of 2009, Swedish government has announced plans to lift the ban on construction of nuclear reactors in Sweden. The reason for this policy stance is to reduce Sweden's increasing dependency on energy imports and $\mathrm{CO}_{2}$ emissions (Guardian, 2009).

\subsubsection{Total Primary Energy Supply and GDP}

In 2006, largest energy consuming countries in descending order were Luxembourg (351 GJ/capita), Canada (204 GJ/Capita), Finland (202 GJ/Capita) and the US (194 GJ/Capita). The average energy consumption for the other IEA member countries was around 95 GJ/Capita (IEA, 2009). The 
US and Canada were deemed unsuitable because of high per person energy consumption and extreme climate zones, and high variability of energy use across the country.

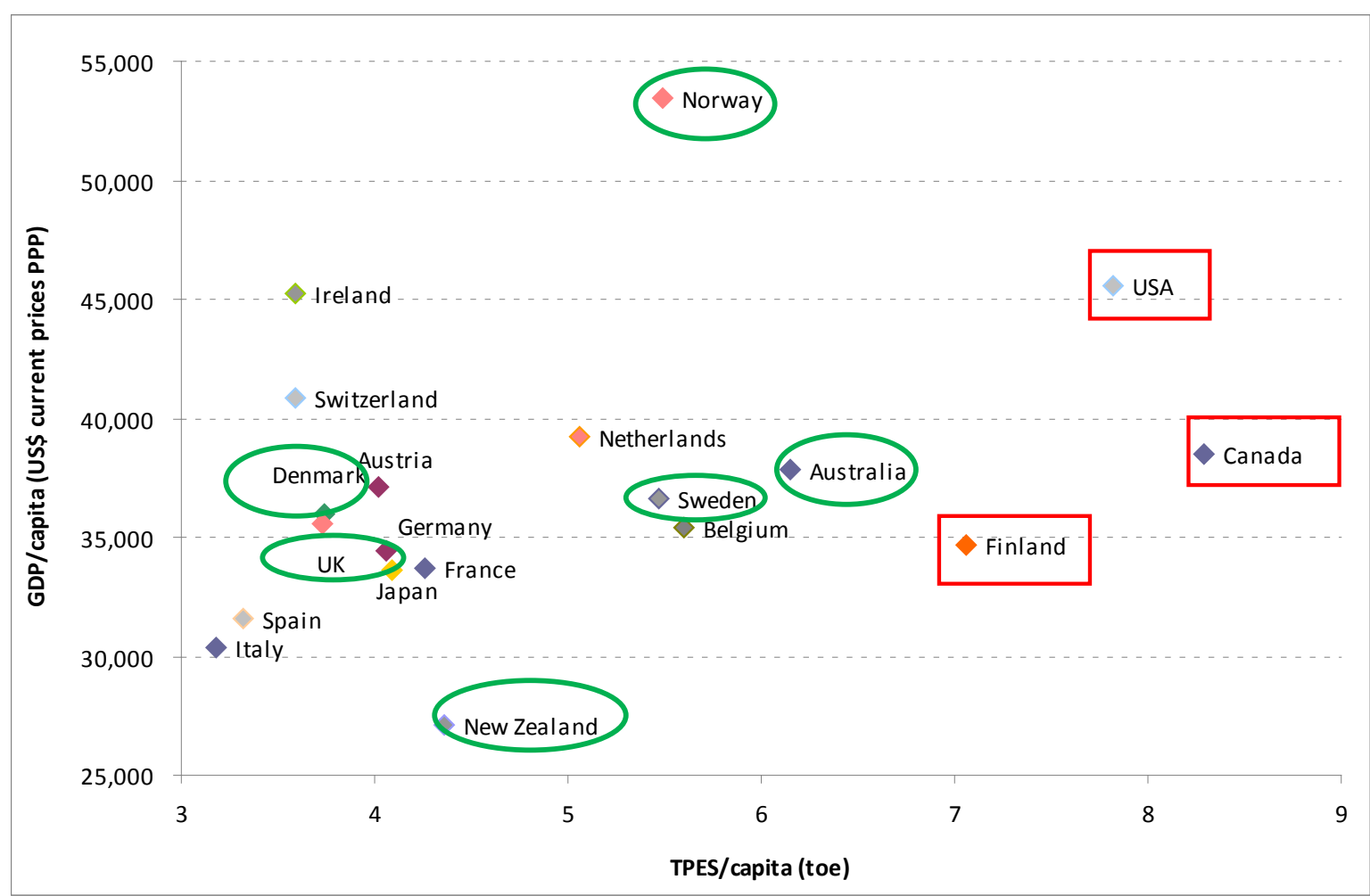

Figure 4.2: Total Primary Energy Supply per person and Gross Domestic Energy per person for OECD countries in 2007 (OECD, 2009)

Figure 4.2 shows the energy related association between per person GDP and per person total primary energy supply for selected OECD countries. Italy has the lowest TPES/capita because it has a mild climate, the least total travel and also produces a least amount of carbon emissions in its gross domestic production (IEA, 2009). USA, Canada and Finland use more energy per person than other countries. New Zealand is an outlier in that it uses considerably more energy per person than its GDP per person would merit $^{27}$.

Figure 4.2 does not illustrate the contribution of severe climates to Canada's and Finland's high energy use. However, Norway and Sweden are also cold

\footnotetext{
${ }^{27}$ This is partly because geothermal is a significant contributor to primary energy supply and it uses relatively large quantities of energy to produce electricity. Also NZ uses 5\% of its TPES for non-energy uses (e.g. gas for urea for agriculture uses)
} 
countries which use less per person energy than Canada or Finland. High GDP per person and the political will to reduce energy consumption are likely to increase access to more efficient technologies and the ability to fund research and innovation to reduce energy use.

Energy in many different forms is vital to economic activity. The level of economic activity or the GDP of an economy depends on services of physical and human capital, labour, materials and land. Examination of these diverse factors across the OECD is complex and limited to countries where data are available. The contribution of energy supply towards GDP is discussed below.

Data from the 20 countries shown in Figure 4.2 were analysed to identify the contribution of energy supply towards GDP. While the results show that in general, per person GDP is positively related to per person energy supply, the relationship between these two quantities is not statistically strong ${ }^{28}$.

It can be argued that consumer energy use by countries would be a more appropriate variable than primary energy supply to explain the relationship between energy and GDP. However, standardised consumer energy use by country is not available. Additionally, "enabling" characteristics of energy which are vital to economic activity, cannot readily be captured in a simple theoretical model such as the above.

A study by Lindenberger and Kummel (2002) suggests that energy is an enabling factor and should not be considered as a normal input. In conventional economics, the influence of energy on GDP is regarded as low

\footnotetext{
${ }^{28}$ The following results were obtained from log linear single independent variable regression.

$\log ($ GDP/person $)=4.4+0.19 \log ($ TPES/person $)$

R squared $=12 \%$ Standard error $=0.064$

The co-efficient of log (TPES/person) has estimated standard error of $0.08, \mathrm{t}=1.6$ and $p<0.001$

The equation above shows that in general, per person GDP is positively related to per person energy supply.

However, this relationship is statistically weak (as R squared is only 12\%). The regression coefficient also known as elasticity in this Cobb-Douglas function shows that a $1 \%$ change in the independent variable energy supply would be accompanied by $0.19 \%$ change in GDP per person. Energy supply per person explains only $12 \%$ of the total variation in GDP per person across the countries. The other $88 \%$ of the variation was due to the factors that are not included in the function.
} 
compared to labour and capital. However, after the first oil crisis this theory was re-examined because a decrease in energy utilisation has resulted in disproportionally large decreases in economic output (Lindenberger \& Kummel, 2002).

\subsection{3 $\mathrm{CO}_{2}$ Emissions and GDP}

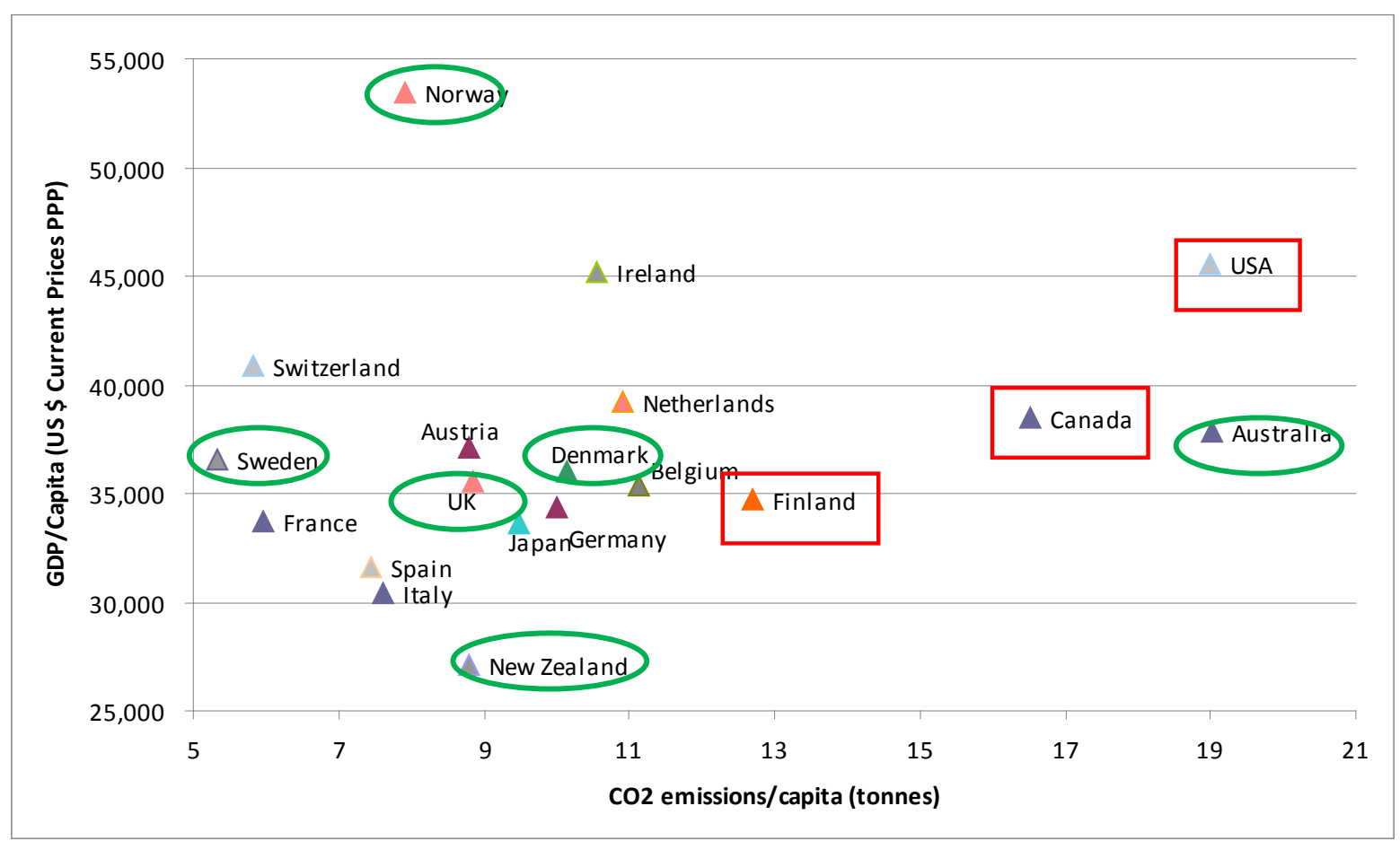

Figure 4.3: $\mathrm{CO}_{2}$ emissions from fuel combustion per person and Gross Domestic Energy per person for OECD countries

Figure 4.3 shows the association between per person $\mathrm{CO}_{2}$ emissions and per person GDP for selected OECD countries. The USA, Australia and Canada emit more per person $\mathrm{CO}_{2}$ than other countries. A likely reason for this is the high use of private passenger transport modes in these countries (IEA, 2007). Additionally, in the US and Australia primary source used to generate electricity is coal Sweden has the lowest per person $\mathrm{CO}_{2}$ emissions because a high proportion of its energy is sourced from renewable sources (30\%). Furthermore, Sweden generates about $47 \%$ of its electricity from nuclear energy. 
However, literature discussed in Chapter Two suggests that countries with high electricity generation from fossil fuels take extra effort to reduce their energy use. It can be argued that some green house gas emission reductions can be achieved by switching to a fuel with a higher calorific value. For example, the use of gas instead of coal is likely to reduce energy use and greenhouse gas emissions.

New Zealand's $\mathrm{CO}_{2}$ per person is again high relative to its GDP per person. Put another way, at a level of 8.8 tonnes $\mathrm{CO}_{2}$ per capita, it might be expected that NZ, GDP per person would be around $\$ 34,000$ whereas it is around $\$ 27,000$.

\subsubsection{Environmental Performance Index (EPI)}

EPI measures progress against Goal 7 of the Millennium Development Goals: Ensure environmental sustainability (United Nations, 2009). The objectives of EPI are to identify countries that are actively working towards "reducing environmental stresses to human health" and "promoting ecosystem vitality and sound natural resource management" (Yale University \& Columbia University, 2008). EPI tracks policy changes across environmental health, air pollution, water resources, biodiversity and habitat, productive natural resources and climate changes to identify the performance of countries.

Figure 4.4 shows 2006 and 2008 EPI for selected countries. The top five performing countries in 2008, in descending order of the index were Switzerland, Norway, Sweden, Denmark and Costa Rica. These countries have resources for environmental management with the exception of Costa Rica, which is a middle income country. UK and Denmark are in the bottom half and Australia was almost at the bottom (Yale University \& Columbia University, 2008). The worst performing countries in descending order are Niger, Angola, Sierra Leone, Mauritania and Mali. These countries are the poorest among the countries. 
New Zealand was at the top in 2006 pilot study but by 2008 it moved down to seventh place. The reason for this is not clear from the study. However, EPI report states that data collection had improved in 2008 when compared with 2006.

EPI suggests countries with the ability to invest in environmental management are progressing towards the objectives of goal 7 of the Millennium Goals. However, the performance of a middle income country such as Costa Rica shows that it is not impossible for the other countries to accomplish these objectives especially when compared with affluent countries such as UK, Denmark, US and Australia.

\section{Environmental Performance Index 2008 and 2006}

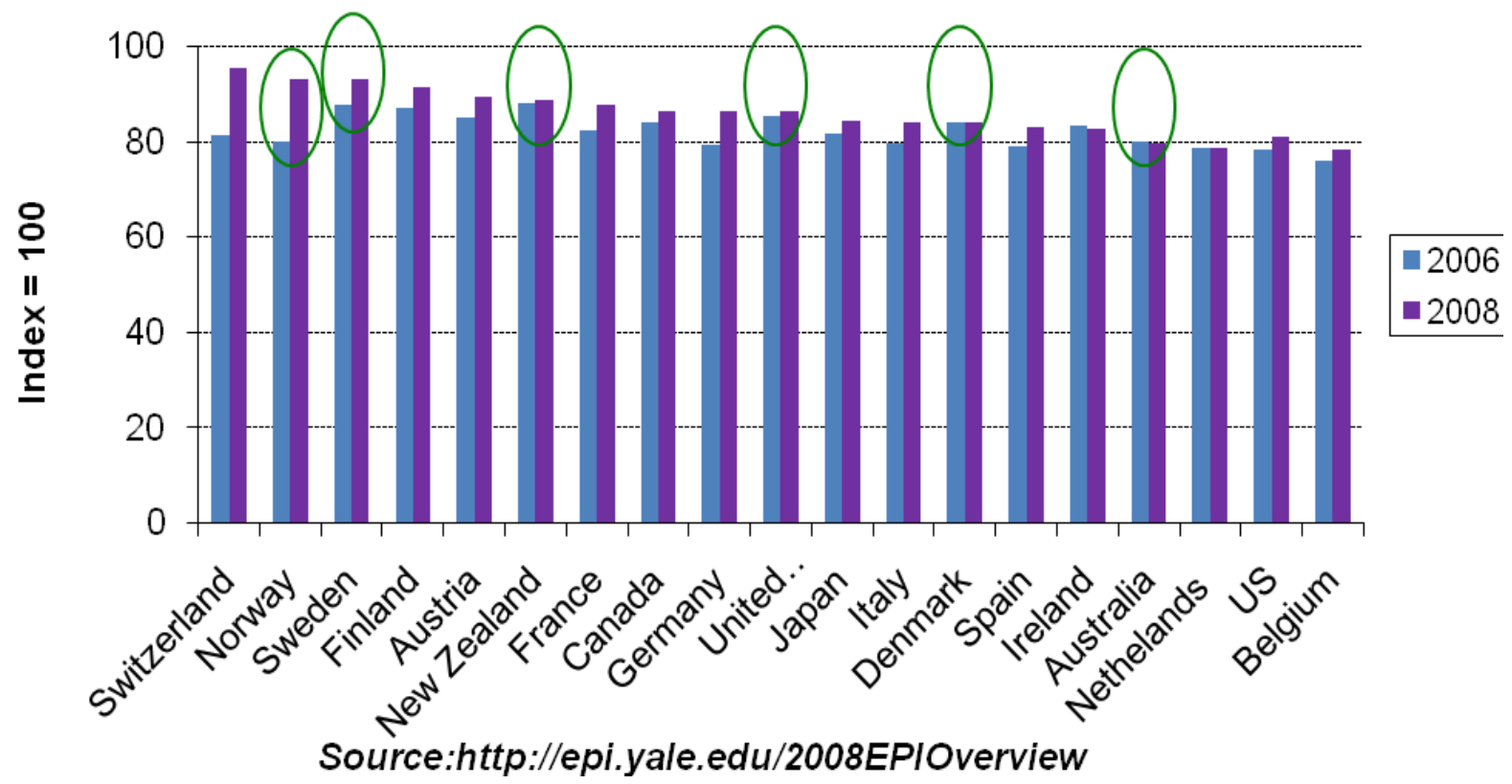

Figure 4.4: Environmental Performance Index for 2006 and 2008 


\subsection{Overview of Countries selected for Benchmarking}

Table 4.1 below shows the characteristics of selected countries focusing on similarities, differences and their policy relevance to New Zealand.

Table 4.1: Overview of Countries in Benchmark Country Selection

\begin{tabular}{|c|c|c|c|}
\hline Country & Similarities & Differences & Relevance for New Zealand \\
\hline Norway & $\begin{array}{l}\text { - } \begin{array}{l}\text { Similar in } \\
\text { population (less } \\
\text { than } 5 \text { million) }\end{array} \\
\text { - Similar } \\
\text { environmental } \\
\text { laws (Salmon et } \\
\text { al, 2008) } \\
\text { - High proportion of } \\
\text { energy from } \\
\text { renewables } \\
\text { Major proportion } \\
\text { of electricity is } \\
\text { from hydro } \\
\text { De-regulated } \\
\text { electricity market } \\
\text { Party to Kyoto } \\
\text { Protocol and need } \\
\text { to limit its GHG } \\
\text { emissions to no } \\
\text { more than } 1 \% \\
\text { above their } 1990 \\
\text { level } \\
\text { Data availability }\end{array}$ & 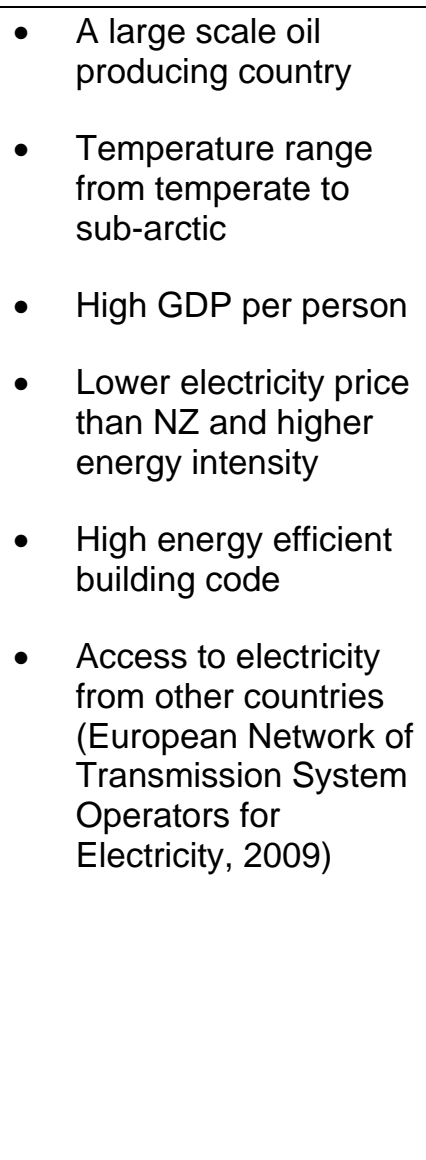 & $\begin{array}{l}\text { - } \begin{array}{l}\text { Develops economy with } \\
\text { considerations to } \\
\text { environment }\end{array} \\
\text { - Negligible household } \\
\text { sector energy savings } \\
\text { from } 1973 \text { - } 1990 \text { but } \\
\text { considerable during } 1990 \\
\text { - } 1999 \text { (Unander, } \\
\text { Ettestøl, Ting, \& } \\
\text { Schipper, 2004) } \\
\text { - Reduced household } \\
\text { sector energy use by } \\
\text { improving dwelling } \\
\text { thermal envelopes } \\
\text { "Collaborative } \\
\text { Governance" and } \\
\text { committed, multi-partisan } \\
\text { long term leadership on } \\
\text { environmental issues } \\
\text { (Salmon et al, 2008) }\end{array}$ \\
\hline
\end{tabular}




\begin{tabular}{|c|c|c|c|}
\hline Country & Similarities & Differences & $\begin{array}{l}\text { Relevance for New } \\
\text { Zealand }\end{array}$ \\
\hline Sweden & $\begin{array}{l}\text { - High proportion of } \\
\text { energy from } \\
\text { renewables } \\
\text { - Similar } \\
\text { environmental laws } \\
\text { (Salmon et al, } \\
\text { 2008) } \\
\text { - Swedish people } \\
\text { demand to phase } \\
\text { out nuclear energy } \\
\text { (OECD/IEA, 2008) } \\
\text { De-regulated } \\
\text { electricity market } \\
\text { Party to Kyoto } \\
\text { Protocol and } \\
\text { needs to limit its } \\
\text { GHG emissions to } \\
\text { no more than } 4 \% \\
\text { above their } 1990 \\
\text { level (OECD/IEA, } \\
\text { 2008) } \\
\text { Data availability }\end{array}$ & $\begin{array}{l}\text { Generates electricity } \\
\text { from nuclear energy } \\
\text { (World Nuclear } \\
\text { Association, 2009) } \\
\text { - Temperature ranges } \\
\text { from temperate to sub- } \\
\text { arctic (second highest } \\
\text { space heating } \\
\text { requirement in the IEA } \\
\text { - measured by degree } \\
\text { days (OECD/IEA, } \\
\text { 2008) } \\
\text { Energy policy goals } \\
\text { are derived from the } \\
\text { EU levels and deals } \\
\text { with the energy system } \\
\text { as a whole } \\
\text { EU binding targets for } \\
\text { total GHG emissions } \\
\text { (OECD/IEA, 2008) } \\
\text { High energy efficiency } \\
\text { Building Standards } \\
\text { (OECD/IEA, 2008) } \\
\text { Access to electricity } \\
\text { from other countries } \\
\text { (ENTSOE, 2009) }\end{array}$ & 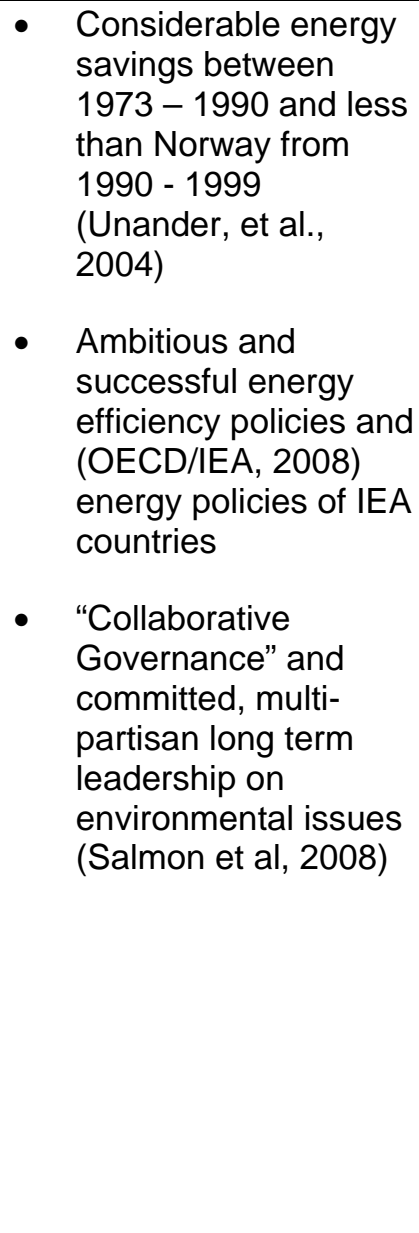 \\
\hline Denmark & 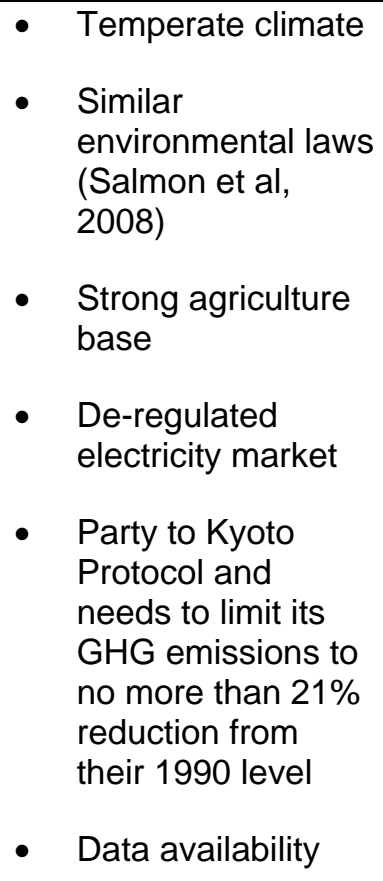 & $\begin{array}{l}\text { - Higher electricity prices } \\
\text { than New Zealand and } \\
\text { lower energy intensity } \\
\text { - } \quad \begin{array}{l}\text { Stringent building } \\
\text { standards }\end{array} \\
\text { - } \quad \text { Self-sufficient in oil } \\
\text { - TPES constant over } \\
\text { the last thirty years } \\
\text { - Access to electricity } \\
\text { from other countries } \\
\text { (ENTSOE, 2009) }\end{array}$ & 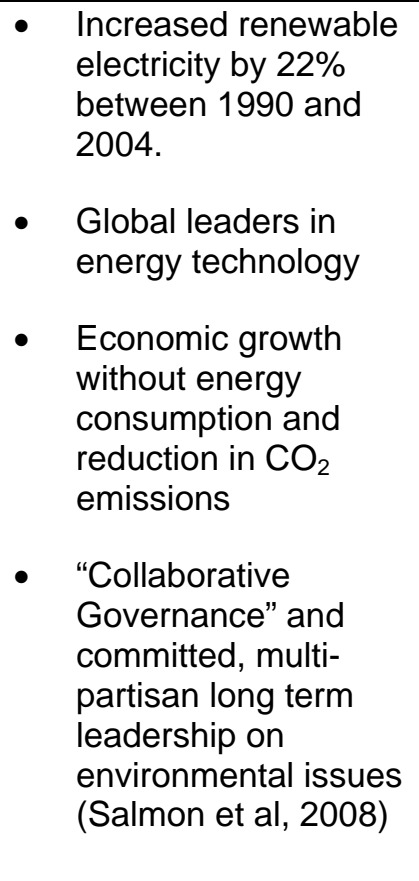 \\
\hline
\end{tabular}




\begin{tabular}{|c|c|c|c|}
\hline Country & Similarities & Differences & $\begin{array}{l}\text { Relevance for New } \\
\text { Zealand }\end{array}$ \\
\hline UK & $\begin{array}{l}\text { - Cultural similarities } \\
\text { owing to NZ being a } \\
\text { British colony and high } \\
\text { migration from UK } \\
\text { (Immigration NZ, 2009) } \\
\text { - Improvements to } \\
\text { dwelling thermal } \\
\text { envelopes } \\
\text { - Temperate climate } \\
\text { - De-regulated electricity } \\
\text { market } \\
\text { - Party to Kyoto Protocol } \\
\text { and needs to limit its } \\
\text { GHG emissions by } \\
12.5 \% \text { below } 1990 \text { level } \\
\text { (international Energy } \\
\text { Agency, 2006) } \\
\text { Data availability }\end{array}$ & 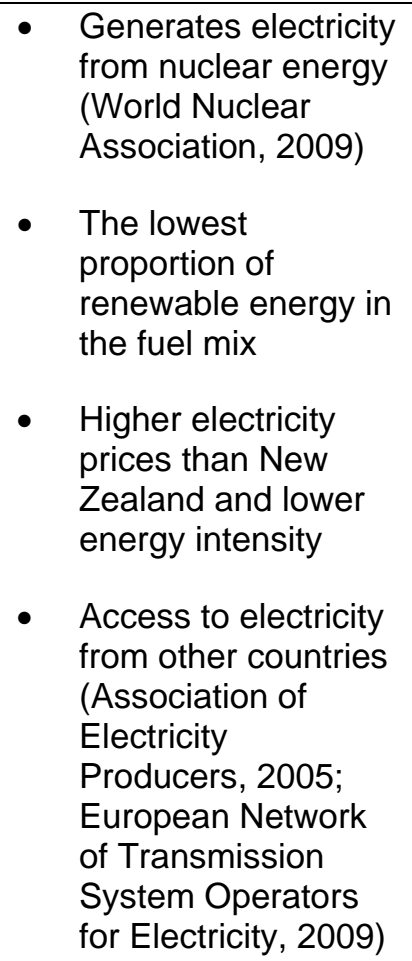 & $\begin{array}{l}\text { - High government } \\
\text { commitment to } \\
\text { reduce } \mathrm{CO}_{2} \\
\text { emissions } \\
\text { (National Audit } \\
\text { Office, 2008) } \\
\text { - Policies to } \\
\text { address energy } \\
\text { affordability }\end{array}$ \\
\hline Australia & 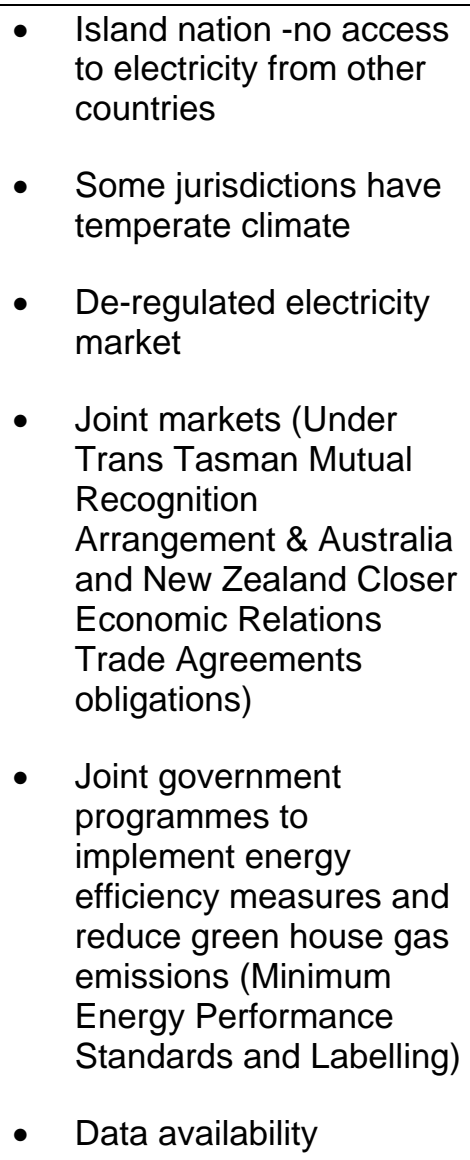 & $\begin{array}{l}\text { - High proportion of } \\
\text { electricity from fossil } \\
\text { fuels } \\
\text { - } \quad \text { Lower electricity } \\
\text { price than NZ and } \\
\text { higher energy } \\
\text { intensity } \\
\text { - Signatory (not } \\
\text { ratified) to Kyoto } \\
\text { obligation with a } \\
\text { target to limit GHG } \\
\text { emissions to 108\% } \\
\text { of the 1990 level } \\
\text { (International Energy } \\
\text { Agency, 2005). }\end{array}$ & $\begin{array}{l}\text { Need to } \\
\text { understand } \\
\text { drivers, similarities } \\
\text { and differences to } \\
\text { obtain an effective } \\
\text { household sector } \\
\text { energy outcome to } \\
\text { New Zealand } \\
\text { under joint } \\
\text { programmes }\end{array}$ \\
\hline
\end{tabular}

The next section analyses household sector energy end-uses. 


\subsection{Changes in household sector end-use}

The tables below show the change in energy performance for household sector end-uses in selected OECD countries. If a country had reduced per person household energy end-use in 2004 compared to 1990, that country is marked with a " $x$ " in the 'Yes' column and otherwise " $x$ " was marked in the 'No' column.

\subsubsection{Changes in space heating energy use}

Table 4.2: Energy used for per person household space heating (International Energy Agency, 2007)

\begin{tabular}{|l|c|c|}
\hline Country & Space heating performance Improved \\
\hline \multirow{2}{*}{ Austria } & Yes & No \\
\cline { 2 - 3 } Canada & $\mathrm{x}$ & $\mathrm{x}$ \\
Denmark & $\mathrm{x}$ & \\
Finland & $\mathrm{x}$ & \\
France & $\mathrm{x}$ & $\mathrm{x}$ \\
Germany & & $\mathrm{x}$ \\
Italy & & $\mathrm{x}$ \\
Japan & & \\
Netherlands & $\mathrm{x}$ & \\
Norway & $\mathrm{x}$ & \\
Spain & & $\mathrm{x}$ \\
Sweden & $\mathrm{x}$ & \\
UK & $\mathrm{x}$ & \\
USA & & \\
\hline
\end{tabular}

Table 4.2 shows the changes in space heating per person between 1990 and 2004. The USA, Sweden, Norway, the Netherlands, France, Finland, Denmark and Canada were able reduce per person space heating during this period whereas the UK and Japan have been increasing. For example, during this period the Netherlands reduced average energy consumption per dwelling by $16 \%$ whereas energy consumption rose in UK by $2 \%$. It should be noted that the Netherlands initiated policies for reducing energy consumption 
a decade before the UK did (House of Commons Information Office, 2009). Reduction of energy use per capita in Sweden, Norway, the Netherlands, France, Finland and Denmark resulted from decades of systematic improvements to energy efficiency and conservation policies. This was a direct result of oil price shocks in the 1970s (IEA, 2009). The increase in household sector energy use in UK and Japan can be attributed to households' demand for warmer homes (House of Commons Information Office, 2009) .

\subsubsection{Changes in water heating energy use}

Table 4.3: Energy used for household per person water heating (International Energy Agency, 2007)

\begin{tabular}{|l|c|c|}
\hline \multirow{2}{*}{ Country } & \multicolumn{2}{|c|}{ Water heating performance Improved } \\
\hline Austria & Yes & No \\
\hline Canada & $\mathrm{x}$ & $\mathrm{x}$ \\
\hline Denmark & & $\mathrm{x}$ \\
\hline Finland & & $\mathrm{x}$ \\
\hline France & & $\mathrm{x}$ \\
\hline Germany & & $\mathrm{x}$ \\
\hline Italy & $\mathrm{x}$ & $\mathrm{x}$ \\
\hline Japan & & $\mathrm{x}$ \\
\hline Netherlands & $\mathrm{x}$ & $\mathrm{x}$ \\
\hline Norway & & $\mathrm{x}$ \\
\hline Spain & $\mathrm{x}$ & \\
\hline Sweden & & \\
\hline UK & & \\
\hline USA & & \\
\hline
\end{tabular}

Table 4.3 above shows the USA, Sweden, Norway, Italy and Canada were the only countries to improve water heating energy use over the period from 1990 to 2004. Canada's reduction in water heating energy is attributed to increased efficiency in water heating equipment (Natural Resources Canada, 2009). The implementation of federal standards for water heating of all water heaters manufactured after 1990 may have resulted in the reduction in water heating per person in the USA (ASaP, 2007). Sweden's success was 
achieved by government subsidised ground-source heat pump systems that are widely used for water heating (Karlsson, 2003).

\subsubsection{Changes in lighting energy Use}

Table 4.4 below shows that energy use for lighting reduced only in Sweden. One possible reason for this is that Swedish authorities started campaigning for efficient lighting in 1993. Sweden claims it took 25 years for the campaign to gain widespread recognition. Sweden also draws heavily from standardisation initiative in other countries such as the US ENERGY STAR $®$ and strives to prevent underperforming inefficient lighting devices from entering the Swedish market (Swedish Energy Agency, 2006). Norwegians' preference for warm cosy lights may be a reason for not being able to reduce electricity use for lighting (Waide, 2007).

Table 4.4: Energy used for per person household lighting (International Energy Agency, 2007)

\begin{tabular}{|l|c|c|}
\hline Country & \multicolumn{2}{|c|}{ Lighting performance improved } \\
\hline Austria & & No \\
\hline Canada & & $x$ \\
\hline Denmark & & $x$ \\
\hline Finland & & $x$ \\
\hline France & & $x$ \\
\hline Germany & & $x$ \\
\hline Italy & & $x$ \\
\hline Japan & & $x$ \\
\hline Netherlands & & $x$ \\
\hline Norway & & $x$ \\
\hline Spain & & $x$ \\
\hline Sweden & & $x$ \\
\hline UK & & \\
\hline USA & & \\
\hline
\end{tabular}




\subsubsection{Changes in household appliances energy use}

Table 4.5: Energy used for household appliances (International Energy Agency, 2007)

\begin{tabular}{|l|c|c|}
\hline \multirow{3}{*}{ Country } & \multicolumn{2}{|c|}{ Appliance performance improved } \\
\hline Austria & Yes & No \\
\cline { 2 - 3 } Canada & & $\mathrm{x}$ \\
Denmark & $\mathrm{x}$ & $\mathrm{x}$ \\
Finland & & $\mathrm{x}$ \\
France & & $\mathrm{x}$ \\
Germany & & $\mathrm{x}$ \\
Italy & & $\mathrm{x}$ \\
Japan & & $\mathrm{x}$ \\
Netherlands & & $\mathrm{x}$ \\
Norway & & $\mathrm{x}$ \\
Spain & $\mathrm{x}$ & $\mathrm{x}$ \\
Sweden & & $\mathrm{x}$ \\
UK & & $\mathrm{x}$ \\
USA & & \\
\hline
\end{tabular}

Table 4.5 shows that appliance energy use decreased only in Norway and Canada whereas appliance energy use has increased in all other countries. A European Commission study found that Norwegians are good at switching off electrical appliances (Sintef, 2008). Another reason is likely to be that TV viewing time in Norway is less than in other countries - for example 18 hours per week in Norway (Statistical Year Book of Norway 2008, Statistics Norway) compared to 33.6 hours per week in New Zealand (EECA TV Usage and Purchasing Survey 2009). Reduction in Canadian appliance energy use are attributed to increased efficiencies in household appliances (Natural Resources Canada, 2009).

Appliance energy use in IEA $15^{29}$ countries has increased by $50 \%$ between 1990 and 2004. This is likely to have huge repercussions on energy consumption profiles around the world. In 2004, appliances and water heating in dwellings in IEA countries used $20 \%$ and $17 \%$ of household sector

\footnotetext{
${ }^{29}$ Austria, Canada, Denmark, Finland, France, Germany, Italy, Japan, Netherlands, New Zealand, Norway, Spain, Sweden, UK and US
} 
energy respectively. Appliance energy performance regulations have reduced per unit energy consumption for all major appliances ${ }^{30}$ except for televisions. Television energy consumption increased because of larger screens and increased ownership (IEA, 2007). Furthermore, energy use by consumer electronics (CE) is increasing all over the world. CE energy use is dominated by computers, televisions and their peripheral devices. Energy use by televisions and computers is not regulated in Australia and New Zealand. Therefore, escalation of household energy use was attributed to unregulated products and multiple-ownership of these products.

IEA (2007) studies indicate large-appliance energy use had reduced with the introduction of Minimum Energy Performance Standards (MEPS) and Minimum Energy Performance Labelling (MEPL). The studies also highlighted the increasing energy use by consumer electronics. Rapid technology development in entertainment devices and their short life span suggest it may not be effective to regulate these products. However, once an energy-using product enters a household, an inefficient product will consume more energy than is necessary both in operation and standby modes.

The UK studies also (Owen, 2006 \& 2007) discuss the increase in electricity use in household consumer electronics. Energy use by televisions, personal computers and their peripheral devices are identified as the major growth areas.

\subsection{Summary}

The UK, Australia, Canada and the US have a cultural heritage similar to New Zealand. Norway, Sweden and Denmark have high renewable energy proportions unlike France where over $75 \%$ of electricity generated from nuclear energy. All selected countries except Norway have lower proportions of renewable energy than New Zealand. Dissimilarities in energy use due to

${ }^{30}$ Refrigerators, washing machines, clothes dryers, dishwashers and televisions 
extreme weather conditions and practices of Canada and the US, remove them from being suitable candidates to benchmark against New Zealand.

All selected countries have higher GDP per person than New Zealand. However, only Denmark and UK from selected candidates use less energy supply per person than New Zealand.

Out of all selected countries, only Sweden and Norway have less $\mathrm{CO}_{2}$ emissions from fuel combustion than New Zealand. Environmental Performance Index shows Norway and Sweden are better environment stewards than New Zealand. Furthermore, the performance of a middle income country like Costa Rica shows that there are other factors beside high income, which enable a country to better manage the environment. 


\begin{tabular}{|c|c|c|}
\hline Criteria & $\begin{array}{l}\text { Similar to New } \\
\text { Zealand }\end{array}$ & Not Similar to New Zealand \\
\hline Culture & $\begin{array}{l}\text { UK, Australia, US, } \\
\text { Canada }\end{array}$ & Japan, Spain, Italy \\
\hline $\begin{array}{l}\text { Percentage of } \\
\text { renewables }\end{array}$ & Norway, Sweden & France, UK, Australia \\
\hline $\begin{array}{l}\text { Electricity from } \\
\text { Nuclear Energy }\end{array}$ & Norway, Denmark & $\begin{array}{l}\text { Sweden, UK, Finland, } \\
\text { Switzerland }\end{array}$ \\
\hline $\begin{array}{l}\text { Electricity from fossil } \\
\text { fuels Generation }\end{array}$ & Norway, Sweden & Australia, UK, Japan \\
\hline Per person GDP & & $\begin{array}{l}\text { Norway, US, Canada, Australia } \\
\text { Sweden, UK, Finland }\end{array}$ \\
\hline Per person $\mathrm{CO}_{2}$ & $\begin{array}{l}\text { Austria, UK, New } \\
\text { Zealand }\end{array}$ & $\begin{array}{l}\text { Sweden, Norway, Finland, } \\
\text { Canada, US, Australia }\end{array}$ \\
\hline EPI & $\begin{array}{l}\text { Finland, Austria, } \\
\text { France, Canada }\end{array}$ & $\begin{array}{l}\text { Switzerland, Norway, Sweden, } \\
\text { UK, Denmark, Australia, US }\end{array}$ \\
\hline Space heating & UK, Austria, Japan & $\begin{array}{l}\text { Norway, Sweden, Denmark, } \\
\text { US, Canada, Netherlands, } \\
\text { Finland }\end{array}$ \\
\hline Water heating & $\begin{array}{l}\text { Austria, Denmark, } \\
\text { UK }\end{array}$ & Norway, Sweden, US, Canada \\
\hline Lighting & $\begin{array}{l}\text { Norway, Canada, } \\
\text { Denmark, US, UK }\end{array}$ & Sweden \\
\hline Appliances & $\begin{array}{l}\text { Austria, Denmark, } \\
\text { Sweden, US, UK }\end{array}$ & Norway \\
\hline
\end{tabular}

The above table shows Norway and Sweden are countries that New Zealand should aspire to be. Their energy mix has high proportion of renewables similar to New Zealand. Even though Sweden unlike Norway has electricity generated by nuclear, both countries do not generate a higher proportion of electricity from fossil fuel, which is similar to New Zealand. Although, both Sweden and Norway have a higher per person GDP than New Zealand, they have lower per person $\mathrm{CO}_{2}$ emissions. 
Australia and the UK policies have not delivered better energy reduction or environmental management. However, a close study may reveal that their successful policies may be more acceptable to people of New Zealand than policies from any other country because of its closer relationship with Australia and the UK. Even from a household energy end-use point of view, both Norway and Sweden have reduced their energy use for space and water heating. Further, Sweden has managed to reduce energy used for lighting whereas Norway has managed to reduce energy used for appliances.

Swedish and Norwegian performances show there is considerable potential to reduce lighting and appliance electricity consumption in IEA countries. It is likely that these countries have curbed electricity use by product regulation and household behaviour change, for an example Norwegians switch off their appliances when not in use. However, IEA highlights the need to understand the trends for energy intensive consumer electronics in the household sector in order to design policies for energy reduction.

Norway and Sweden seem to be more effective in reducing energy used in their household sector compared to other countries. It should be noted that the successes they have achieved are due to their unrelenting desire over a long period of time to reduce energy consumption and greenhouse gas emissions through high use of renewable energy and general attitude towards environment stewardship.

Even though energy saving policies seem similar, how they were implemented and their successes vary among countries, due to socioeconomic drivers as well as household behavioural patterns and consumer choices. Key drivers for reducing energy use seem to be high GDP per person, high proportion of renewables in total primary energy supply, reduction in $\mathrm{CO}_{2}$ emissions and investments in environmental management. The above discussed factors are likely to have contributed to the implementation of a better environmental management program, which 
resulted in higher EPI in these countries. Therefore Norway and Sweden are suitable candidates to be benchmarked against. 


\section{Chapter 5 - Television Energy Use}

\subsection{Introduction}

Households purchase energy to obtain services for maintaining healthy, comfortable and relaxing life styles. Most often these services take priority over reductions in energy use or greenhouse gas emission policies that governments are promoting. However, according to New Zealand's Energy Outlook 2009/2010 household sector energy demand seems to be impervious to the price on carbon.

Using electrical appliances for increasing comfort, reducing the effort required for household chores and entertainment is an integral part of modern lifestyle. Ownership of electrical and electronic equipment in households is increasing worldwide (International Energy Agency, 2009a). New Zealand studies (Isaacs, et al., 2006) and international studies (International Energy Agency, 2009a; Owen, 2006, 2007) confirm this trend. IEA studies (2007) show that, of household energy consumption, energy used by appliances is currently in second place after space heating. HEEP data suggest that New Zealand is lagging behind in appliance energy use compared to other IEA countries.

The study reported in this chapter focuses on energy use by television (TV) and television auxiliary appliances. There are several reasons for selecting, for further study, TV ownership, the associated technology, and TV operation and energy use. Firstly, according to a Ministry for the Environment report (UMR Research, 2006), a TV set is considered to be the most commonly owned consumer electronic appliance in New Zealand, followed by mobile telephone.

Secondly, Australian and New Zealand studies suggest that the electricity consumption of TVs is significant: it currently takes fourth place in households behind electricity use for space conditioners (including space heaters), water 
heaters and refrigerators (Department of the Environment Water Heritage and the Arts, 2008; Isaacs, et al., 2006).

Thirdly, television ownership in households is increasing due to emerging new technologies and the take-up of auxiliary entertainment devices. Another consequence of increasing TV ownership is the increasing energy usage and associated emissions, to manufacture TVs to satisfy the market demand.

Fourthly, TV consumption patterns are likely to represent both current and future trends in consumer electronics and information and communication technology (ICT) devices, albeit with some differences across types of appliance.

Finally, TVs were topical at the time this study was undertaken in 2009, because the Energy Efficiency and Conservation Authority was developing a Regulatory Impact Statement (RIS) for consultation before proceeding with Minimum Energy Performance Standards and/or Labelling (MEPS/L) regulations for TVs.

The main purpose of this study is therefore to better understand TV and auxiliary appliance energy use in New Zealand while, as noted, an immediate application is to establish a base of evidence necessary for regulating TV for MEPS/L. The study also provides a baseline estimation of the TV stock and ownership characteristics at a particular point in time, useful for further studies. Statistically significant changes between two points in time are likely to indicate changing trends in technology and household behaviour; to date there has been no robust data on these. Statistics New Zealand does not collect appliance ownership data. Understanding these patterns and trends is useful for designing cost-effective policies and interventions to reduce electricity use in consumer electronics.

This study, although carried out at only one point in time, has been able to collect some data to indicate emerging changes in household energy end-use patterns. This is valuable information, given that household energy use is 
gradually changing over time: some energy end-uses may be falling in terms of energy consumption whilst other end-uses are likely to be increasing. For example, a shift from electric resistance heating to heat pumps may be reducing electricity used for space heating (note that the take- back effect and increased use of air conditioning offset this) but total household electricity use is likely to be increasing as a result of growth in household consumer electronics.

Initially, this study was designed as a pilot survey to understand TV end-use and purchasing decisions of households as a proxy for demand for general consumer electronics and ICT devices. However, the author, as an employee of the Energy Efficiency and Conservation Authority (EECA), was able to identify EECA's immediate organisational need to better understand prevailing and future trends in TV ownership and use. Hence, the survey has also provided a New Zealand household TV profile to contribute to the Regulatory Impact Statement as noted above. The author acknowledges that this comprehensive survey dataset would not exist without EECA sponsorship.

\subsection{Television Survey Method}

An internet-based online consumer research survey method was selected as the most cost-effective means of developing a profile for ownership and use of television and TV auxiliary devices in New Zealand. The A C Nielsen Market Research company was selected to conduct the survey, as they were EECA's preferred suppliers at the time. Participants were randomly selected from the general public; the sample was weighted for household income, geographic region, age group and ethnicity to represent the Census 2006 New Zealand population. A large sample size $(n=1003)$ was selected in order to obtain nationally representative subsets from the survey data set.

According to an Internet Service Providers Survey (Statistics New Zealand, 2008), 79\% of New Zealand households could be reached by an online survey. Furthermore, with the availability of internet connections at libraries 
and at work places, the assumption was that an internet-based sample broadly covers the whole population. However, the author acknowledges that the survey is definitely biased against low income households without computers and easy access to the internet. The margin of error at a $95 \%$ confidence level for the sample of 1000 for a $50 \%$ figure is plus or minus $3.1 \%$. The results from this sample of $\sim 1000$ households were extrapolated to the total New Zealand household sector to estimate energy use by household TVs and auxiliary devices. The number of permanent private occupied dwellings was estimated at 1.6 million for the year ending June ${ }^{31}$.

The questionnaire was designed by the A C Nielsen project team under the guidance of an EECA project team led by the author. The survey was held in May 2009. The survey questionnaire had 43 questions and was designed to identify the following: the way people are using TVs in their homes; the drivers of new technology adoption; the proportion of the population who use devices other than televisions to watch mainstream television programmes; the average age of the television stock; household perceptions of TV energy use; household behaviour relating to TV retirement; how often households remove a TV from their homes; whether people associate environmental awareness with TV use behaviour; the relative importance of TVs to a household; household TV purchasing decisions; demographics of the respondents and by distribution of housing tenure and geographic area. During the design phase of the survey, the project team consulted widely including EECA and BRANZ in New Zealand, and the Department of Environment, Water, Heritage and the Arts in Australia.

\subsection{Survey Approach and Hypotheses}

To estimate energy consumption, basic parameters such as the number of TVs per household, TV technology and size, and total TV operating hours were extracted from the survey findings. Data on average TV energy use by

\footnotetext{
31 Interpolating data from Projected Families and Households by Type and Regional Council Area - Medium series 2006 (base) to 2031 (Statistics New Zealand, 2009a).
} 
size and technology were obtained from reports commissioned by the $E_{3}$ Committee $^{32}$. Importantly for the present study, data gathered by the survey was also used to determine whether households associate television watching with energy conservation and environmental awareness.

The ordinary least square multiple regression technique was used to estimate functional forms identifying the determinants of television energy use. Determinants (explanatory variables) considered were household income, household occupancy, average age of occupant, and access to flat panel displays Hypothesis development for the regression is as follows.

- Household income is often proxied by occupation and earning capability of the main income earners. Main income earners of a household are likely to be too busy to spend a lot of time watching TV. However, the other members of the household may watch more TV because they have access to up to date technology and ample leisure time. On the other hand, low income households may consider that watching TV is a relatively inexpensive form of entertainment compared to other options such attending theatre or live sports events). Overall, these considerations suggest that TV watching may be weakly negatively associated with household income.

- Households with a high occupancy rate are likely to watch more TV than others. As number of occupants increases it is likely that the occupants may prefer watching TV at different times or different programs. I therefore hypothesise that TV viewing my rise with household numbers.

- Households with low average age may spend more time watching TV. As average age of occupants increases other commitments of occupants, such as housework, studies, and other voluntary work undertaken are likely to increase. However, for many elder people, TV

\footnotetext{
${ }^{32}$ This is a committee 'consisting of officials from the Commonwealth, State and Territory government agencies and representatives from New Zealand, responsible for managing the Australian end-use energy efficiency program.' For more details visit http://www.energyrating.gov.au/naeeec.html
} 
viewing may increase. My hypothesis is that viewing will (overall) fall with household average age.

- The age of a TV set may influence viewing, as a new TV is likely to be a more pleasurable form of entertainment. The obvious hypothesis here is that viewing will be higher for newer TVs, controlling for income; i.e. that viewing will fall with TV age.

\subsection{Survey Results and Analysis ${ }^{33}$}

\subsubsection{New Zealand TV Stock Profile}

Survey data suggest the New Zealand television stock to be around 3.56 million television sets in mid-2009. The New Zealand population in mid-2009 was around 4.3 million (Statistics New Zealand, 2009b); there is therefore on average almost one TV set $(\sim 0.83)$ for each person in New Zealand. The television stock consists of 2.31 million Cathode Ray Tubes (CRTs), 0.68 million Liquid Crystal Displays (LCDs) and 0.25 million plasma televisions. Some respondents were not able to distinguish between LCD and plasma TVs and 0.32 million identified their TVs as flat panel displays.

\subsubsection{TV Ownership}

Households, on average, have 2.2 working TVs in 2009 compared with 2 working TVs in 2006 (UMR Research, 2006). TVs in storage increased from 0.2 to 0.5 per household from 2006 to 2009. Furthermore, digital TV has penetrated to about $31 \%$ of households, while $11 \%$ of households do not know whether their TVs are digital or not. $25 \%$ of households have access to other forms of technology such as projectors or computers to watch mainstream TV.

Figure 5.1 shows that, most often, households have two operating TVs (40\%) with significant numbers having one (27\%) and three TVs (21\%). However,

\footnotetext{
${ }^{33}$ Note that in this chapter all Tables are based on the results of the survey, unless otherwise specified.
} 
some households have 4 TVs (8\%), 5 TVs (2\%) or 6 or more TVs (1\%). Only $1 \%$ of households did not have any TVs. One household had 11 TVs (from a sample size of 1003). Interestingly, about $38 \%$ of households have one or more TVs unused or in storage.

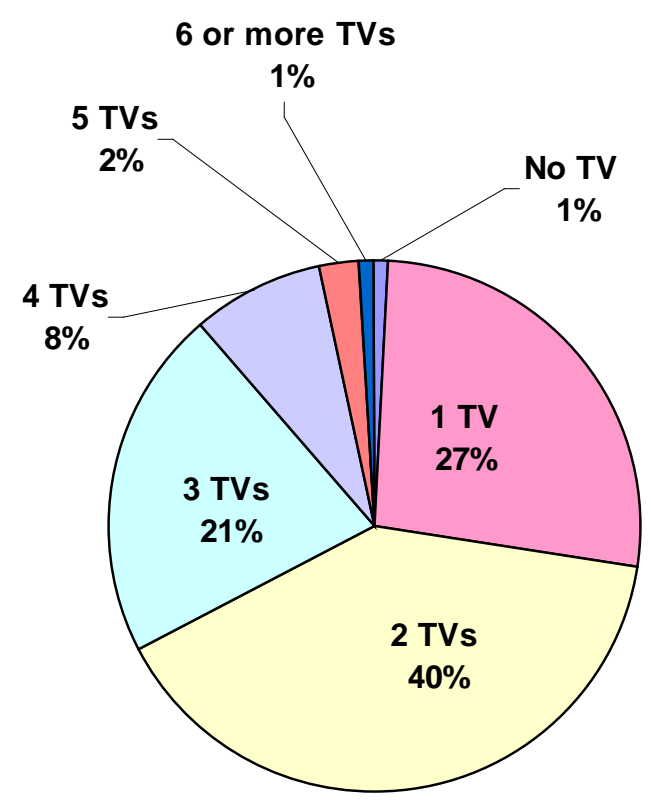

Figure 5.1: New Zealand Household Television Ownership Distribution

Most households have a TV in their family room (66\%), followed by the bedroom of a person 18 years or older (50\%), in the formal living room $(15 \%)^{34}$ and the remainder in other rooms.

\subsubsection{Size Distribution of Television Stock}

The size of a TV is measured across the diagonal of the TV screen. The most common sizes available in the market are portable (less than $50 \mathrm{~cm})$, small (50 $-74 \mathrm{~cm})$, medium $(75-100 \mathrm{~cm})$, large $(101-125 \mathrm{~cm})$ and very large $(126 \mathrm{~cm}$ or more). New Zealand's television stock is dominated by small size TVs (38\%), followed by medium (26\%), portable (18\%), large (15\%) and very large (3\%). Penetration of large and very large televisions in New Zealand is limited at present. Households tend to move an "old", small working-order TV

\footnotetext{
${ }^{34}$ Note that these percentages add to more than $100 \%$ because most households have more than one television.
} 
to another room and these therefore dominate the TV stock. However, with price reductions for large televisions and digital transmission, the profile of the TV stock is likely to change rapidly.

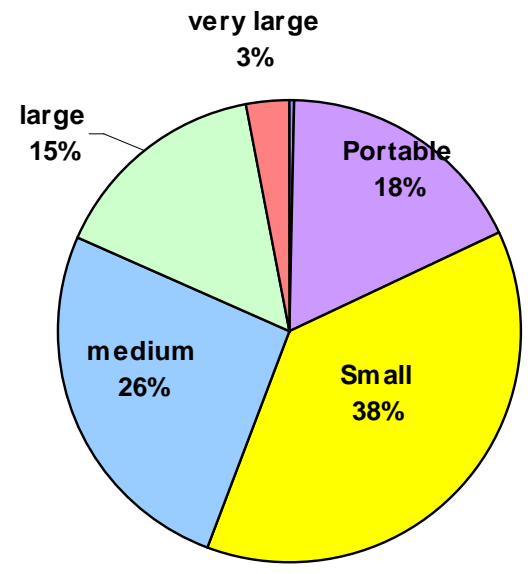

Figure 5.2: New Zealand Household Television Stock Distribution by Size

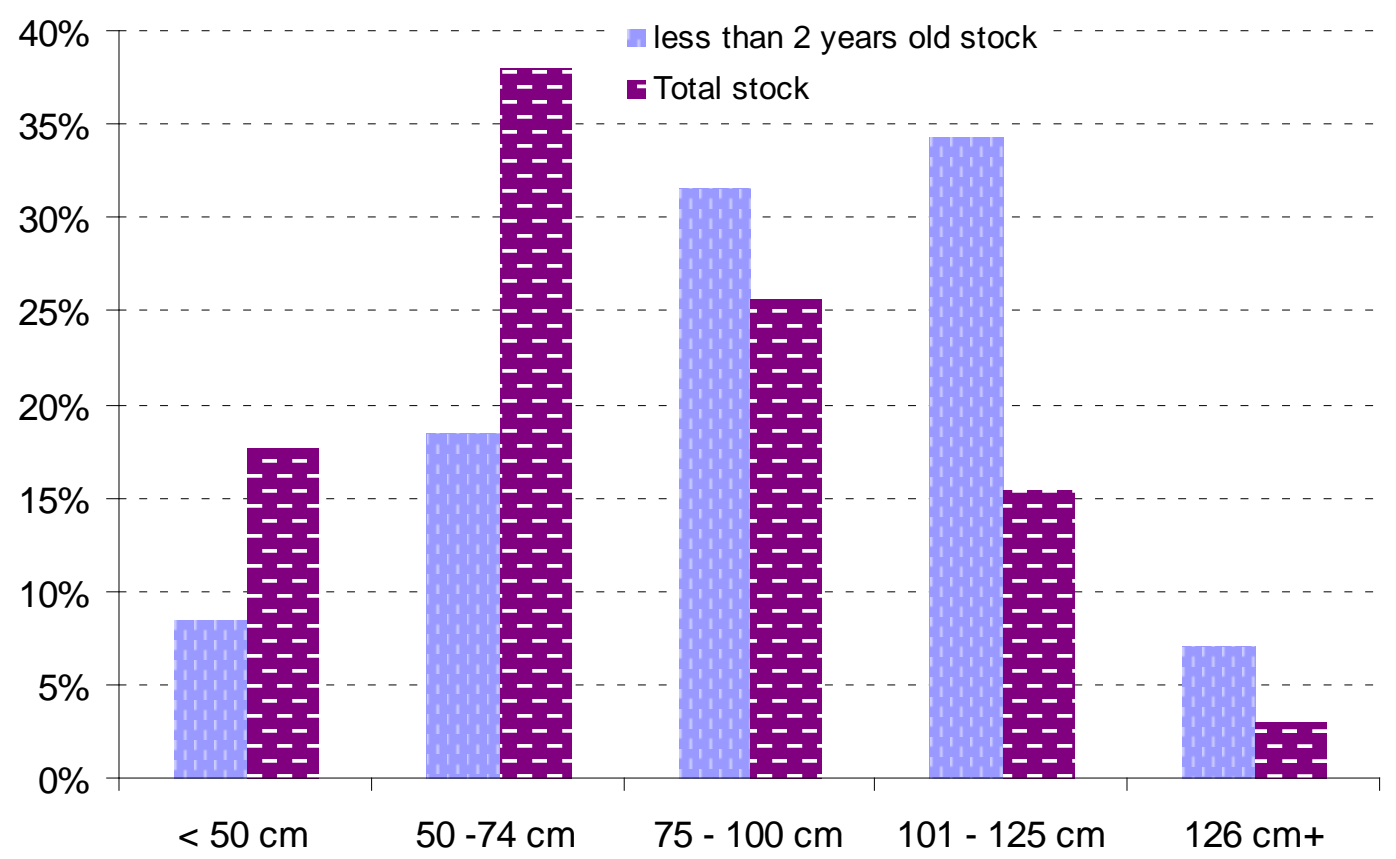

Figure 5.3: Size Distribution of TV total stock and newer (less than twoyear old) TV stock by percentage 
Of households with TVs two years old or less, 31\% of households have a portable TV, followed by $61 \%$ with small, $45 \%$ with medium, $29 \%$ with large and $8 \%$ with very large TVs.

Figure 5.3 shows the size distribution of the total TV stock and the newer (less than two year old) TV stock. One of every four TVs is less than two years old. Small TVs dominate the total TV stock whereas large TVs dominate the stock that is less than two years old. The figure also shows that during the last two years demand has increased for large and very large-size TVs. Within a short period, it can be expected that the modal TV in the New Zealand stock will be large in size.

\subsubsection{Technology Distribution of TV Stock}

Figure 5.4 shows CRT (65\%) is the most widely owned technology, followed by LCD (19\%), LCD/plasma (9\%) and plasma (7\%). Demand for LCD and plasma TVs has been increasing over the last two years, as indicated by Figure 5.5. This is highly likely to indicate future changes in technology.

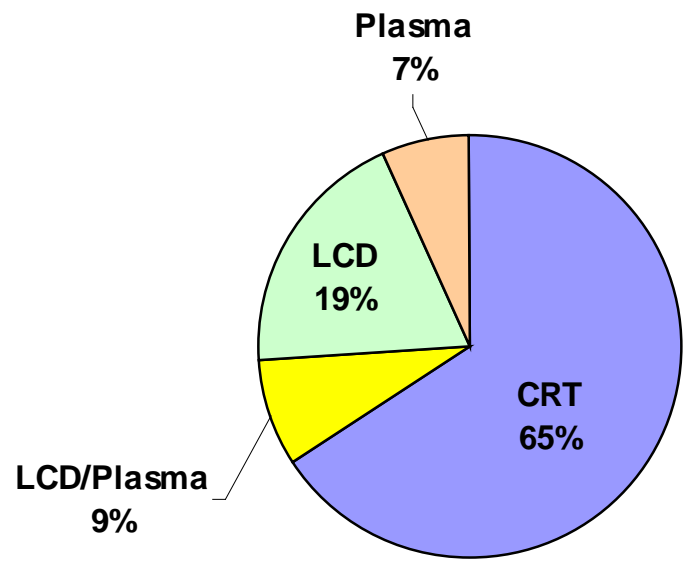

Figure 5.4: Technology Distribution of NZ television stock 


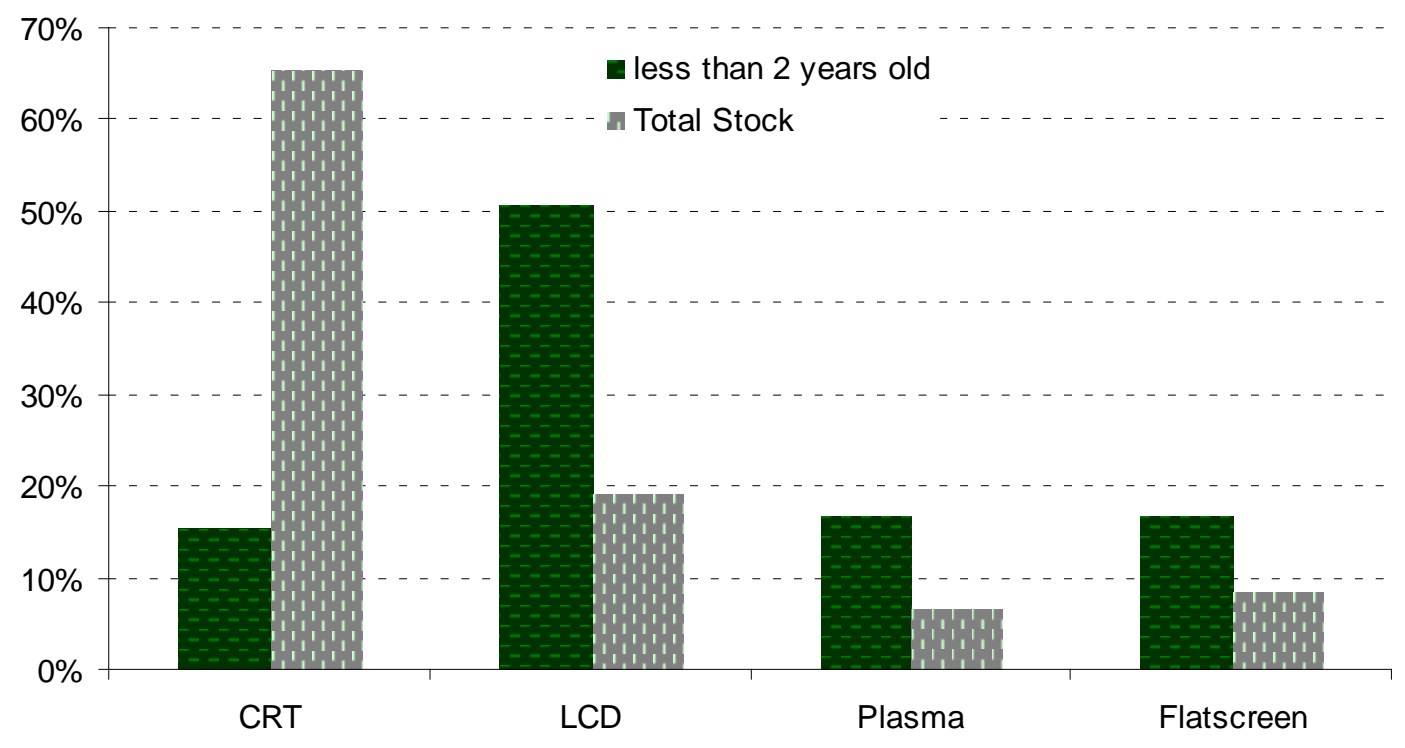

Figure 5.5: Technology Distribution of TV total stock and newer stock (less than two years old)

Figure 5.5 shows the trends in technology distribution by contrasting the total TV stock and the TV stock less than two years old. The total TV stock is dominated by cathode ray tube (CRT) technology, while the less-than-two years-old stock percentages show that CRT TVs are now dramatically less popular than other technologies, especially the market leader, liquid crystal displays (LCDS). However, the continued domination of the total stock by CRTs stems from the reluctance of New Zealand households to get rid of their working-order 'old' TVs. With the digital TV signal transmission phasing in by 2015 (according to the expected government schedule) ${ }^{35}$, older CRT TVs in households are likely to be phased out from New Zealand by 2015 . Flat screens were identified as their TV technology by some survey respondents, who were not able to differentiate between LCDs and plasma television technologies. LCD and plasma proportions would rise if the flat screen category were decomposed into LCD and plasma TVs.

Analysis of the survey results also shows that $82 \%$ of households own a CRT, followed by an LCD (33\%), a LCD/plasma (15\%) and a plasma TV (12\%).

\footnotetext{
${ }^{35}$ For more details see http://www.mch.govt.nz/publications/digital-futures/discussion-document.html
} 


\subsubsection{The Age Distribution of the TV stock}

Figure 5.6 shows the age distribution of the television stock by technology. It shows that newer televisions are dominated by LCD, plasma and flat screen technologies. LCDs, in particular, are clearly becoming the dominant technology. The average age of a TV in a New Zealand household is about five years. On average, a household's main TV is four years old while second and third televisions are around six years old. About $65 \%$ of those TVs which are less than two years old are used as the main TV, 22\% as second TVs and $10 \%$ as third TVs.

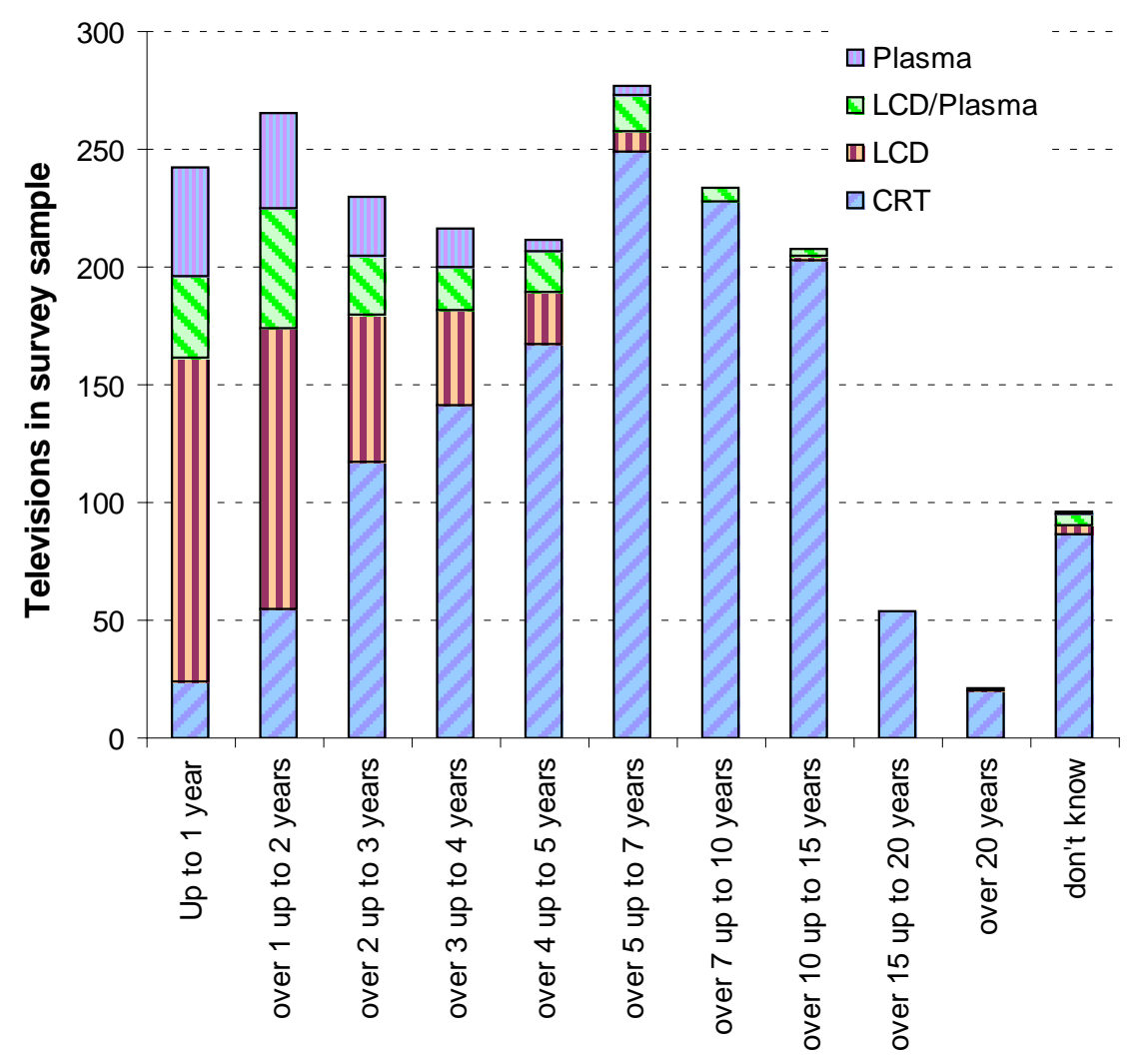

Figure 5.6: New Zealand Televisions by Age and Technology

Figure 5.7 also shows that in the last few years large and very large-screen TVs have been increasing in number. Close to half the stock acquired in the last year were large or very large TVs (screens over $100 \mathrm{~cm}$ ). 


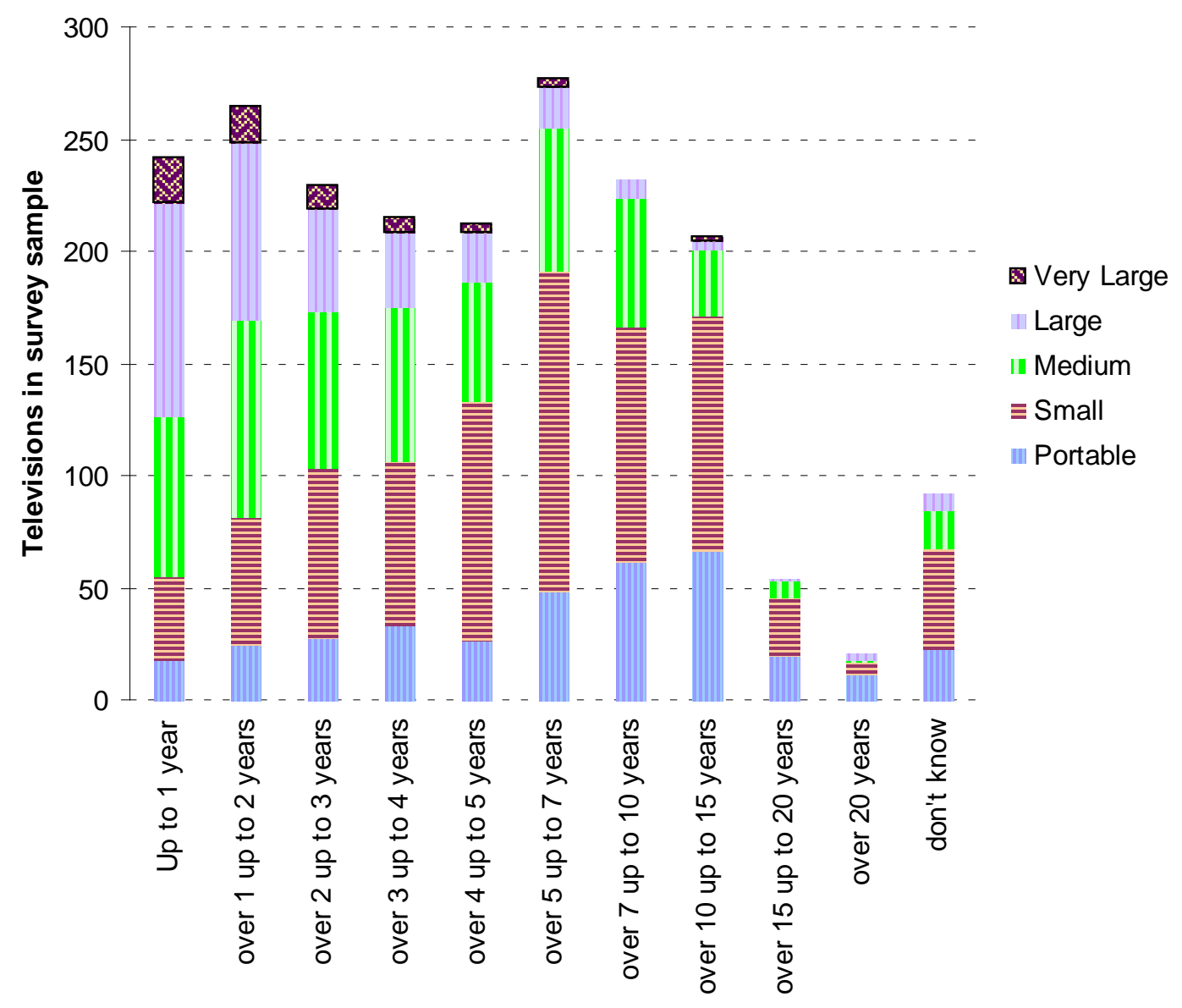

Figure 5.7: New Zealand Televisions by Age and Size

About $25 \%$ of households use other devices for television viewing. This consists of $6 \%$ using projection TVs and 19\% using computers or monitors with separate tuner/decoders.

\subsubsection{Television use by type of activity}

On average, households 'watch' 48.8 hours of television a week ${ }^{36}$. This amounts to around 22 hours per week per television. Main uses are watching TV channels, followed by viewing DVDs, use as a games console and use for background noise. Most studies of TV use capture only television viewing hours but this study captured the hours of operation, including hours used for background noise.

\footnotetext{
${ }^{36}$ Hours that all TVs are in use/total number of households $=$ TV-hours/household
} 
Table 5.1: Television use per activity for an average household

\begin{tabular}{|l|c|}
\hline Activity & $\begin{array}{c}\text { No. of hours per week per } \\
\text { household }\end{array}$ \\
\hline To watch TV channels & 33.7 \\
To view DVD & 5.3 \\
Use as Games Console & 2.9 \\
Use for background noise & 2.6 \\
To View VCR & 1.1 \\
To view from hard drive & 1.1 \\
Browse internet & 0.6 \\
To get teletext & 0.5 \\
To listen to music with & \\
screen saver on & 0.4 \\
To view movie from files & 0.4 \\
To display photographs & 0.1 \\
To view BluRay & 0.1 \\
\hline Total time TVs are in use & $\mathbf{4 8 . 8}$ \\
\hline
\end{tabular}

Based on the hypothesis development discussed above, a multiple regression analysis was undertaken to identify factors that may help explain total TV viewing times. Total viewing time was taken as the dependent variable and the number of TVs per household, average age of TV, number of occupants, average household income and average occupant age were tested as independent variables. 
Table 5.2: Factors Influencing Total TV Use Time

\begin{tabular}{|l|l|l|l|l|l|l|}
\hline $\begin{array}{l}\text { Dependent } \\
\text { variable }\end{array}$ & $\mathbf{R}^{2}$ & $\begin{array}{l}\text { Standard } \\
\text { Error }\end{array}$ & $\begin{array}{l}\text { Explanatory } \\
\text { variables } \\
\text { use time }\end{array}$ & $\begin{array}{l}\text { Regression } \\
\text { co-efficient }\end{array}$ & P-value & $\begin{array}{l}\boldsymbol{t} \text { - } \\
\text { Stat }\end{array}$ \\
\hline Total TV & $11 \%$ & 56.7 & No. of TVs & 16.7 & $0.000^{\star *}$ & 8 \\
\hline & & & $\begin{array}{l}\text { Average TV } \\
\text { age }\end{array}$ & -0.31 & 0.61 & -1 \\
\hline & & $\begin{array}{l}\text { No. of } \\
\text { occupants }\end{array}$ & 3.58 & 0.056 & 2 \\
\hline & & $\begin{array}{l}\text { Average } \\
\text { Income }\end{array}$ & -0.00022 & $0.004^{\star *}$ & -3 \\
\hline & & $\begin{array}{l}\text { Av. } \\
\text { Occupant } \\
\text { age }\end{array}$ & -0.0396 & 0.805 & -0.2 \\
\hline
\end{tabular}

$$
\star *: p<0.01 \quad *: p<0.05
$$

The regression model results suggest that the independent variables tested explain relatively little of the variation in total TV use time, so the results must be treated with caution. However, results from Table 5.2 suggest that the hypotheses offered above are borne out. Average household income has a strong and statistically significant relationship to total viewing time. However, the small coefficient on average income suggests the effect is small (as average income increases total viewing time decreases, but not by much). The income coefficient indicates TV viewing time is likely to be an inferior good. As household income increases, people may prefer to participate in other activities such as viewing sports events in person, or attending theatre etc. The number of TVs per household also has a strong and statistically significant relationship to total viewing time: as the number of TVs per household increases, total viewing time increases. Total viewing time is also weakly but positively related to the number of household occupants.

\footnotetext{
${ }^{37}$ Average for all the TVs in the household
} 
Analysis of the usage of TV is indicated in Figure 5.8, which shows 95\% of the households use their TVs to watch TV, followed by getting teletext (39\%), for background noise (34\%), to display photographs (23\%) and listen to music (12\%).

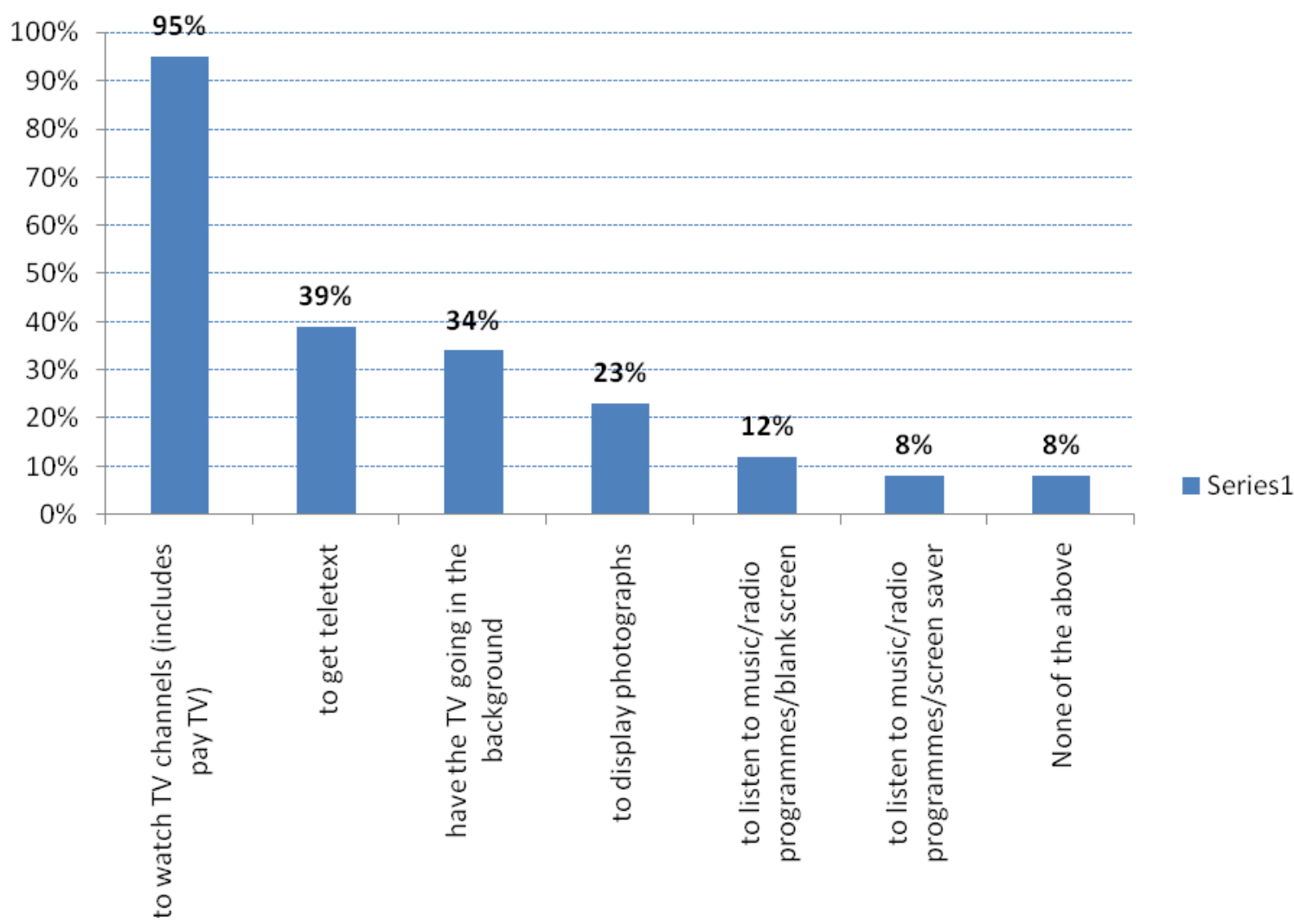

Figure 5.8: New Zealand Households' TV use by activity

\subsubsection{Stock of TV auxiliary devices}

Figure 5.9 shows the penetration of auxiliary devices. Auxiliary devices considered in this study are set-top boxes, digital versatile disc (DVD) players and recorders, video cassette recorders, games consoles, hard disc recorders, sub woofers and speakers, audio components, integrated stereos, and audio video receivers.

DVD players have a higher penetration rate than other devices. Note that since there is on average more than one device per household, the penetration rate is over $100 \%$. However, the literature (International Energy Agency, 2009a) suggests that use of video cassette recorders is falling with 
the increasing use of DVDs, mainly because DVDs have a better picture quality than VCRs. Additionally, the economic well-being most developed countries have enjoyed in the last few years, as well as declining DVD player and recorder prices, have influenced the increased ownership of DVD players and recorders.

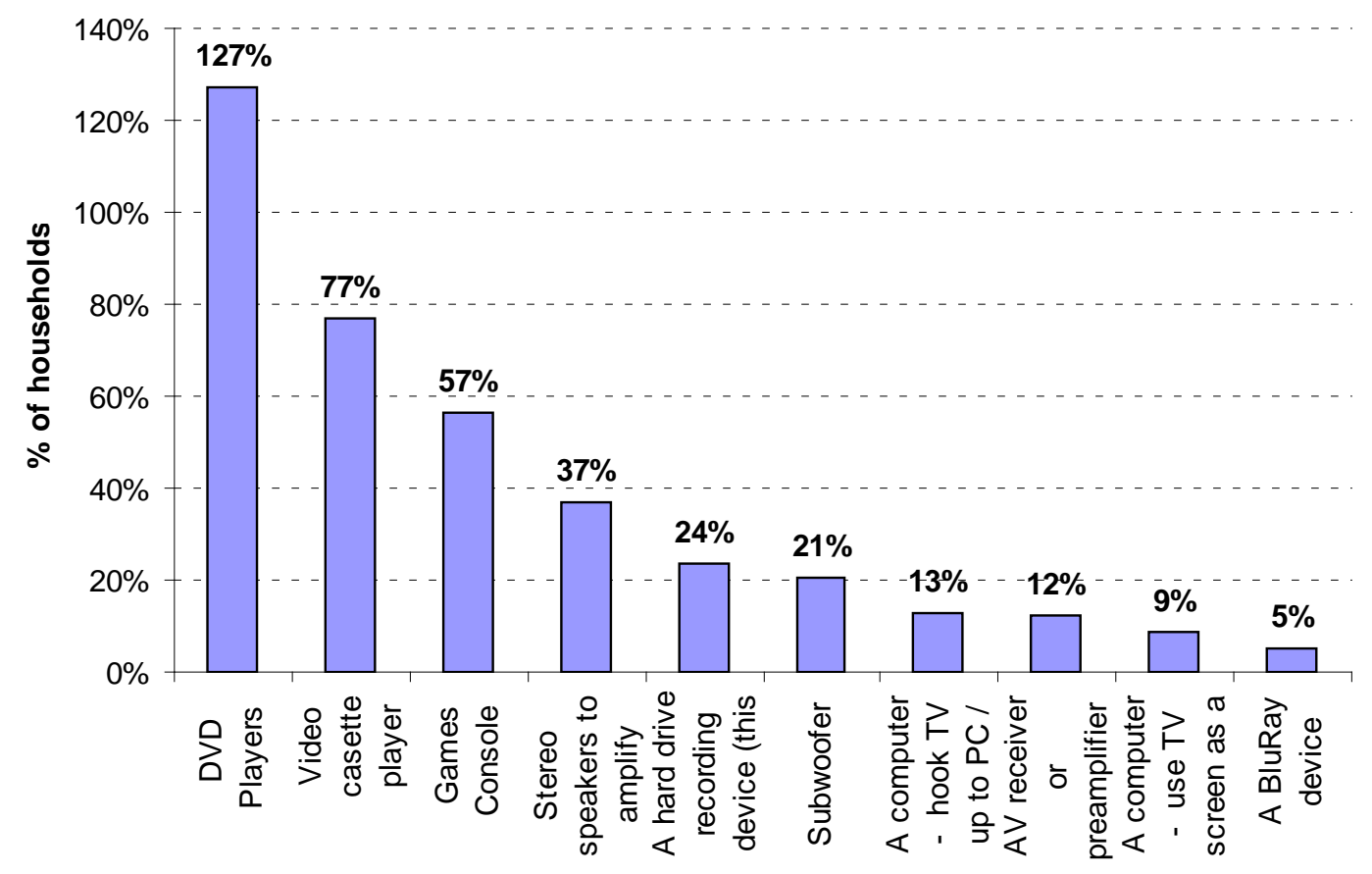

Figure 5.9: Penetration rate of auxiliary devices 


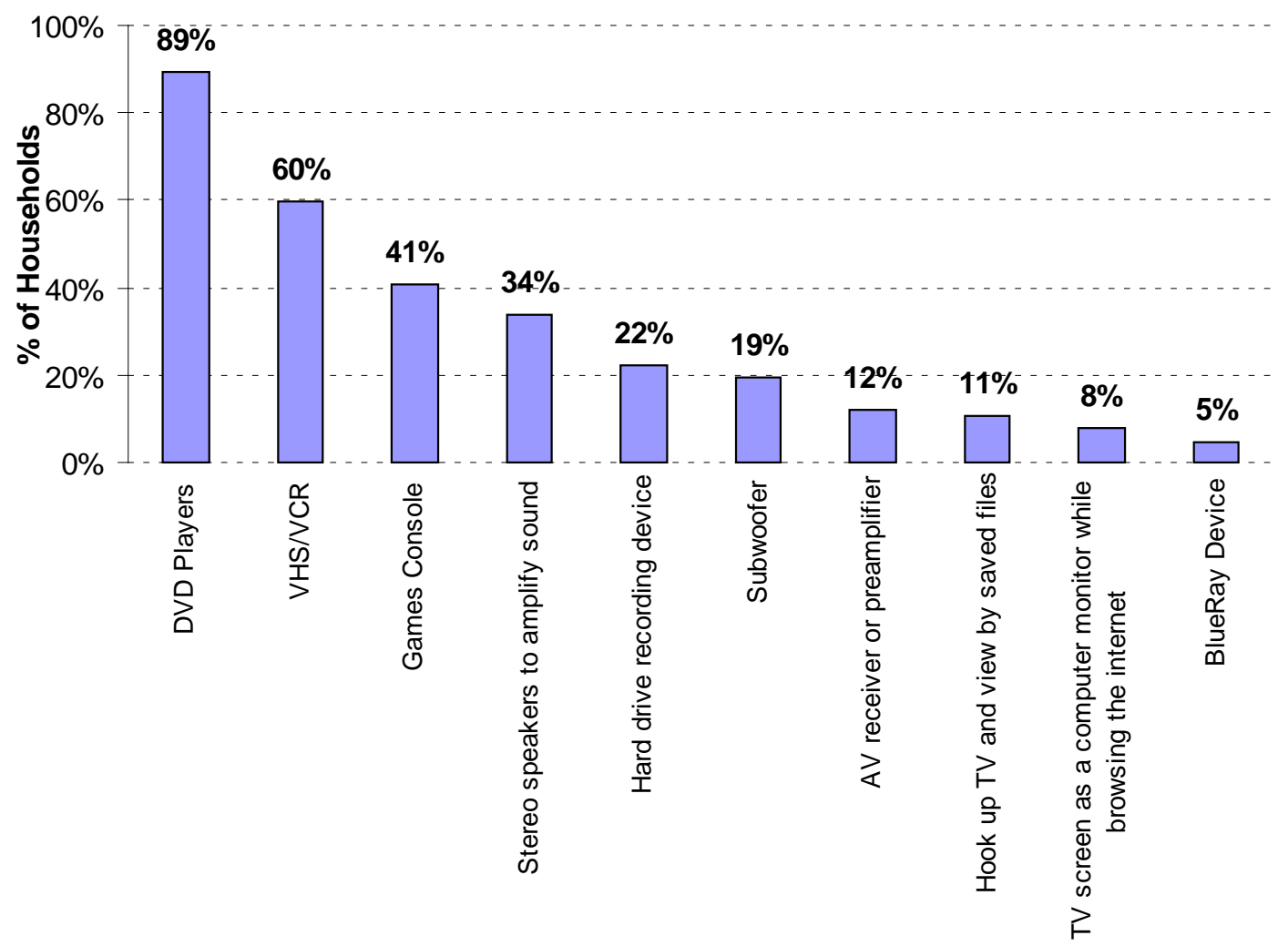

Figure 5.10: Ownership of auxiliary devices

Figures 5.9 and 5.10 show that even though the penetration rate is high, not all households have access to the auxiliary devices. Moreover, the density of auxiliary devices is higher in some households compared to others. The survey results also show that some households have DVD players for their second and third TVs. Similarly, the survey shows that the penetration rate of games consoles is greater than the ownership rate, indicating that some households with games consoles own more than one.

Set-top boxes have also been increasingly popular following their recent introduction. However, 35\% of households do not have set-top boxes compared to $65 \%$, or around one million households in NZ that have at least one set-top box for their TVs. Digital signals are currently broadcast by satellite and cable services for selected areas ${ }^{38}$. $77 \%$ of set-top boxes receive signals from satellite dishes (note that some households have more

\footnotetext{
${ }^{38}$ According to Freeview Limited the Freeview satellite service is available for whole of New Zealand and freeview high definition digital terrestrial television service is available for about $75 \%$ of NZ households.
} 
than one set-top box). Around $11 \%$ and $10 \%$ receive their signals for set-top boxes from cables and aerials respectively.

\subsubsection{Energy Use of New Zealand TV stock}

Household energy use is an important element of total NZ energy use, even if not currently increasing. As noted earlier, appliances account for a significant proportion of total household energy use. TVs and auxiliary devices are an important set of appliances and their use is growing. It seems that a focus on some of the behavioural and technological factors associated with their use may help to better understand that use.

IEA studies indicate that electricity use for household appliances has been increasing worldwide (International Energy Agency, 2009b). Between 2007 and 2008, overall household sector electricity use in New Zealand was approximately steady (it declined slightly from $44.81 \mathrm{PJ}$ to $44.76 \mathrm{PJ}$ although this is not statistically significant). Overall household sector energy use also remained almost steady (Ministry of Economic Development, 2009). However, sectoral indicators alone cannot identify the end uses or the underlying factors that have caused this decline. Therefore TVs and their auxiliary devices were selected to understand some of the behavioural and technological factors associated with TV energy use.

Electricity use by New Zealand TVs depends on the number of TVs, the types of TV sets by size, technology, and the hours TVs are used. To make estimates of electricity use, some assumptions had to be made.

A key set of assumptions relates to technology types. As discussed earlier, some respondents identified flat panel displays (FPD) as their TV technology because they were not aware of the difference between an LCD and a plasma set. Since plasma technology ${ }^{39}$ is not available in portable, small or medium sizes, all FPDs of those sizes were regarded as LCDs. All small and medium size TVs recorded in the survey as plasmas were also taken to be LCDs.

${ }^{39}$ Size of a normal plasma is between $106 \mathrm{~cm}$ and $256 \mathrm{~cm}$ (Digital CEnergy Australia, 2007) 
Large and very large FPDs were divided equally between LCD and plasma ${ }^{40}$. Large and very large $\mathrm{CRT}^{41} \mathrm{TV}$ s are assumed to be medium size televisions. All "don't know" technology selections of TVs were assumed to be small in size and CRT in technology.

Regulating standby energy used by household appliances has been identified as a way of reducing energy use. According to the survey findings, $46 \%$ of households use a remote control's standby button, followed by TV on/off button (37\%) and switch off at the wall (17\%) to turn off their TV. Therefore there is in principle some potential to reduce standby electricity use of TVs.

When electricity use is aggregated across the sample using the assumptions and parameters above and scaled up to a figure for all New Zealand households, total electricity use by televisions and associated auxiliary devices was estimated at $4.34 \mathrm{PJ}$ or close to $10 \%$ of New Zealand household electricity consumption. This consists of 3.3 PJ and 0.2 PJ for 'on mode' (device is operating) electricity use by televisions and TV auxiliary appliances respectively. 'Standby mode' (device is not operating and not switched off from the wall) electricity use by televisions and TV auxiliary appliances is estimated at $0.01 \mathrm{PJ}$ and $0.84 \mathrm{PJ}$ respectively, totalling around $0.85 \mathrm{PJ}^{42}$. Counter-intuitively, standby energy use by TV auxiliary appliances is higher than for televisions. In contrast, 'on mode' energy use for televisions is higher than for auxiliary devices. One likely reason is that most auxiliary devices such as DVD players and games consoles cannot function without televisions in 'on mode'. Secondly, viewing channels is the most common activity households undertake with their TVs and the connected TV auxiliary appliances are likely to be on 'standby mode' during such viewing.

\footnotetext{
${ }^{40}$ Since there are no large or very large sized CRTs, LCD and plasma were considered $50 \%$ \& $50 \%$.

${ }^{41}$ Size of a common CRT is less than $86 \mathrm{~cm}$ (Digital CEnergy Australia, 2007)

42 Counter-intuitively, standby energy use by TV auxiliary appliances is higher than for televisions. In contrast, 'on mode' energy use for televisions is higher than for auxiliary devices. One likely reason is that most auxiliary devices such as DVD players and games consoles cannot function without televisions in 'on mode'. Secondly, viewing channels is the most common activity households undertake with their TVs and the connected TV auxiliary appliances are likely to be on 'standby mode' during such viewing.
} 
Table 5.4: Total energy use by televisions and auxiliary devices

\begin{tabular}{|l|c|c|c|}
\hline & TV (PJ) & $\begin{array}{c}\text { Auxiliary } \\
\text { devices (PJ) }\end{array}$ & $\begin{array}{c}\text { Total } \\
(\mathbf{P J})\end{array}$ \\
\hline $\begin{array}{l}\text { "Active" mode electricity } \\
\begin{array}{l}\text { "Standby" mode electricity } \\
\text { use }\end{array}\end{array}$ & 3.29 & 0.2 & 3.49 \\
\hline $\begin{array}{l}\text { Total electricity use for all } \\
\text { NZ TV }\end{array}$ & 0.01 & 0.84 & 0.85 \\
\hline
\end{tabular}

Table 5.4 shows the energy usage profile of televisions and auxiliary devices. Standby energy use in TVs and auxiliary devices impacts on total electricity use - especially at an increased penetration rate. Early collaboration with the international community to introduce MEPS/L to TVs and standby energy use initiatives is likely to contain energy use. It will help to prevent inefficient TV and TV auxiliary appliances entering the New Zealand market and the households to utilise the most efficient technologies available.

According to survey findings, only $15 \%$ of households have adjusted their TVs to suit the current room conditions. $E_{3}$ Committee studies suggest that setting the brightness level to the 'home' mode at the time of purchase could reduce TV electricity use at least by 25\% (US Environmental Protection Agency, Unknown $)^{43}$ Studies suggest manufacturers set brightness high to suit shop floor conditions, not for normal households. Therefore it is likely that $85 \%$ of households consume more energy than necessary. The $E_{3}$ Committee recommends the Australian and New Zealand governments set minimum performance standards concerning the 'out of box' household use condition. Manufacturers can ensure a better energy performance in home use by setting the brightness level to "home" mode as the default. If the television is set to be on 'display' mode, the standard would require that the television rating lose two stars.

\footnotetext{
${ }^{43}$ See http://reviews.cnet.com/green-tech/tv-consumption-chart/?tag=contentBody;nextPage for more details.
} 
Technological development has increased TV energy use. Digital broadcasting ${ }^{44}$, High Definition (HD) TV $^{45}$ and digital ${ }^{46}$ TV have improved TV picture quality, which is a high priority for New Zealand households (this is discussed further below). Finer details offered by HDTV require larger screen sizes which are more common in LCD and plasma technologies. Furthermore, Australian studies suggest that households' preference for large size screens was increasing even before the advent of digital transmission (Digital CEnergy Australia, 2007, 2009). Most large screen TVs currently in the market consume more electricity to deliver better picture quality to households. A Sony CRT analogue 36 inch TV (KV-36FS210) consumes about 87 W per hour where as a Sony LCD high definition 32 inch TV (KLV-32M1) consumes about 125 W per hour (Natural Resources Defense Council, 2005).

However, there are HDTVs that are more efficient than the Standard CRT TVs (Ostendorp, Foster, \& Calwell, 2005). Sony research indicates that efficient OLED ${ }^{47}$ models may consume about $40 \%$ less electricity compared to a conventional LCD model (International Energy Agency, 2009a). However, these TVs are not widely available in New Zealand.

A recent UK study showed that with falling prices of large and thin televisions with better quality of pictures, ownership rates have risen, resulting in more electricity consumption (Crosbie, 2008). However an estimate of the amount was not given.

The survey in the present study also found that $85 \%$ of respondents were not aware of the amount of electricity that is used by a TV. Arguably all households consider the upfront cost of buying a TV, but most do not appear to consider their running cost. The difference in annual electricity consumption between a 0 Star and 5 Star energy rating ${ }^{48}$ could be as much

\footnotetext{
${ }^{44}$ Sending TV signal as 1s and 0s instead of in waves.

${ }^{45}$ All HDTVs are digital but not vice versa. HDTV has better picture quality because it has higher aspect ratio, resolution and a higher frame rate than standard television.

${ }^{46}$ Digital TV is developed taking into account bandwidth, colour, and audio components of TV signal at the design stage to improve picture quality. Furthermore signal content is flexible and can be transmitted either as an interlaced or progressive signal. Picture closely resembles the shape of a movie screen.

${ }_{48}^{47}$ Organic Light Emitting Diodes

${ }^{48}$ Note: different to Energy Star®. For more details see http://www.energyrating.gov.au/con3.html
} 
as $880 \mathrm{kWh}$ (Digital CEnergy Australia, 2009) which is around $\$ 176^{49}$ a year. Furthermore, if half a million households use 5 star energy rated TVs instead of 0 star TVs, the amount of electricity saved would be the equivalent of the annual output of a $50 \mathrm{MW}$ electricity generation plant.

When total costs over the life-cycle are considered, the impact of higher yearby-year energy use on overall TV running costs can be considerable: energy use directly influences running costs. Even though an ENERGY STAR ${ }^{50}$ rating is displayed on energy efficient TVs in New Zealand, there is typically no information about their energy consumption, or how the level of performance relates to the latest ENERGY STAR standards (the 4.0 standard became effective in the US in May $2010^{51}$ and can be expected to be introduced into New Zealand in due course). Most respondents expect to obtain details on running costs of TVs from appliance shops, the internet, or TV manuals, in that order but the costs of gathering such information can be prohibitive to all buyers but the most committed.

\subsubsection{Factors Influencing Purchasing Decisions}

For TV sets purchased by households in the survey, $78 \%$ of households bought new TVs and 22\% bought second-hand TVs. One in four households borrowed money to purchase a TV. This seems to indicate the importance of TVs to households. Some literature from the UK considers a TV as an essential appliance for a household (Roberts, 2008). One of the present survey's questions aims to establish the important features when purchasing a TV, in order of priority, for a household. Respondents were asked to provide an importance weighting between 1 and 100; to select the most important first and then the least important; and to place all other attributes on the slider in order of importance. The results show that householders give top priority to picture resolution followed by price, technology, screen size, running cost/energy use, brand, ENERGY STAR $®$ label, fit with current room arrangements/fixtures and overall environmental impact. It seems when

\footnotetext{
${ }^{49}$ At a price of 20 cents per kWh

50 Normally ENERGY STAR® is awarded to the top $25 \%$ most energy efficient appliances.

${ }^{51}$ http://www.msnbc.msn.com/id/36925652/ns/technology and science-tech and gadgets/
} 
households decide on purchasing a TV, overall environmental impact is given the least priority, although it can be argued that placing some weight on energy use may reflect a degree of environmental awareness.

Table 5.2: Purchasing criteria Weights for households

\begin{tabular}{|l|c|c|c|}
\hline & $\begin{array}{c}\text { All } \\
\text { households }\end{array}$ & $\begin{array}{c}\text { TV bought } \\
\text { last year }\end{array}$ & $\begin{array}{c}\text { Did not buy TV } \\
\text { last year }\end{array}$ \\
\hline $\begin{array}{l}\text { Picture } \\
\text { resolution }\end{array}$ & 80 & 81 & 80 \\
\hline Technology & 72 & 77 & 70 \\
\hline Price & 76 & 73 & 77 \\
\hline Size Screen & 72 & 73 & 72 \\
\hline Brand & 46 & 49 & 44 \\
\hline Energy Use & 49 & 46 & 50 \\
\hline Aesthetic & 39 & 42 & 39 \\
\hline $\begin{array}{l}\text { Energy star } \\
\text { rating }\end{array}$ & 42 & 42 & 43 \\
\hline Fit & 42 & 39 & 43 \\
\hline $\begin{array}{l}\text { Environmental } \\
\text { impact }\end{array}$ & 36 & 34 & 37 \\
\hline Sample Size & 1001 & 249 & 752 \\
\hline
\end{tabular}

Table 5.2 shows the average weighting all households have given to each criterion (all households column); the average weighting given by households who have purchased a TV within the last two years, for each criterion; and the average weighting households who have not purchased a TV within the last two years have given to each criterion. Picture resolution was the top priority for all groups.

Type of technology, screen size, brand and aesthetic value (or how the TV looks) was higher for those who bought a TV last year compared with those buying earlier. The influence of price, energy use, ENERGY STAR® rating, fit with current room arrangements/fixtures, and overall environmental impact were less important for those who bought a TV in the last year, than for those buying earlier. Thus matters such as price, energy use and environmental 
impact appear to be dropping in significance to households. Technology and brand appear to be becoming more important, perhaps suggesting that as consumers become more affluent over time, factors such as price diminish in terms of priority considerations. Households' purchasing behaviour also suggests that technology and brand are closely associated with picture quality. This is consistent with households demanding service quality, and the fact that energy is used to power that service rates as very low in terms of their priorities.

Regression analysis was used to further examine the relationship between purchasing criteria (the weighting placed on price, brand, technology, ${ }^{52}$ screen size, picture resolution, ENERGY STAR®, running cost/energy use, aesthetic value, overall environmental impact and fit with current room arrangement) and other factors (average TV age, number of occupants, average income, total viewing time, average occupant age and access to flat screen TVs).

Table 5.3: Analysis of selected factors that may influence household purchasing choices (declared importance weights)

\begin{tabular}{|l|l|l|l|l|l|l|}
\hline $\begin{array}{l}\text { Dependent } \\
\text { variable }\end{array}$ & $\mathbf{R}^{2}$ & $\begin{array}{l}\text { Standard } \\
\text { Error }\end{array}$ & $\begin{array}{l}\text { Significant } \\
\text { variables }\end{array}$ & $\begin{array}{l}\text { Regression } \\
\text { Co-efficient }\end{array}$ & P-value & $\begin{array}{l}\mathbf{T} \\
\text { Stat }\end{array}$ \\
\hline $\begin{array}{l}\text { Weight } \\
\text { placed on } \\
\text { Price }\end{array}$ & $8 \%$ & 23.44 & $\begin{array}{l}\text { Average } \\
\text { income }\end{array}$ & $-5.3^{\star} 10^{\wedge}(-5)$ & 0.083 & -2 \\
\hline & & & $\begin{array}{l}\text { Average } \\
\text { occupant } \\
\text { age }\end{array}$ & -0.44 & $0.000^{\star \star}$ & -7 \\
\hline \hline
\end{tabular}

\footnotetext{
${ }^{52}$ The technology dependent variable indicates 100 high technology TV and 0 for low technology TV
} 


\begin{tabular}{|c|c|c|c|c|c|c|}
\hline $\begin{array}{l}\text { Dependent } \\
\text { variable }\end{array}$ & $\mathbf{R}^{2}$ & $\begin{array}{l}\text { Standard } \\
\text { Error }\end{array}$ & $\begin{array}{l}\text { Significant } \\
\text { variables }\end{array}$ & $\begin{array}{l}\text { Regression } \\
\text { Co-efficient }\end{array}$ & $P$-value & $\begin{array}{l}T \\
\text { Stat }\end{array}$ \\
\hline \multirow[t]{3}{*}{ Brand $^{53}$} & $1 \%$ & 32.76 & $\begin{array}{l}\text { Total } \\
\text { viewing } \\
\text { time }\end{array}$ & 0.035 & 0.07 & 2 \\
\hline & & & $\begin{array}{l}\text { Average } \\
\text { occupant } \\
\text { age }\end{array}$ & -0.2 & $0.02^{*}$ & -2 \\
\hline & & & $\begin{array}{l}\text { Access to } \\
\text { flat screen } \\
\text { TV }\end{array}$ & 4.3 & 0.09 & 2 \\
\hline \multirow[t]{4}{*}{ Technology } & $6 \%$ & 26.5 & $\begin{array}{l}\text { Average TV } \\
\text { age }\end{array}$ & 0.7 & $0.016^{*}$ & 2 \\
\hline & & & $\begin{array}{l}\text { Average } \\
\text { income }\end{array}$ & 0.0001 & $0.0001^{\star \star}$ & 4 \\
\hline & & & $\begin{array}{l}\text { Total } \\
\text { viewing } \\
\text { time }\end{array}$ & 0.04 & $0.015^{\star}$ & 2 \\
\hline & & & $\begin{array}{l}\text { Access to } \\
\text { flat screen } \\
\text { TV }\end{array}$ & 10.21 & $0.000^{\star \star}$ & 4 \\
\hline \multirow[t]{4}{*}{$\begin{array}{l}\text { Picture } \\
\text { Resolution }\end{array}$} & $1 \%$ & 19.57 & $\begin{array}{l}\text { Average } \\
\text { TV age }\end{array}$ & 0.44 & $0.04^{*}$ & 2 \\
\hline & & & $\begin{array}{l}\text { Average } \\
\text { income }\end{array}$ & $5.34^{\star} 10^{\wedge}(-5)$ & $0.03^{*}$ & 2 \\
\hline & & & $\begin{array}{l}\text { Total } \\
\text { viewing } \\
\text { time }\end{array}$ & -0.01 & 0.09 & 2 \\
\hline & & & $\begin{array}{l}\text { Access to } \\
\text { flat screen } \\
\text { TV }\end{array}$ & 2.7 & 0.07 & 2 \\
\hline
\end{tabular}

\footnotetext{
${ }^{53}$ All other dependent variables are also importance weights, e.g. 'Weight placed on Brand' etc.
} 


\begin{tabular}{|c|c|c|c|c|c|c|}
\hline $\begin{array}{l}\text { Dependent } \\
\text { variable }\end{array}$ & $\mathbf{R}^{2}$ & $\begin{array}{l}\text { Standard } \\
\text { Error }\end{array}$ & $\begin{array}{l}\text { Significant } \\
\text { variables }\end{array}$ & $\begin{array}{l}\text { Regression } \\
\text { Co-efficient }\end{array}$ & $P$-value & $\begin{array}{l} \\
\text { Stat }\end{array}$ \\
\hline \multirow[t]{2}{*}{$\begin{array}{l}\text { Running } \\
\text { cost/Energy } \\
\text { use }\end{array}$} & $5 \%$ & 27.36 & $\begin{array}{l}\text { Total } \\
\text { viewing } \\
\text { time }\end{array}$ & -0.04 & $0.02^{\star}$ & -2 \\
\hline & & & $\begin{array}{l}\text { Access to } \\
\text { flat screen } \\
\text { TV }\end{array}$ & -3.5 & 0.09 & -2 \\
\hline \multirow[t]{2}{*}{$\begin{array}{l}\text { Aesthetic } \\
\text { value of TV }\end{array}$} & $3 \%$ & 27.82 & $\begin{array}{l}\text { Average } \\
\text { income }\end{array}$ & 0.0001 & $0.000^{\star \star}$ & 4 \\
\hline & & & $\begin{array}{l}\text { Access to } \\
\text { flat screen } \\
\text { TV }\end{array}$ & 4.32 & $0.048^{*}$ & 2 \\
\hline \multirow[t]{4}{*}{$\begin{array}{l}\text { Impact on the } \\
\text { Environment }\end{array}$} & $5 \%$ & 27.38 & $\begin{array}{l}\text { Number of } \\
\text { occupants }\end{array}$ & 2.5 & $0.004^{\star \star}$ & 3 \\
\hline & & & $\begin{array}{l}\text { Average } \\
\text { Income }\end{array}$ & -0.0001 & $0.000^{\star \star}$ & 4 \\
\hline & & & $\begin{array}{l}\text { Total } \\
\text { viewing } \\
\text { time }\end{array}$ & -0.06 & $0.0001^{* *}$ & -4 \\
\hline & & & $\begin{array}{l}\text { Average } \\
\text { occupant } \\
\text { Age }\end{array}$ & 0.2 & $0.008^{\star \star}$ & 3 \\
\hline $\begin{array}{l}\text { Fit with } \\
\text { current room } \\
\text { arrangement }\end{array}$ & $2 \%$ & 29.83 & $\begin{array}{l}\text { Average } \\
\text { income }\end{array}$ & 0.0001 & $0.000^{\star \star}$ & 5 \\
\hline
\end{tabular}

$* *: p<0.01 \quad *: p<0.05$

Table 5.3 shows that average income significantly affects the importance weighting placed on price, technology, picture resolution, the aesthetic value, environment and 'fit with current room arrangement' purchasing criteria. The $R^{2}$ for the regressions shows that none of the variables explains much of the 
variance in the model. However, the coefficients show some statistically significant, if small, effects. Weight placed on technology and aesthetic value, as expected, are significantly associated with households' ownership of flat screen TVs. Interestingly, the importance attached to running costs/energy use was inversely associated with viewing time; this is plausible if those more conscious of the importance of running costs reduce their viewing time.

The survey also asked respondents their reasons for purchasing a new TV set. The main reason households purchase a new TV is to have a bigger screen (38\%) followed by 'to upgrade technology' (34\%), 'death of the old TV' (26\%), 'gift '(15\%), that a new 'TV was on sale' (12\%) and 'to purchase an additional TV' (12\%). Note that some households had more than one TV and some households choose more than one reason for buying a TV.

When households purchase a new TV, they move the current TV to another room (26\%), give it away (19\%), retire it to landfill/inorganic collection (14\%), put it in storage (10\%), sell it (9\%), trade it in (3\%), or send it to another destination (8\%). Only $19 \%$ of the existing stock is permanently retired. Depending on the age of old TVs, destinations differ. Only $8 \%$ of the respondents get rid of their TV where it is more than 2 years old and less than five years old. However, where the 'old' TVs are more than 5 years old, $44 \%$ of the respondents retire them.

\subsubsection{TV retirement age}

The most common retirement age for TVs is between 5 and 15 years of age (66\%); followed by $14 \%$ of households retiring their TV when it is over 15 years of age. Most households shift their old TV to another room (27\%), when a new TV is purchased. Only $16 \%$ retire their old TV to a landfill or inorganic collection, and $5 \%$ recycle. Some $10 \%$ of households store their TVs for future use. 


\subsection{Comparisons of New Zealand survey results with International data on Appliance Energy Use}

The IEA acknowledges that data gaps make understanding electrical and electronic equipment energy use difficult (International Energy Agency, 2009b). With estimated data, the IEA study indicates that in the US, Canada, the UK, Japan and Australia, electricity use for consumer electronics (CE) and information communication technology (ICT) has been increasing since the mid-1990s (International Energy Agency, 2009b). GfK ${ }^{54}$ Sales and Technology (2009) states that LCD TV global sales increased to 145 million TVs in 2009 compared with 108 million TVs in 2008.

The IEA has identified home electronic and ICT devices as the key factor for increasing electricity use by $41 \%$ in a group of 19 IEA countries between 1990 and 2006 (International Energy Agency, 2009a, 2009b). Two main drivers are likely to be the tendency towards a '24/7' or 'always on' society ${ }^{55}$ and rapid advances in technology to meet societal demands and appetites, even where commercially fostered. Furthermore, households seem to have more time to make use of these services (Loveday, et al., 2008).

\subsubsection{Europe}

There is little information on appliance ownership available in the public domain for European countries. GfK Retail and Technology (2009) expects sales for TVs, computers and mobile telephones to rise in Western Europe, surpassing sales in North America.

European households seem to be more aware of energy use by televisions than are households in other countries. According to a GfK survey, 74\% of respondents in France, Germany, Italy, Spain and the UK considered energy efficiency important (36\% of them considered it a very important factor) when purchasing a television (GfK Retail and Technology, 2009). The criteria

\footnotetext{
${ }^{54}$ One of the largest marketing research companies in the world

${ }^{55}$ Defined as television and radio programming, 'on demand' TV, computer access to the internet and email, callcentre services for banking, mail order shopping and 24 hour shopping at supermarkets or "a society that requires what it wants 'now'” (Loveday et al, 2008).
} 
important to European respondents when buying a TV were, from highest to lowest priority, picture quality, price, energy consumption in "on mode", screen size, energy consumption in "stand-by mode" and digital reception. Energy consumption is the third most important criterion for European households whereas New Zealand households have it at the sixth place. [NZ data noted above] - bring out key differences.

A recent UK government report suggests that energy use for space heating on the one hand, and appliances and lighting on the other, had increased by $28 \%$ and 148\% respectively between 1970 and 2005 (Loveday, et al., 2008).

Norway is not a typical European country, as it has very high income levels, around twice as much as New Zealand's. However, in some respects (see Chapter 4 it is similar to New Zealand; it is interesting therefore to assess the extent to which its TV use patterns are different from those in New Zealand. Norwegians watched TV for 2 hours and 22 minutes a day in 2008, compared with New Zealanders' $\sim 5$ hours per day. Norwegian TV use seems to be declining where as New Zealand's TV use is increasing. They watched TV less in 2008 than in 2007. However, their internet usage increased over the same period. Like households in New Zealand, Norwegians' access to home computers, the internet, and broadband has also increased steadily over the years. This may indicate Norwegians' increasing tendency to watch normal TV on their computers, a trend which New Zealanders may soon follow. Furthermore, VHS ownership has declined and DVD ownership has increased in Norway (Statistics Norway, 2009), a pattern similar to that which is beginning to emerge in New Zealand.

Europe is scheduled to switch off their analogue TV broadcast services between 2005 and 2015 (International Energy Agency, 2009a), somewhat earlier than New Zealand [source]. 


\subsubsection{Japan}

Electricity use in Japan has been increasing as a result of the proliferation of household appliances (International Energy Agency, 2007). Therefore, the Japanese government has established a "New Climate Change Policy Program" (2002) which includes energy regulations for household appliances as well as an aim of changing household behaviour to achieve its Kyoto targets. This programme was responsible for producing one of the highest energy efficiency standards in the world - the "Top-runner Standard". Japan has been the first country to regulate ${ }^{56}$ the amount of energy consumed by televisions and VCRs (1997), computers (1999,) and DVD players (2005,) ${ }^{57}$. Furthermore, TVs', VCRs' and DVD players' standby energy consumption is required to be used in overall energy performance targets. Recently it expanded regulations to include DVD recorders with integral TV tuners, routers and switches (International Energy Agency, 2008).

Ex-post evaluations show Japan's standby appliance energy use has fallen. It may have been as a result of the 'top-runner' standard. TV ownership in 2005 was 2.09 TVs per household and average TV usage time was 4 hours and 32 minutes per day (International Energy Agency, 2008). This compares with New Zealand households' average of $\sim 5$ hours TV watching per day.

The Japanese government has acknowledged the influence of household behaviour patterns on energy use. The regulations to change occupant behaviour under the "New Climate Change Policy Program" included "easing set room air temperature", encouraging "family members to stay together in the living room and not in their individual rooms" and "reducing the number of hours spent watching TV". Some evidence suggests that the regulations that attempt to change occupant behaviour do not appear to be very effective (Shimoda, Asahi, Taniguchi, \& Mizuno, 2007).

Japan is scheduled to switch off their analogue TV broadcast services by 2011 (International Energy Agency, 2009a).

\footnotetext{
${ }^{56}$ Top Runner Programme under The Energy Conservation Law (1999)

57 Television, VCR, computer and DVD player regulations were further amended in 2005, 2005, 2003 and 2007 respectively. ,
} 


\subsubsection{The US}

In 2009, average occupancy of a US home is 2.5 people, whereas TV ownership is 2.86. On average, US homes view 5 hours of TV per day, comparable with New Zealand viewing. This does not taken into account the total number of hours the TV is operated during the week (e.g. background noise, radio etc). There seems to an increasing trend of using the internet and mobile phones to view programmes on TV channels. There is also an observed trend of households using more than one screen at the same time for internet access and to view TV whilst going online (The Nielsen Company, 2009). It is likely that these trends will be copied in New Zealand in due course.

DVD ownership (88\%) and use is increasing in the US at the expense of VCRs (72\%). US studies also indicate that TVs and set-top boxes use about $6 \%$ of household electricity (Ostendorp, et al., 2005). This is less than that in New Zealand where, as noted above, TV and auxiliary appliance use constitutes about $10 \%$ of household electricity use.

In 2009, the US government allocated US $\$ 300$ million for efficient appliance rebates and the ENERGY STAR® programme, which includes TV among other electronic devices. The ENERGY STAR $®$ programme ${ }^{58}$ has also developed a labelling programme for set-top boxes to inform consumers about the energy consumption of these devices ahead of the scheduled switch-off of analogue TV broadcast services by 2009. The ENERGY STAR ${ }^{\circledR}$ label is widely promoted by Australia, Canada, the EU, Norway, Japan and $\mathrm{NZ}$ to increase appliance energy efficiency (International Energy Agency, 2009a).

\footnotetext{
${ }^{58}$ The ENERGY STAR® label is widely promoted by Australia, Canada, the EU, Norway, Japan and NZ to increase appliance energy efficiency (International Energy Agency, 2009a).
} 


\subsubsection{Australia}

Australia introduced MEPS/L to TVs on 1 October 2009 ahead of New Zealand. According to a Nielsen Report, $80 \%$ of Australian households have two TVs or more compared to New Zealand with $72 \%$. As in New Zealand, LCD sets are preferred to plasma sets.

Unlike New Zealand's preference for picture quality, the most important factors for Australians when purchasing a TV were price followed by picture quality. Furthermore, TV ownership is estimated between 2.4 and 2.7 per household (E3 Committee). The market share for 2007 consists of $48 \%$ LCD, $35 \%$ CRT and $17 \%$ plasma TVs compared to New Zealand's $65 \%$ of CRT, $19 \%$ of LCD, $7 \%$ of plasma and 9\% combination of LCD and plasma TVs. Australia has been the international leader in adopting flat panel display TV technology, reaching $50 \%$ of sales in 2006 . Escalated demand for digital TVs may have been influenced by Australia's schedule to switch-off analogue TV broadcast services by 2013 (International Energy Agency, 2009a).

Australia, the US and New Zealand consumers seem to be largely unaware of the repercussions of unrestrained household energy use, to judge from the low weighting energy use has among selection criteria considered by New Zealand households when purchasing a TV set, and to judge from the low weight placed on similar criteria in US and Australian surveys. Most European households seem to be more conscious of issues relating to energy efficiency, conservation and environmental impacts. The reasons for this awareness are complex and cultural, but probably reflect European households' longer term commitment to environment sustainability and European governments' conscious efforts to foster environmental awareness. For example the environmental awareness work conducted by UK Committee on Climate Change and DEFRA. 


\subsection{Implications for Future Household Sector Electricity Use}

Television and auxiliary appliance electricity use in the New Zealand household sector is increasing. Advances in technology, an increase in ownership and hours of operation as well as standby electricity use are the main drivers. To date, advances in technology such as from CRT to LCD sets have increased energy use, but innovations now emerging such as OLEDs may slow or reverse this trend. The penetration rate of technology and TV auxiliary appliances used with TVs in New Zealand compared to the US, Japan and Australia seems to be lagging. Norwegian and US trends show a shift from watching TV programmes using a TV to a growing popularity of TVwatching through video streaming from computers. Energy use by computers is likely to rise because this may act as an additional TV. The energy and other implications of this remain to be explored. Further studies are required to determine the direction New Zealand households may take with TV programme-watching using computers. This may become more important with the availability of TV programmes from the web.

Technological solutions need to be utilised to their full extent to reduce energy use by household entertainment devices. A UK study (Roberts, 2008) sees a TV as an essential household item and not as a luxury item. Thus, to limit ownership of TVs and related devices, policies on TV retirement and life-cycle cost need to be carefully considered, and targeted more at secondary TV sets.

Increased knowledge and awareness of the impacts of escalating energy use by households may help to some extent in containing energy use. A GfK survey of European countries has highlighted the impact of environmental awareness on household purchasing decisions (GfK Retail and Technology, 2009). Therefore, changing consumer behaviour through increasing knowledge and awareness may provide wider environmental benefits, though this remains undemonstrated in the New Zealand context. Reliance on reducing energy consumption through changes in technology or household behaviour in isolation is unlikely to be effective and integrated solutions are required for achieving long-term benefits. 


\subsection{Topics for further studies}

The present study has underlined that technological, behavioural and other household factors can influence TV energy use. It is intended that some findings from the survey described in this chapter will be compared with the BRANZ Household Energy End-use Project 2 metered energy use data. Comparison of these two sets of findings may help to identify gaps in knowledge and policy initiatives needed to increase household awareness and conservation of electricity.

International statistics suggest that there are emerging trends in households' convergent use of mobile phones, televisions and computers at the same time. Further research is needed to explore and understand these trends in the New Zealand context.

Another increasingly popular topic in the international community is regulating the energy using functionality of a product rather than the product itself. For example regulating the function of heating and cooling rather than products with a heat pump or resistive heating technology is likely to provide coverage for all new products that come into the market. Regulating TV technology is complex because it includes picture, sound and operation of other associated appliances. However, regulating energy use to display a picture, sound or other operations may prevent energy inefficient new products coming into the market.

As noted above, there also seems to be a considerable gap between the European countries and countries such as Australia, the US and New Zealand in household understanding of the environmental impact of appliance energy use. A cross cultural study would be useful in identifying the effective European measures that may have assisted in disseminating messages relating to environmental impact, and exploring their application in New Zealand. 


\section{Chapter 6: Discussion}

The adverse impacts on the environment caused by energy production have accentuated the need to deepen the understanding of such impacts and implement policies to reduce global energy use.

Energy is fundamental to all sectors - industrial, commercial, transport and household -- and is utilised in the production and consumption of most goods and services. Industrial and commercial sectors have commercial drivers to minimise costs and consequently to reduce energy consumption. Their primary reason is to reduce energy use as a way of minimising cost. Furthermore, businesses can gain a competitive advantage over their trading partners by reducing greenhouse gas emissions in their businesses.

Moreover, as consumer awareness of the link between energy use, greenhouse gas emissions and climate change increases, goods and services produced with less energy use are likely to gain popularity among consumers. Some businesses are still focused on short-term profits and consequently, disregard greenhouse emission reduction practices and energy efficiency, without considering long term repercussions. This problem is not easily overcome, but the introduction of a price on carbon in countries such as New Zealand will help to increase awareness of the disadvantages of fossil energy use, even if carbon prices remain low. However, a detailed discussion of these issues is beyond the scope of this thesis. Similarly, this thesis does not discuss energy use in the transport sector because of its complexity.

In contrast, the drivers for household sector energy use are largely health, comfort and entertainment, with energy cost being a consideration but often not a dominant one. Energy facilitates households to obtain services such as heating, cooling, lighting and operating appliances. Use of these services is unique to each household and is influenced by household behaviour. Household behaviour is underpinned by values, norms, attitudes, habits, routines and practices. Interaction and differing levels of influence of the 
above factors make understanding household energy use complex. Some of these factors may have a greater influence than others on household behaviour and are likely to be more difficult to change to have an impact on energy use. However, successes in public campaigns such as anti-smoking and polio eradication show that household habits and practices are not impossible to change over the long term. Chapter 2 and 3 discussed a range of factors that can influence household energy use.

Technology availability is a catalyst to changing behaviour; a good example of this is the use of a food processor instead of a knife, replacing a labour intensive device with an energy intensive appliance, but saving human effort and time. Ease of use may encourage households to use appliances more often (especially if other features such as time taken for cleaning an appliance is not too much of a barrier, or is not taken into account by the appliance purchaser at time of purchase) leading to an increase in the consumption of energy. Collectively, these appliances consume increased levels of energy notwithstanding any efficiency improvements in such appliances. Furthermore, electricity suppliers need to maintain additional capacity to satisfy the power demanded when these appliances are operated, if they tend to draw peak-period electricity.

Increased public awareness can influence household behaviour and government policies to reduce energy consumption. More frequent occurrences of extreme weather conditions may act as a background factor to increase awareness of the impact climate change has on households. Another factor is publicity about the health repercussions of uninsulated and under-heated housing, increased awareness of which is likely to be responsible for tightening of building codes and the increasing popularity of heat pumps.

Official energy publications indicate that New Zealand household electricity use per household has remained steady over the last two decades despite decreasing household size, suggesting some energy efficiency gains. The picture is complex but energy use appears to have been influenced by a 
number of factors. These include households shifting from wood to electricity for space heating, households maintaining a slightly increased home temperature, increased house area per person, and an increased number of appliances and lighting fixtures per household.

New Zealand houses are considered cold compared to other developed countries. This perception may be valid because most houses were built prior to the introduction of mandatory insulation in the New Zealand building code. However, the HEEP study noted that official energy publications considered only metered electricity and gas usage, which excludes wood or coal used by households. According to this study, wood usage was hugely understated. Energy obtained from wood is not easily estimated because wood can be procured from unaccounted sources such as gardens, farms and building sites; further, the energy content varies for different wood types.

Space heating uses the highest proportion of energy in New Zealand homes. When the existing housing stock was built, efficient energy use was not given a high priority because of the availability and low price of significant sources of energy, including wood as noted. Most architects and builders have not incorporated basic practices - although this is showing signs of change - to their house designs that can reduce life-time energy use because the main focus was to minimise capital cost, or meet aesthetic requirements. In most cases, costs involved to upgrade the energy efficiency of these houses are small compared to the energy savings that can be obtained during the lifetime of these houses. The impetus to upgrade is weakened by under-developed government building guidelines, although these are improving, the limited financial capacity of some households, and the split incentives that prevail in the rental housing sector.

Many New Zealand households are becoming aware of the benefits of heating and cooling. Recent research suggests cooling is becoming more popular in summer months. Therefore the New Zealand government like other governments around the world has introduced technological standards to improve the efficiency of space heating and cooling. Even though energy 
efficiency is improving in heating and cooling systems, savings in energy seem to be outweighed by the increasing energy demand for comfort. Increasing household incomes over time are likely to strengthen the energy demand.

According to the Year 10 HEEP Report in 2006, the next highest proportion of household energy is consumed by water heating followed by lighting and appliance operation. Unlike space and water heating, lighting and appliances are mainly operated by electricity. However, studies including the study of energy use by televisions undertaken as a part of this thesis suggest lighting energy use is likely to be overtaken by energy use for appliances. Furthermore, efficiency gains in lighting technologies and government promotion of energy efficient lighting may have reduced lighting electricity use. This presumption cannot be confirmed until a metered study is undertaken.

Appliance energy use seems to be increasing among New Zealand households. A comparison of the appliances owned by households now relative to the last decade shows an increased ownership of consumer electronic products. IEA studies suggest energy use in small appliances is increasing compared to larger appliances. Hence, a good understanding of consumer electronic energy use may offer solutions to reduce household energy use.

Consumer electronics are regarded as items with short life spans. Their technology, design and quality are constantly improving and offered to the market as new products. Therefore, standardizing these products for energy efficiency becomes complex. Furthermore, the objective of the consumer electronics manufacturers is to capture market share rather than energy efficiency. Even though some consumer electronic devices individually consume negligible amount of electricity, collectively they impact on energy use. Therefore delivering the most efficient solutions in terms of electricity use can deliver many benefits. Currently, no regulations are in place to require design that minimises electricity use, at the conception of a consumer electronic product. Many regulations follow the evolving products to reduce 
electricity use. Some people support the view that regulating electricity use by functionality ${ }^{59}$ of a product would be more effective in curbing the growing electricity use in consumer electronic appliances. A counter argument is that human beings thrive on innovation, research and development. However, the experience of a proliferation of energy-inefficient consumer appliances suggests that market incentives for energy efficiency are weak, and that other factors tend to dominate consumer decisions. Because of the collective benefits of greater energy efficiency, there is thus a case for regulation of appliance energy efficiency. This does not constitute a diminution of the freedom to innovate, but the importance of moderating adverse environmental effects means there is a strong case for guiding innovators to achieve more socially responsible solutions.

Another adverse impact of rapid turnover of consumer electronic is the accumulation of electronic waste in landfills. While some countries (Dully, S.,Lückefett, H., Ulbricht, C., \& Westkämper, E. ,2009) \& (European Commission, 2010)such as the Netherlands are making progress in addressing the issue of electronic appliance end-of-life management, there are no effective policies in New Zealand to dispose of or recycle electronic items completely. Television survey shows that there are vast numbers of televisions in storage. It is likely that other consumer electronic devices are also in storage and will end up in landfills eventually.

Earlier chapters also discussed the changing lifestyles associated with widespread use of televisions and computers. Households seem to operate consumer electronic devices longer now than they did previously, because of new technologies and more attractive services (e.g. internet and TV). Longer hours of activity in homes mean that lighting, preparing food, and higher heating levels are sustained over longer periods. Such behaviour leads to increased energy use in households. It may also mean changes in household practices. It may mean there is less differentiation in average energy use between night and day. Households can bank, communicate, correspond,

\footnotetext{
${ }^{59}$ Functionality of TV is energy use for service delivered such as watching a programme on TV regardless of size or
} technology of a TV set 
entertain, cook and conduct almost all their other daily activities during night time.

Household sector energy use is likely to rise in the future in New Zealand, but with good management it may not. Since heating constitutes the highest proportion of energy use, energy-efficient home design (or design adjustment through retrofitting) is integral to providing comfort through efficient and costeffective heating. Recommended levels of temperature and lighting for a room are not changing, even though the number of rooms per house and room size are increasing. For a given size of room, a given level of comfort is now achievable at lower cost if the most efficient technology available is used. Even though lifetimes of insulation, heating systems and lighting fixtures can be measured in decades, gradual replacing of such fixtures and systems with modern devices with high energy efficiencies could lead to a reduction in the household energy consumption. On the other hand, most houses in New Zealand are under-heated and as more people become aware of the consequences of living in under-heated homes, energy use for heating is likely to increase. Along with this goes the risk of take back - some households have a tendency to consume more energy after heat loss in their homes is reduced with better insulation. However, it appears more likely that levels of take back will decline as New Zealand households' incomes rise over time. This matter is likely to be better illuminated as energy use is monitored following the roll-out of the government's 'Warm Up New Zealand' programme.

Emerging lighting technologies suggest that energy use for lighting could decrease. Most of these technologies are based on light emitting diodes. Currently, they are expensive, but past experience of technological innovation suggests that their prices are likely to decrease over the longer term. However, increased periods of electricity use in households are likely to offset the reduction in electricity consumption achieved by efficiency gains. A campaign to moderate the use of lighting as new LED lights are introduced may assist New Zealanders to conserve electricity. 
Television energy use depends on household behaviour. Unlike heating and lighting, consumer electronic products do not provide an essential service in terms of human physiology. However, televisions and computers are widely used for entertainment, and to increase household knowledge, facilitate communication and assist research. Many households regard them as vital to everyday operation and consequently, such appliances are operated over extended periods.

Most of the literature on TV and their usage draw on television ratings to estimate the number of hours the televisions are used in households. Therefore it does not capture the television used for the other purposes such as background noise. This is one of the few studies available that was expressly designed to understand the household television and peripheral device ownership, usage and energy use. The major findings from the study are as follows; televisions consume 4.34 PJ of electricity annually; New Zealand households own 3.56 million TV sets; each household own 2 or 3 TV sets; currently small size TV sets dominate the total stock but large size TV sets dominate the aged two years or less TV stock; currently CRT TVs dominate the total stock whereas LCD is popular in the aged two years of less TV stock; main TV of household is around four years and the second and third TVs are about six years old; on average televisions are used 50 hours a week; households use TVs to watch TVs followed by to get teletext and for background noise; DVD players are the most popular auxiliary devices followed by VCR and games consoles; $85 \%$ of survey respondents were not aware of TV and associated appliance energy use; the main reason for purchasing a TV set was to increase screen size followed by to upgrade technology; when a new TV set was bought, most households' moved their the old TV set to another room.

Better understanding trends in television appliance were a central aim of this thesis. The study of televisions reported earlier in this thesis revealed that household ownership of TVs and auxiliary appliances, and duration of operation of these appliances are increasing in New Zealand. More New Zealand households prefer large flat screen TVs. Even though energy efficient 
TVs are available, lack of information and awareness may lead to high TV energy use in households. It also revealed that households use televisions for background noise. 2006 Census statistics show that single occupant households' are increasing. Therefore it can result in increasing TV energy use.

There are many limitations to the television usage and purchasing study. This study is based on a survey of adults: the adult who reported the hours of operation of television may well have underestimated children's television viewing habits, especially if there is a TV in a child's bedroom. A metering study would help to confirm the hours of TV operation but the reasons for operating TV or understanding other behavioural influences on the operation of TVs may require a multi-disciplinary integrated study. This study does not look at the influence of falling TVs and associated appliance prices and TV advertisements on TV ownership and usage.

The television study represents a single product in the consumer electronics product category. The consumer electronic sector provides and promotes information, communication and entertainment appliances that are increasingly pervasive in our homes and in other spaces. Furthermore, these devices can be integrated for better service, such DVD player and stereo, to obtain a sound and image quality similar to that of a cinema. This makes them even more appealing to consumers.

More generally, perhaps the most powerful driver of increased demand for household energy use is likely to be the increase over time in household incomes. Over the last century, this income effect has dominated energy demand growth, both worldwide and in New Zealand. The big question that sits alongside this is whether energy prices may rise as fast as incomes grow, especially as fossil fuel supplies become constrained by carbon pricing. As energy demand increases the sources that can be easily converted into useful forms of energy could become scarcer, and energy prices will increase, but while this effect may be visible for liquid fuels, it is not likely to dominate with other forms of energy, where innovation is rapid and the multiplicity of 
technologies is likely to allow substitution among energy forms to restrain price increases.

Low income households without government assistance may well continue to struggle to purchase energy for essential services such as heating to maintain health. Household health provides many benefits to a community in the long term such as happily employed households that produce educated and productive occupants. If governments are committed to such goals, they have the ability to design effective energy policies that can improve the standard of living of households and also decrease household expenditure at the same time.

Understanding effective and efficient ways of reducing household energy use is paramount in the context of increasing population, the rising number of dwellings and decreasing household size, and increasing size of dwellings. If current household consumption patterns are maintained, the demand for energy will also increase with the ageing population. Current population projections for developed countries show that the proportion of older people is increasing over time. Ageing people's physiology requires a slightly higher temperature than for other age-groups. As the proportion of ageing people in the population increases, maintaining such temperatures may require the consumption of additional energy. Further research will be necessary to ascertain the net effect of rising temperatures resulting from climate change on energy demand, as heating demand moderation in some colder parts of New Zealand will be offset by demands for more household cooling in warmer parts of the country.

Households' ability to understand and pursue energy reducing practices is likely to have an indirect influence on energy use in the business sector. Household occupants are decision-makers in the business sector and can make a large impact there. If they use their knowledge of more efficient energy use and consider the flow-on effects of avoiding imprudent energy consumption, New Zealand is likely to have a better chance of achieving energy sustainability, reliability and resilience. 
However, the experience of trying to improve household energy efficiency discussed in this thesis suggests that energy use reduction is not easy. The measures taken to reduce household electricity or energy use so far do not appear to be particularly effective, or sometimes do not produce any response at all, in a number of countries. Regulating energy use for products does not seem to be effective because the regulatory regime does not take into account the underlying reasons for appliance choice behaviour. Japan's attempt to regulate energy use behaviour was not successful, because household behaviour is not set, as discussed in chapter 3 . Working on households' understanding of environmental issues and attempting to change their behaviour to reduce energy consumption through government policies seem to be the most appropriate way forward. The literature suggests that as household awareness increases, household energy use is likely to decrease; a big question is whether the slow pace of such changes can be accelerated.

Chapter 4 analysed the energy performances of selected OECD countries and their relevance to New Zealand. The main lesson learnt was that countries that were successful had long term commitments to reducing their energy use and greenhouse gas emissions. Nordic countries seem to have been more successful than the other countries in achieving energy security and reliability.

Many European governments have raised the awareness of energy consumption practices of their communities. Their energy consumption patterns show decreasing trends. Countries such as Norway and Sweden started raising this awareness after the oil crises in the 1970s. It is only now that they are experiencing a relatively consistent pattern of energy use reduction. However, if other countries follow a similar path it may be 2050 before they will see a significant energy use reduction pattern. Given the risks of going beyond dangerous climate change by this date, fossil fuel use will have to be curbed drastically before 2050. Therefore it is important that all countries look for solutions that can produce fast and effective results. In most cases, these will require interventions that are multi-disciplinary in nature. 
Household energy consumption patterns alone do not indicate the effectiveness of efficiency and conservation policies. Consumption patterns of households and energy wastage need to be considered in a richer behavioural framework to understand hidden energy consumption patterns. Even though countries attempt to indicate their superiority in social responsibility through reduction in energy use, many countries have shifted from producing goods to providing services, which consume less energy. However, this does not mean that they are consuming less. In most cases, they purchase their goods from highly energy intensive production regimes (Greening, Davis, \& Schipper, 1998). Even though it is complex, understanding, internalising and measuring life cycle costs of consumption provide the best estimation of a country's impact on the environment, including the effect of energy consumption patterns.

Ultimately, acting in a socially responsible and informed manner, within a framework of 'reasonable' government energy use regulation, is likely to be the most effective means of achieving energy sustainability and reliability. Such actions will also help New Zealanders to face and adapt to conditions arising out of climate change. Critical actions encompass encouragement of energy efficient consumption, reduction of direct and indirect energy wastage, actions to support the standard of living of vulnerable people such as those experiencing fuel poverty, enlightened guidelines for energy information campaigns, minimum energy performance standards, and regulation providing that household appliances should display important information such as lifecycle energy costs. 


\section{Chapter 7: Conclusion}

New Zealanders are becoming more aware that growing energy use may represent an economic and environmental risk to their future well-being (ShapeNZ, 2007). ${ }^{60}$ This thesis has examined New Zealand trends in household energy consumption, the sources of pressure for increased energy use and, in particular, the role of appliances in household energy use. Some international data on household energy use has enabled New Zealand's patterns to be seen in a wider context. Patterns of television use provided a detailed case study of changing appliance energy use patterns, and the level of awareness of energy and environmental issues associated with television use.

It can be expected that New Zealand household energy consumption will increase over the next decade to 2020. Major drivers will be the increasing number of households, and the resulting increase in household energy consumption for space and water heating, lighting and appliances. Drawing from chapter 1's analysis of household sector energy use per household between 1997 and 2007, this implies that energy consumption per household will be more or less constant.

The number of households in New Zealand will increase in the next decade owing to an increase in population and decrease in household size. As the number of occupants per household decreases, per capita energy use will increase because fewer occupants share the energy services provided by appliances such as heaters and televisions.

Space heating demand by New Zealand households will likely to increase. Households will continue to become more aware of the warmth, comfort and health benefits delivered through home heating, a process which has become

\footnotetext{
${ }^{60}$ A ShapeNZ survey $(n=960)$ found that $86 \%$ of respondents felt that 'the management of New Zealand's energy needs and where we get our energy from' represented an issue. Responses included 'A problem now' (39\%) and 'An urgent and immediate problem' (47\%). Other responses included 'Not really a problem at all' (2\%), 'A problem for the future' (11\%); and Don't know (1\%). This poll was conducted between April 4-7, 2007, by ShapeNZ, a national public online survey panel run by the New Zealand Business Council for Sustainable Development (www.nzbcsd.org.nz).
} 
evident in the last few years. This increased demand will to some extent be offset by increased home insulation, the retrofitting of which has recently been accelerated by programmes such as Warm Up New Zealand. Since currently many New Zealand houses are not adequately heated, energy use for space heating will increase to meet the demand associated with this heightened awareness. In addition to the effect of insulation, improving energy efficiencies in the housing stock and in heating systems, and emerging new technologies may help to counter the trend of increasing energy use.

Use of more energy efficient water heating systems in both new and old housing may help to reduce or maintain the energy use for water heating. More widespread use of technologies such as solar thermal, heat pump and instantaneous water heating systems as well as more efficient water flowing systems (Willis, Stewart, Panuwatwanich, Jones, \& Kyriakides, 2010) will reduce water heating energy use.

The focus of this study was New Zealand household sector electricity consumed by televisions and their associated devices. This has been increasing rapidly but it has still not reached the per capita levels of the UK, Australia, Japan or the USA. Average screen size of a TV in Australia has increased from $68 \mathrm{~cm}$ to $106 \mathrm{~cm}$ between 2003 and 2008 (Digital CEnergy Australia, 2009). Television energy use is being driven by an increasing number of television sets per household as well as increased energy use per set as screen sizes grow (Harrington, Jones, \& Harrison, 2006). However, IEA studies indicate that some smaller size TV screens are consuming more energy than large TV screens (International Energy Agency, 2009) indicating a case for Minimum Performance Standards and Labelling. Furthermore many households use TV monitors to access the Internet. Since many computers are not switched off and used as communications devices this may have implications for household energy use especially with increased screen size.

There is a window of opportunity for New Zealand to implement strong minimum energy performance standards for televisions designed to receive 
new digitally broadcasted television signals (final switchover is currently scheduled for 2013). Household penetration of auxiliary devices for televisions is also increasing. Regulating auxiliary device electricity consumption in standby and operation mode can reduce household energy use.

The survey carried out with this thesis shows that an average New Zealand household owns more than two televisions and operates them for more than 48 hours a week. Currently most televisions in New Zealand households have Cathode Ray Tube technology. The survey results show households' increasing preference for LCD technology (with plasma televisions being a minority and declining preference). One reason is that LCDs provide a better quality picture. This is further enhanced by digital television broadcasting signals. Another reason is the aesthetic appeal of the slim shape compared to bulky CRT technology. While energy efficient LCD televisions consume less electricity than a similar size CRT television set, LCD sets also tend to be larger than CRTs, and the acquisition of an LCD set usually means that the household TV energy usage does not fall - the household increases its total number of televisions, and their use (even if use of old CRTs is sporadic).

However, information, communication and entertainment device energy use is unpredictable because it depends on household behaviour, which is influenced by a multitude of behavioural drivers as discussed in chapter 3 . Among the factors New Zealand households consider when buying televisions, concern over energy usage does not rate highly, nor does a concern about end-of-life environmental impact.

The thesis addressed the question of how distinctive New Zealand is in regard to household energy use. The international literature, particularly IEA indicators, suggests that, in contrast to New Zealand's experience, Nordic countries have successfully implemented policies to reduce energy use in the household sector. Success can be attributed to a desire to reduce energy use and greenhouse gas emissions, translated into a carefully designed and implemented set of policies, such as those increasing awareness of 
consequences of high energy use. The Nordic experience suggests that energy reductions from such policies can take years, if not decades, to come to fruition.

Household energy use is complex because household behaviours are closely linked with the availability of changing technologies, changing fashions (such as the advent of LCD televisions), as well as underlying drivers of household energy use such as rising incomes and shrinking household size. New Zealand policy makers tasked with improving energy efficiency may not only need to take advantage of opportunities such as the digital TV changeover to promote greater efficiency, but may also need to aim to implement consistent energy-saving policies over a long period of time before any reduction in energy use can be observed. Policies will also have to recognise that while New Zealanders are conscious of the need to be economical with energy, this study has reinforced the finding that energy saving is not the top priority consideration for most households when making everyday purchase or use decisions that determine overall household energy use. One implication is that making energy efficient choices easier for households and raising the profile of energy saving at key decision points may need to be consistently encouraged by the government. The government may also need to encourage energy retailers to provide more detailed billings on household energy enduses to identify energy wastage in energy using practices. 


\section{References}

EEUDB (1996). from EECA's Energy End-use Database:

EEUDB (2002). from EECA's Energy End-use Database:

Abrahamse, W., \& Steg, L. (2009). How Do Socio-Demographic and

Psychological Factors Relate to Households' Direct and Indirect Energy

Use and Savings? Journal of Economic Psychology, In Press,

Accepted Manuscript.

Abrahamse, W., Steg, L., Vlek, C., \& Rothengatter, T. (2005). A review of intervention studies aimed at household energy conservation. Journal of Environmental Psychology, 25, 273-291.

Abrahamse, W., Steg, L., Vlek, C., \& Rothengatter, T. (2007). The effect of tailored information, goal setting, and tailored feedback on household energy use, energy-related behaviors, and behavioral antecedents. Journal of Environmental Psychology, 27(4), 265-276.

Agular, R., Oliveira, M., \& Gonçalves, H. (2002). Climate change impacts on the thermal performance of Portuguese buildings. Results from SIAM Study. Building Services Engineering Research and Technology, 23(4), 223-231.

Amine, L. (2003). An integrated micro- and macrolevel discussion of global green issues: "It isn't easy being green". Journal of International Management, 9(4), 373-393.

Amitrano, L. (2004). New Zealand residential energy use: An international comparison. Porirua: Building Research Aotearoa New Zealand.

Anker-Nilssen, P. (2003). Household energy use and the environment--a conflicting issue. Applied Energy, 76(1-3), 189-196.

Anonymous (1991). Staying a Step Ahead of the Future. Electrical World, 205(4), 22.

Anonymous (2003). Eco friendly and energy efficient. Appropriate Technology, 30(1), 55.

Aoe, T. (2007). Eco-efficiency and ecodesign in electrical and electronic products. Journal of Cleaner Production, 15(15), 1406-1414.

Aries, M. B. C., \& Newsham, G. R. (2008). Effect of daylight saving time on lighting energy use: A literature review. Energy Policy, 36(6), 18581866.

ASaP (2007). Residential water heaters. Retrieved from http://www.standardsasap.org/products/res_waterheaters.htm

Ashina, S., \& Nakata, T. (2008). Energy-efficiency strategy for $\mathrm{CO}_{2}$ emissions in a residential sector in Japan. Applied Energy, 85, 101-114.

Ashina, S., \& Nakata, T. (2008). Quantitative analysis of energy-efficiency strategy on $\mathrm{CO}_{2}$ emissions in the residential sector in Japan - Case study of Iwate prefecture. Applied Energy, 85, 204-217.

Association of Electricity Producers (2005). Frequently asked questions about Electricity Retrieved 15 September, 2009, from http://www.aepuk.com/need_info.php\#10

Atanasiu, B., \& Bertoldi, P. (2008). Residential electricity consumption in New 
Member States and Candidate Countries. Energy and Buildings, 40(2), 112-125.

Audenaert, A., Cleyn, S., \& Vankerckhove, B. (2008). Economic analysis of passive houses and low-energy houses compared with standard houses Energy Policy, 36, 47-55.

Auffhammer, M., Blumstein, C., \& Fowlie, M. (2008). Demand-side management and energy efficiency revisited. Energy Journal, 29(3), 91-104.

Baker, K., \& Rylatt, R. (2008). Improving the prediction of UK domestic energy-demand using annual consumption-data. Applied Energy, 85, 475-482.

Baker, P., Blundell, R., \& Micklewright, J. (1989). Modelling Household Energy Expenditures Using Micro-Data. The Economic Journal, 99(397), 720-738.

Ball, R., Cullen, R., \& Gan, C. (1999). The diffusion of Energy Efficiency Innovations Among Residential Energy Consumers (Statsistical Data Included). New Zealand Economic Papers, 33(1), 115.

Banfi, S., Farsi, M., Filippini, M., \& Jakob, M. (2008). Willingness to pay for energy-saving measures in residential buildings. Energy Economics, 30, 503-516.

Barbara, F., \& Timothy, C. (2008). A New Market Paradigm for Zero-Energy Homes: A Comparative Case Study. Environment, 50(1), 18.

Barnard, T., Baker, L., Hales, S., \& Howden-Chapman, P. (2007). The role of housing age and socio-economic status in New Zealand excess winter hospitalisation patterns Paper presented at the Fifth Housing and Health Conference Coventry.

Barry, M., \& Chapman, R. (2009). Distributed small-scale wind in New Zealand: Advantages, barriers and policy support instruments. Energy Policy, 37(9), 3358-3369.

Becker, L., Seligman, C., Fazio, R., \& Darley, J. (1981). Relating attitudes to residential energy use. Enviroment and Behaviour, 13, 590-609.

Belzen, D., \& Cort, K. (2004). Statistical Analysis of Historical State-Level Residential Energy Consumption Trends. Paper from Northwest National Laboratory,

Birgitta, G., Linda, S., \& Charles, V. (2002). Measurement and determinants of environmentally significant consumer behavior. Environment and Behavior, 34(3), 335.

Blackwell, S. F. (2009). Electricity conservation in context: a mixed methods study of residential conservation behaviour during an electricity shortage in New Zealand. Victoria University of Wellington, Wellington.

Bladh, M., \& Krantz, H. (2008). Towards a bright future? Household use of electric light: A microlevel study Energy Policy, 36, 3521-3530.

Boardman, B. (1991). Fuel Poverty: from cold homes to affordable warmth. London: Belhaven Press.

Boonekamp, P. (2006). Actual interaction effects between policy measures for energy efficiency - A qualitative matrix method and quantitative simulation results for households. Energy, 31, 2848-2873.

Brandon, G., \& Lewis, A. (1999). REDUCING HOUSEHOLD ENERGY CONSUMPTION: A QUALITATIVE AND QUANTITATIVE FIELD STUDY. Journal of Environmental Psychology, 19(1), 75-85. 
Brecha, R. (2008). Emission scenarios in the face of fossil-fuel peaking. Energy Policy, 36, 3492-3504.

Brown, R., \& Koomey, J. G. (2002). Electricity Use in California: Past Trends and Present Usage Patterns. Energy Policy, 31(9), 849-864.

Camilleri, M. J., French, L. J., \& Isaacs, N. P. (2007). The effect of mandatory insulation on household energy consumption. Paper presented at the XXXVth International Association of housing Science IAHS World Congress on Housing Science.

Camilleri, M. J., Isaacs, N. P., \& French, L. J. (2006). Standby and Baseload in New Zealand Houses - A Nationwide Statistically Representative Study. Paper presented at the American Council for Energy Efficient Economy.

Carlsson-Kanyama, A., \& Lindén, A.-L. (2007). Energy efficiency in residences--Challenges for women and men in the North. Energy Policy, 35(4), 2163-2172.

CAROLYN S. TURNER, \& KENNETH J. GRUBER (1989). Occupant-use factors influencing optimal results from energy conservation strategies. International Journal of Consumer Studies, 13(3), 219-235.

Chapman, R. (2004). A cost-benefit evaluation of housing insulation: results from the New Zealand 'Housing, Insulation and Health' study Wellington.

Chapman, R., Howden-Chapman, P., O'dea, D., Viggers, H., \& Kennedy, M. (2009). Retrofitting houses with insulation: a cost-benefit analysis of a randomized community trial. Journal of Epidemiology and Community Health, 63, 271-277.

Cholewa, T., \& Siuta-Olcha, A. (2010). Experimental investigations of a decentralized system for heating and hot water generation in a residential building. Energy and Buildings, 42(2), 183-188.

Clark, C., Kotchen, M., \& Moore, M. (2003). Internal and external influences on pro-environmental behaviour: Participation in a green electricity program. Journal of Environmental Psychology, 23, 237-246

Clark, S., Jones, M., \& Page, I. (2005). New Zealand 2005 House Condition Survey. Wellington: BRANZ.

Correlje, A., \& van der Linde, C. (2006). Energy supply security and geopolitics: A European perspective. Energy Policy, 34(5), 532-543.

Critchley, R., Gilbertson, J., Grimsley, M., Green, G., \& Group, W. f. S. (2007). Living in cold homes after heating improvements: Evidence from Warm-Front England's Home Energy Efficiency Scheme. Applied Energy, 84, 147-158.

Crosbie, T. (2008). Household energy consumption and consumer electronics: The case of television. Energy Policy, 36, 2191-2199.

Crosbie, T., \& Guy, S. (2008). En'lightening energy use: the co-evolution of household lighting practices. International Journal of Environmental Technology and Management, 9(2/3), 220-234.

Dale, L., Antinori, C., McNeil, M., McMahon, J., \& Fujita, K. (2009). Retrospective evaluation of appliance price trends. Energy Policy, 37, 597-605.

Darby, S. (2006). Social learning and public policy: Lessons from an energyconscious village. Energy Policy, 34, 2929-2940. 
Davie, G., Baker, M., Hales, S., \& Carlin, J. (2007). Trends and determinants of excess winter mortality in New Zealand: 1980-2000. BMC Public Health, 7(263).

Department of Energy and Climate Change (2010). Energy Consumption in the United Kingdon Retrieved 04 March, 2010, from http://www.decc.gov.uk/en/content/cms/statistics/publications/ecuk/ecu k.aspx

Department of Statistics (1976). Report on the Temperature/Insulation Study. Wellington.

Department of the Environment Water Heritage and the Arts (2008). Energy Use in the Australian Residential Sector 1986-2020. Canberra.

DEPARTMENT of the PRIME MINISTER and CABINET (2008). Final Report of the House Prices Unit: House Price Increases and Housing in New Zealand - March 2008. Wellington.

Development, N. Z. B. C. f. S. (2007). ShapeNZ Research Report. Auckland.

Dietz, T., Fitzgerald, A., \& Shwom, R. (2005). Environmental Values. Annual Review of Environmental Resources, 30, 335-372.

Digital CEnergy Australia (2007). Television Energy Rating Labels: Options for MEPS and Energy Rating Metric and Introduction Timin.

Digital CEnergy Australia (2009). Consultation Regulatory Impact Statement Proposed Minimum Energy Performance Standards and Labelling for Televisions.

Dincer, I., \& Rosen, M. (1999). Energy, environment and sustainable development. Applied Energy, 64, 427-440.

Druckman, A., \& Jackson, T. (2008). Household energy consumption in the UK: A highly geographically and socio-economically disaggregated model. Energy Policy, 36(8), 3177-3192.

Duke, R., Williams, R., \& Payne, A. (2005). Accelerating residential PV expansion: demand analysis for competitive electricity markets. Energy Policy, 33(15), 1912-1929.

Dully, S., Lückefett, H., Ulbricht, C., \& Westkämper, E. (2009). National Registration for Producers of Electronic Waste

Dunlap, R., Van Liere, K., Mertig, A., \& Emmet Jones, R. (2000). Measuring Endorsement of the New Ecological Paradigm: A Revised NEP Scale. journal of Social issues, 56(3), 425-442.

Dzloubinski, O., \& Chipman, R. (1999). Trends in Consumption and Production: Household Energy Consumption. DESA Discussion Paper No.6,

Easterlow, D., Smith, S., \& Mallinson, S. (2000). Housing for Health. Housing Studies, 15(3), 367-385.

Elias, A. (2008). Energy efficiency in New Zealand's residential sector: A systemic analysis. Energy Policy, 36, 3278-3285.

Emery, A. F., \& Kippenhan, C. J. (2006). A long term study of residential home heating consumption and the effect of occupant behavior on homes in the Pacific Northwest constructed according to improved thermal standards. Energy, 31(5), 677-693.

Energy Information Agency (2001). The effect of Income on Appliance in US Households. Retrieved 20/12/2007.

Energy Information Agency (2008). International Energy Annual 2006. Retrieved 20 May 2009: http://www.eia.doe.gov/emeu/iea/coal.html 
Equipment Energy Efficiency Committee (2009). Consultation Regulatory Impact Statement: Proposed Minimum Energy Performance Standards and Labelling for Televisions, Report 2009/03.

Espey, J. (2004). Turning on the lights: A Meta-Analysis of Residential Electricity Demand Elasticities. Journal of Agricultural and Applied Economics, 36(1), 65-81.

European Commission (2010). 2009 Environment Policy Review. Luxembourg: Office for Official Publications of the European Communities, 2010.

European Network of Transmission System Operators for Electricity (2009). We are the European TSOs. We are ENTSO-E Retrieved 15 September, 2009, from http://www.entsoe.eu/association/

Farahbakhsh, H., Ugursal, V., \& Fung, A. S. (1998). A residential end-use energy consumption model for Canada. International Journal of Energy Research, 22(13), 1133-1143.

Farinaccio, L., \& Zmeureanu, R. (1999). Using a pattern recognition approach to disaggregate the total electricity consumption in a house into the major end-uses. Energy and Buildings, 30(3), 245-259.

Fernandez, V. (2001). Observable and Unobservable determinants of replacement of home. Energy Economics, 23(3), 305-323.

Firth, S., Lomas, K., Wright, A., \& Wall, R. (2008). Identifying trends in the use of domestic appliances from household electricity consumption measurements. Energy and Buildings, 40(5), 926-936.

Fischer, M., \& Grossmann, M. (2006). Weathering power's demand. Energy Risk, 42.

Fisher, G., Kjellstrom, T., Kingham, S., Hales, S., \& Shrestha, R. (2007). Health and Air Pollution in New Zealand. Wellington.

Fong, W., Matsumoto, H., Lun, Y., \& Kimura, R. (2007). Influences of Indirect Lifestyle Aspects and Climate on Household Energy Consumption Journal of Asian Architecture and Building Engineering, 6(2), 395-402.

French, L. J. (2008). Active Cooling and Heat Pump Use in New Zealand Survey Results, Study Report No. 186. Wellington: BRANZ.

French, L. J., Camilleri, M. J., Isaacs, N. P., \& Pollard, A. R. (2007). Temperatures and heating energy in New Zealand houses from a nationally representative study--HEEP. Energy and Buildings, 39(7), 770-782.

Gabzdylova, B., Raffensperger, J., \& Castka, P. (2009). Sustainability in the New Zealand Wind Industry: drivers, stakeholders and practices. Journal of Cleaner Production, 17(11), 992 - 998.

Gatersleban, B., Steg, L., \& Vlek, C. (2002). Measurement and determinants of environmentally significant consumer behaviour. Enviroment and Behaviour, 34, 335-362.

Geller, H., Harrington, P., Rosenfeld, A. H., Tanishima, S., \& Unander, F. (2006). Polices for increasing energy efficiency: Thirty years of experience in OECD countries. Energy Policy, 34(5), 556-573.

GfK Retail and Technology (2009). Energy Efficiency as a selling point. Retrieved from http://www.gfkverein.de/download/TV_Energy_efficiency.pdf

Gillingham, K. (2009). Economic efficiency of solar hot water policy in New Zealand. Energy Policy, Article in Press. 
Goldblatt, D. L., Hartmann, C., \& Dürrenberger, G. (2005). Combining interviewing and modeling for end-user energy conservation. Energy Policy, 33(2), 257-271.

Government Social Research Unit (2010). Behaviour change: GSR knowledge review Retrieved 12 April, 2010, from www.gsr.govt.uk/resources/behaviour_change_review.asp

Greening, L., Greene, D., \& Difiglio, C. (2000). Energy Efficiency and Consumption - the rebound effect - a survey. Energy Policy, 28, 389401.

Greening, L. A., Davis, W. B., \& Schipper, L. (1998). Decomposition of aggregate carbon intensity for the manufacturing sector: comparison of declining trends from 10 OECD countries for the period 1971-1991. Energy Economics, 20(1), 43-65.

Griffin, J. (2007). Insulation in existing housing. Wellington: BRANZ.

Grübler, A., Nebojša, N., \& Victor, D. (1999). Modelling Technological Change. Annual Review of Energy and Environment, 24, 545-569.

Gyberg, P., \& Palm, J. (2009). Influencing households' energy behaviour--how is this done and on what premises? Energy Policy, 37(7), 2807-2813.

H M Treasury (2009). Budget 2009.

Haas, R. (1997). Energy efficiency indicators in the residential sector : What do we know and what has to be ensured? Energy Policy, 25(7-9), 789802.

Haas, R., Biermayr, P., Zoechling, J., \& Auer, H. (1998). Impacts on electricity consumption of household appliances in Austria: A comparison of time series and cross-section analyses Energy Policy, 26, 1031-1041.

Hajat, S., \& Haines, A. (2002). Association of cold temperatures with GP consultations for respiratory and cardiovascular disease amongst the elderly in London. Internatonal Epidemiological Association, 31(825830).

Hall, D., Turner, P., \& Dickinson, D. (2009). Turning involvement into action consumer. Wellington: Synovate Ltd.

Halvorsen, B., \& Larsen, B. (2001). The flexibility of household electricity demand over time. Resource and Energy Economics, 23, 1-18.

Hansen, J., Sato, M., Kharecha, P., Beerling, D., Berner, R., MassonDelmotte, V., et al. (2008). Target atmospheric $\mathrm{CO}_{2}$ : Where should humanity aim? Open Atmos. Sci. J., 2, 217-231.

Hargreaves, C., Johnstone, N., Laroui, F., \& van Leeuwen, M. (1998). Comparative energy and environmental policy for the residential sector: applying Dutch standards to the UK housing stock. Energy Economics, 20, 173-202.

Hargreaves, R. (2003). Mitigating the impacts of Climate Change on the Built Environment: BRANZ.

Harrington, L., Jones, K., \& Harrison, B. (2006). Trends in Television energy use: where it is and where it is going. Paper presented at the ACEEE Summer Study, California.

Harris, J., Diamond, R., Iyer, M., Payne, C., Blumstein, C., \& Siderius, H. (2008). Towards a sustainable energy balance: progressive efficiency and the return of energy conservation. Energy Efficiency, 1, 175-188.

Hart, M., \& de Dear, R. (2004). Weather sensitivity in household appliance energy end-use. Energy and Buildings, 36(2), 161-174. 
Hartmann, P., \& Ibáñez, V. (2007). Managing customer loyalty in liberalized residential energy markets: The impact of energy branding. Energy Policy, 35, 2661-2672.

Healy, J., \& Clinch, J. (2004). Quantifying the severity of fuel poverty, its relationship with poor housing and reasons for non-investment in energy-saving measures in Ireland. Energy Policy, 32, 307-3200.

Helgason, S. (1997). International Benchmarking Experiences from OECD Countries. Paper presented at the International Benchmarking, Copenhagen.

Heneley, A., \& Pierson, J. (1998). Residential Energy Demand and the interaction of price and temperature. Energy Economics, 20, 157-171.

Hirsch, R. (2005). The Inevitable Peaking of World Oil Production. Atlantic Council Bulletin, XVI(3), 1-9.

Holm, E. (2001). The Swedish nuclear dilemma. Journal of Environmental Radioactivity, 52(2-3), 113-115.

Hong, S. H., Gilbertson, J., Oreszczyn, T., Green, G., \& Ridley, I. (2009). A field study of thermal comfort in low-income dwellings in England before and after energy efficient refurbishment. Building and Environment, 44(6), 1228-1236.

Hong, S. H., Oreszczyn, T., \& Ridley, I. (2006). The impact of energy efficient refurbishment on the space heating fuel consumption in English dwellings. Energy and Buildings, 38(10), 1171-1181.

House of Commons Information Office (2009). Programmes to Reduce Household Energy Consumption. London: UK Parliament - House of Commons.

Howden-Chapman, P., Crane, J., Matheson, A., Viggers, H., Cunningham, M., Blakely, T., et al. (2005). Retrofitting houses with insulation to reduce health inequalities: aims and methods of a clustered, randomised trial in community settings. Social Science and Medicine 61, 2600-2610

Howden-Chapman, P., Pierse, N., Nicholls, S., Gillespie-Bennett, J., Viggers, H., Cunningham, M., et al. (2008). Effects of improved home heating on asthma in community dwelling children: randomised community study. British Medical Journal, 337.

Howden-Chapman, P., Signal, L., \& Crane, J. (1999). Housing and health in older people, ageing in place. Social Policy Journal of New Zealand, 13, $14-30$.

Howden-Chapman, P., Viggers, H., Chapman, R., O'dea, D., Free, S., \& O'Sullivan, K. (2009). Warm homes: Drivers of the demand for heating in the residential sector in New Zealand. Energy Policy, 37(9), 33873399.

Huston, P. (2008). Heat Pump Energy Efficiency Performance Installation \& Maintenance. irhace(September/October).

Hutchinson, E., Wilkinson, P., Hong, S., Oreszczyn, T., \& Group, t. W. F. S. (2006). Can we improve the identification of cold homes for targeted home energy-efficiency improvements. Applied Energy, 83, 1198-1209.

IEA (2009). Towards a more energy efficient future: Applying indicators to enhance energy policy.

Immigration New Zealand (2009). Immigration New Zealand Statistics Retrieved 24 September 2009

Indu, R. P., \& Rangan, B. (2007). Methodology for estimation of potential for 
solar water heating in a target area. Solar Energy, 81(2), 162.

Intergovernmental Panel on Climate Change (2007). Climate Change 2007:

The Physical Sciences Basis - Summary for Policymakers Working

Group 1.

International Energy Agency (2005). Energy Policies of IEA Countries: Australia Review. Paris: OECD/IEA.

international Energy Agency (2005). Energy Policies of IEA Countries: Norway 2005 Review. Paris: IEA/OECD.

International Energy Agency (2006). Energy Policies of IEA Countries: Denmark 2006 Review. Paris: OECD/IEA.

international Energy Agency (2006). Energy Policies of IEA Countries: The United Kingdom 2006 Review. Paris: OECD/IEA.

International Energy Agency (2007). Energy Use in the New Millennium: Trends in IEA Countries. Paris.

International Energy Agency (2007). Information Paper: Experience with energy efficiency regulations for electrical equipment

International Energy Agency (2007). Mind the Gap: Quantifying PrincipalAgent Problems in Energy Efficiency. Paris: OECD/IEA.

International Energy Agency (2008). Energy Policies of IEA Countries: Sweden 2008 Review. Paris: OECD/IEA.

International Energy Agency (2008). Energy Technology Perspectives 2008: Scenarios \& Strategies to 2050. Paris: OECD/IEA.

International Energy Agency (2008). IEA energy efficiency policy recommendations to the G8 2007 Summit Helligendamm. Paper presented at the G8 2007 Summit

International Energy Agency (2008). Promoting Energy Efficiency Investments. Paris.

International Energy Agency (2009). Gadgets and Gigawatts: Policies for Energy Efficient Electronics. Paris: OECD/IEA.

International Energy Agency (2009). Towards a more energy efficient future: Applying indicators to enhance energy policy In IEA (Ed.). Paris: OECD/IEA.

Isaacs, N., Camilleri, M. J., French, L. J., Pollard, A. R., Saville-Smith, K., Fraser, R., et al. (2006). Energy Use in New Zealand Households: Report on the Year 10 Analysis for the Household Energy End-use Project (HEEP). Wellington: Building Research Association New Zealand.

Isaacs, N. P. (2004). Supply Requires Demand - Where does all of New Zealand's Energy Go? Paper presented at the Royal Society of New Zealand.

Isaacs, N. P. (2007). The Need for new electricity generation - The role of Demand.

Isaacs, N. P., Camilleri, M. J., \& Pollard, A. R. (2004). Household Energy Use in a Temperate Climate. Paper presented at the American Council for Energy Efficient Economy (ACEEE) Summer study on Energy Efficiency in Buildings.

Isaacs, N. P., Saville-Smith, K., Amitrano, L., Camilleri, M. J., French, L. J., Pollard, A. R., et al. (2004). Energy, Income and Well-being - Where is the Link? Paper presented at the The Social Policy, Research and Evaluation Conference. 
Ismet Ugursal, V., \& Fung, A. S. (1996). Impact of appliance efficiency and fuel substitution on residential end-use energy consumption in Canada. Energy and Buildings, 24(2), 137-146.

Jaber, J. O., Mamlook, R., \& Awad, W. e. (2005). Evaluation of energy conservation programs in residential sector using fuzzy logic methodology. Energy Policy, 33(10), 1329-1338.

Johansson, P., Nylander, A., \& Johnsson, F. (2006). Electricity dependency and $\mathrm{CO} 2$ emissions from heating in the Swedish building sector-Current trends in conflict with governmental policy? Energy Policy, 34(17), 3049-3064.

Jollands, N., Waide, P., Ellis, M., Onoda, T., Laustsen, J., Tanaka, K., et al. (2010). The 25 IEA energy efficiency policy recommendations to the G8 Gleneagles Plan of Action. Energy Policy, In Press, Corrected Proof.

Jones, K., \& Harrison, B. (2007). The impact of Changing TV technologies and Market Trends on the Energy Consumption on TVs and the need for a better TV Energy Test Method. Paris: International Energy Agency.

Kaiser, M., \& Pulsipher, A. (2003). LIHEAP reconsidered. Energy Policy, 31, 1441-1458.

Kander, A., \& Lindmark, M. (2006). Foreign trade and declining pollution in Sweden: a decomposition analysis of long-term structural and technological effects. Energy Policy, 34(13), 1590-1599.

Kannan, R., \& Strachan, N. (2009). Modelling the UK residential energy sector under long-term decarbonisation scenarios: Comparison between energy systems and sectoral modelling approaches. Applied Energy, 86, 416-428.

Kenneth, B. M., III, \& Ronald, S. (2001). Economic development and end-use energy demand. The Energy Journal, 22(2), 77.

Kerkhof, A. C., Benders, R. M. J., \& Moll, H. C. (2009). Determinants of variation in household $\mathrm{CO} 2$ emissions between and within countries. Energy Policy, 37(4), 1509-1517.

Kettering, M. (2001). Cradle to Grave: The Environmental Impacts from Coal. Boston: Clean Air Task Force.

Kim, H. C., Keoleian, G. A., \& Horie, Y. A. (2006). Optimal household refrigerator replacement for life cycle energy greenhouse gas emissions and cost Energy Policy

34, 2310-2323.

Kirchhoff, S. (2009). How will the $\$ 787$ billion stimulus package affects you? USA Today,

Komiyama, R., \& Marnay, C. (2008). Japan's Residential Energy Demand Outlook to 2030 Considering Energy Efficiency Standards "Top Runner Approach". LBNL-292E,

Kondo, Y., Moriguchi, Y., \& Shimizu, H. (1998). CO2 Emissions in Japan: Influences of imports and exports. Applied Energy, 59(2-3), 163-174.

Koomey, J. G., Mahler, S. A., Webber, C. A., \& McMahon, J. E. (1999). Projected regional impacts of appliance efficiency standards for the US residential sector. Energy, 24(1), 69-84.

Koomey, J. G., Webber, C. A., Atkinson, C. S., \& Nicholls, A. (2001). Addressing energy-related challenges for the US buildings sector: 
results from the clean energy future study. Energy Policy, 29, 12091221.

Labandeira, X., Labeaga, J., \& Rodríguez, M. (2006). A residential energy system for Spain. Energy Journal, 27(2), 87-111.

Lah, O. (2009). The Climate for Change. Victoria University, Wellington. Lefèvre, N., de T'Serclaes, P., \& Waide, P. (2006). Barriers to Technology Diffusion: The Case of Compact Fluorescent Lamps

Lenzen, M., Weir, M., Cohen, C., Hayami, H., Pachauri, S., \& Schaeffer, R. (2006). A comparative multivariate analysis of household energy requirements in Australia, Brazil, Denmark, India and Japan. Energy, 31(2-3), 181-207.

Lindén, A.-L., Carlsson-Kanyama, A., \& Eriksson, B. (2006). Efficient and inefficient aspects of residential energy behaviour: What are the policy instruments for change? Energy Policy, 34(14), 1918-1927.

Lindenberg, S., \& Steg, L. (2007). Normative, gain and hedonic goal frames guiding environmental behaviour. Journal of Social issues, 63, 117-137.

Lindenberger, D., \& Kummel, R. (2002). Energy-Dependent Production Functions and the Optimization Model 'PRISE' of Price-Induced Sectoral Evolution. International Journal of Applied Thermodynamics, 5(3), 101-107.

Lloyd, B. (2006). Fuel Poverty in New Zealand. Social Policy Journal of New Zealand(27).

Lloyd, B. (2007). The Commons revisited: the Tragedy continues. Energy Policy, 35, 5806-5818.

Lloyd, B., Bishop, T., \& Callau, M. (2007). Retrofit alternatives for State Houses in Cold Regions of New Zealand: Report No 2. Dunedin: University of Otago.

Lo, S. N. G., Norton, B., \& Mannis, A. (2001). Domestic Energy use and air quality; a case study of the city of Belfast. Applied Energy, 68, 1-18.

Loveday, D. L., Bhamra, T., Tang, T., Haines, V. J. A., Holmes, M. J., \& Green, R. J. (2008). The energy and monetary implications of the [']24/7' [']always on' society. Energy Policy, 36(12), 4639-4645.

Lowe, R., \& Oreszczyn, T. (2008). Regulatory standards and barriers to improved performance for housing. Energy Policy, 36, 4475-4481.

Macalister, T. (2009, 05 February 2009). Sweden lifts ban on nuclear power Guardian,

Mackay, D. (2009). Sustainable Energy - without the hot air

Mäenpää, I., \& Siikavirta, H. (2007). Greenhouse gases embodied in the international trade and final consumption of Finland: An input-output analysis. Energy Policy, 35(1), 128-143.

Manasouri, I., Newborough, M., \& Probert, D. (1996). Energy Consumption in UK Households: Impact of Domestic Electrical Appliances. Applied Energy, 54(3), 211-285.

Martinot, E., \& Borg, N. (1998). Energy-efficient lighting programs: Experience and lessons from eight countries. Energy Policy, 26(14), 1071-1081.

McChesney, I., Cox-Smith, I., \& Amitrano, L. (2008). Thermal insulation in New Zealand homes: A Status Report.

Melhuish, M. (2006). Energy and Sustainable Development in New Zealand. Sustainable Energy Watch 2005/2006.

Mills, E. (1991). Evaluation of European lighting programmes : Utilities finance 
energy efficiency. Energy Policy, 19(3), 266-278.

Mills, E. (2004). Inter-comparison of North American residential energy analysis tools. Energy and Buildings, 36(9), 865-880.

Milne, G., \& Boardman, B. (2000). Making cold homes warmer: the effect of energy efficiency improvements in low-income homes $A$ report to the Energy Action Grants Agency Charitable Trust. Energy Policy, 28(6-7), 411-424.

Ministry for the Environment (2005). Warm Homes Technical Report: Home Heating Methods and Fuels of New Zealand.

Ministry for the Environment (2008). New Zealand's Greenhouse Gas Inventory 1990 - 2006: An overview. Wellington.

Ministry of culture and heritage (2009). Digital Broadcasting Decisions and Announcements, from http://www.mch.govt.nz/publications/digitaltv/\#analogue

Ministry of Culture and Heritage (2009). Digital Futures: Planning for Digital Television and New Uses

Ministry of Economic Development (2005). Chronology of New Zealand Electricity Reform.

Ministry of Economic Development (2009). New Zealand Energy Data File. Wellington.

Mohamed, Z., \& Bodger, P. (2005). Forecasting electricity consumption in New Zealand using economic and demographic variables. Energy, 30, 1833-1843.

Moll, H. C., K, N., Kok, R., Engström, R., Throne-Holst, H., \& Clark, C. (2005). Pursuing more sustainable consumption by analyzing household metabolism in European countries and cities. Journal of Industrial Ecology, 9, 259-275.

Munksgaard, J., \& Pedersen, K. A. (2001). CO2 accounts for open economies: producer or consumer responsibility? Energy Policy, 29(4), 327-334.

Murtishaw, S., Schipper, L., \& Unander, F. (1999). The "Mine/Your" Method of International Comparison of Carbon Emissions. Paper presented at the 2000 ACEEE Summer Study on Energy Efficiency in Buildings.

Nakagami, H. (1996). Lifestyle change and energy use in Japan: Household equipment and energy consumption. Energy, 21(12), 1157-1167.

Nakata, T. (2004). Energy-economic models and the environment. Progress in Energy and Combustion Science, 30(4), 417-475.

Nässén, J., \& Holmberg, J. (2005). Energy efficiency--a forgotten goal in the Swedish building sector? Energy Policy, 33(8), 1037-1051.

Nässén, J., Sprei, F., \& Holmberg, J. (2008). Stagnating energy efficiency in the Swedish building sector - Economic and organisational explanations. Energy Policy, 36, 3814-3822.

National Audit Office (2007). Cost-effectiveness analysis in the 2006 Climate Change Programme Review. London.

National Audit Office (2008). Programmes to reduce household energy consumption. London.

National Institute of Water \& Atmospheric Research (2009). New Zealand national climate summary - the year 2008. Climate Summaries, 2009, from http://www.niwa.co.nz/_data/assets/pdf_file/0008/81890/aclimsum_08 
.pdf

Natural Resources Canada (2009). Improving Energy Performance in Canada: Report to Parliament under the Energy Efficiency Act for the Fiscal Year 2007 - 2008.

Natural Resources Defense Council (2005). Televisions: Active Mode Energy Use and Opportunities

Nerberg, S. (2006). Sustainability begins at home. Azure: Design Architecture \& Art, 22(16), 78-79.

Nesbakken, R. (1998). Price Sensitivity of Residential Energy Consumption in Norway. Discussion papers No. 232 September 1998 Statistics Norway, Research Department,

Nilssen, P. (2003). Household energy use and the environment-a conflicting issue. Applied Energy, 76, 189-196.

Nimmo, K., \& McChesney, I. (2007). Heat Pump Survey - Report 3: Winters 2005 and 2006. Christchurch: Community Energy Action.

Nomura, N., \& Akai, M. (2004). Willingness to pay for green electricity in Japan as estimated through contingent valuation method. Applied Energy, 78, 453-463.

O'Doherty, J., Lyons, S., \& Tol, S. J. (2008). Energy-using appliances and energy-saving features: Determinants of ownership in Ireland. Applied Energy, 85, 650-662.

OECD (2009). OECD Fact Book 2009: Economic, Environmental and Social Statistics. Paris.

Oikonomou, V., Riethergen, M., \& Patel, M. (2007). An ex-ante evaluation of a White Certificates schemes in The Netherlands: A case study for the household sector. Energy Policy, 35, 1147-1163.

Ostendorp, P., Foster, S., \& Calwell, C. (2005). Televisions: Active Mode Energy Use and Opportunities for Energy Savings.

Owen, P. (2006). The Rise of the Machines: A review of Energy using Products in the home from the 1970s to today. London: Energy Saving Trust.

Owen, P. (2007). The ampere strikes back: How consumer electronics taking over the world. London: Energy Savings Trust.

PA Consultants (2001). Valuing New Zealand's Clean Green Image. Wellington.

Page, I. (2006). Energy use takeback and home insulation.

Parliamentary Office of Science and Technology (2005). Household Energy Efficiency. London.

Peeters, L., Van der Veken, J., Hens, H., Helsen, L., \& D'Haeseleer, W. (2008). Control of heating systems in residential buildings: Current practice. Energy and Buildings, 40(8), 1446-1455.

Pérez-Lombard, L., Ortiz, J., \& Pout, C. (2008). A review on buildings energy consumption information. Energy and Buildings, 40(3), 394-398.

Peters, G. P., \& Hertwich, E. G. (2006). Pollution embodied in trade: The Norwegian case. Global Environmental Change, 16(4), 379-387.

Pichert, D., \& Katsikopoulos, K. (2007). Green defaults: Information presentation and pro-environmental behaviour. Journal of Environmental Psychology(28), 63-73.

Pollard, A. R. (2008). Getting Energy Smart. Build (August/September), 53.

Poortinga, W., Steg, L., Vlek, C., \& Wiersma, G. (2003). Household 
preferences for energy-saving measures: A conjoint analysis. Journal of Economic Psychology, 24, 49-64.

Power, A. (2008). Does demolition or refurbishment of old and inefficient homes help to increase our environmental, social and economic viability? Energy Policy, 36, 4487-4501.

Prime Minister of Australia (2009). \$42 Billion Nation Building and Jobs Plan Retrieved 18 June 2009, 2009, from http://www.pm.gov.au/media/Release/2009/media_release_0784.cfm

Rabin, M. (1998). Psychology and Economics. Journal of Economic Literature, 36(1), 35.

Reinders, A. H. M. E., Vringer, K., \& Blok, K. (2003). The direct and indirect energy requirement of households in the European Union. Energy Policy, 31(2), 139-153.

Reiss, P., \& White, M. (2008). What changes energy consumption? Prices and public pressures. Rand Journal of Economics, 39(3), 636-663.

Richardson, I., Thomson, M., Infield, D., \& Delahunty, A. (2009). Domestic lighting: A high-resolution energy demand model. Energy and Buildings, 41, 781-789.

Robert, B., \& Denzil, G. F. (2000). Residential end-use electricity demand: Results from a designed experiment. The Energy Journal, 21(2), 51.

Roberts, S. (2008). Altering existing buildings in the UK. Energy Policy, 36, $4482-4486$.

Roberts, S. (2008). Demographics, energy and our homes. Energy Policy, 36, 4630-4632.

Roberts, S. (2008). Energy, equity and the future of the fuel poor. Energy Policy, 36, 4471-4474.

Rockström, J., Steffen, W., Noone, K., Parsson, A., Chapin, F., Lambin, E., et al. (2009). Planetary Boundaries: Exploring the Safe Operating Space for Humanity. Ecology and Society, 14(2).

Rosas-Flores, J. A., \& Gálvez, D. M. (2010). What goes up: Recent trends in Mexican residential energy use. Energy, In Press, Corrected Proof.

Rosenquist, G., McNeil, M., Iyer, M., Meyers, S., \& McMahon, J. (2006). Energy efficiency standards for equipment: Additional opportunities in the residential and commercial sectors. Energy Policy, 34, 3257-3267.

Rudge, J., \& Gilchrist, R. (2005). Excess winter morbidity among older people at risk of cold homes: a population-based study in a London borough Journal of Public Health

Sanne, C. (2000). Dealing with environmental savings in a dynamical economy - how to stop chasing your tail in the pursuit of sustainability. Energy Policy, 28, 487-495.

Sartori, I., Wachenfeldt, B. J., \& Hestnes, A. G. (2009). Energy demand in the Norwegian building stock: Scenarios on potential reduction. Energy Policy, 37(5), 1614-1627.

Schellnhuber, H. J. (2008). Global warming: Stop worrying, start panicking? . Proceedings of the National Academy of Sciences, 105, 14239 - 14240.

Schipper, L., \& Hawk, D. (1991). More efficient household electricity-use: An international perspective. Energy Policy.

Schipper, L., \& Ketoff, A. (1989). Energy efficiency - the perils of a plateau. Energy Policy, 17(6), 538-542.

Schipper, L., Unander, F., Marie-Lilliu, C., Walker, I., \& Murtishaw, S. (2000). 
Indicators of Energy Use and Efficiency in New Zealand: An International Perspective: Comparison of Trends Through 1995.

Schweiker, M., \& Shukuya, M. (2009). Comparison of theoretical and statistical models of air-conditioning-unit usage behaviour in a residential setting under Japanese climatic conditions. Building and Environment, 44(10), 2137-2149.

Schweitzer, M., \& Tonn, B. (2003). Non-energy benefits of the US Weatherization Assistance Program: a summary of their scope and magnitude. Applied Energy, 76, 321-335.

Schweizer-Ries, P. (2008). Energy sustainable communities: Environmental psychological investigations. Energy Policy, 36, 4126-4135.

Shannon, S., Lloyd, B., Roos, J., \& Kohlmeyer, J. (2003). Impact of Housing on Health in Dunedin NZ (No. EVH3). Otago: University of Otago

Shimoda, Y., Asahi, T., Taniguchi, A., \& Mizuno, M. (2007). Evaluation of cityscale impact of residential energy conservation measures using the detailed end-use simulation method. Energy, 32(9), 1617-1633.

Shorrock, L., \& Utley, J. (2003). Domestic energy fact file 2003.

Siller, T., Kost, M., \& Imboden, D. (2007). Long-term energy savings and greenhouse gas emission reductions in the Swiss residential sector. Energy Policy, 35, 529-539.

Sintef (2008). New knowledge about power consumption distribution Retrieved 21 September, 2009, from http://www.sintef.no/Home/Petroleum-and-Energy/SINTEF-EnergyResearch/Xergi/Xergi-2008/New-knowledge-about-powerconsumption-distribution/

Sorrel, S. (2009). Jevons' Paradox revisited: The evidence for backfire from improved energy efficiency. Energy Policy, 37, 1456-1469.

Sorrel, S., Dimitropoulos, J., \& Sommerville, M. (2009). Empirical estimates of the direct rebound effect: A review. Energy Policy

37, 1356-1371.

Sowmy, D. S., \& Prado, R. T. A. (2008). Assessment of energy efficiency in electric storage water heaters. Energy and Buildings, 40(12), 21282132.

Spees, K., \& Lave, B. (2007). Demand Response and Electricity Market Efficiency. The Electricity Journal, 20(3), 69-85.

St. George, A. (2009). Is Online really changing TV? NZ marketing 28. Statistics New Zealand (2005). New Zealand in the OECD. Wellington.

Statistics New Zealand (2008). Internet Survey Provider Survey: March 2008 Retrieved 16 October 2009, 2009, from http://www.stats.govt.nz/browse_for_stats/industry_sectors/information _technology_and_communications/InternetServiceProviderSurvey_HO TPMar08.aspx

Statistics New Zealand (2009). Subnational Family and Household Projections: 2006(base) - 2031 - Hot Off the Press Retrieved 03 November 2009, from http://search.stats.govt.nz/search?w=household\%20projections\&af=cty pe\%3Astatistics

Statistics New Zealand (2009). Top 20 Statistics Retrieved 10 November 2009, from http://www.stats.govt.nz/top-20-statistics.aspx

Statistics Norway (2009). Continued decline in newspaper reading. Norwegian 
media barometer 2008 Retrieved 10 November, 2009, from http://www.ssb.no/english/subjects/07/02/30/medie_en/

Steg, L. (2008). Promoting household conservation. Energy Policy, 2008(36), 4449-4453.

Steg, L., Dreijerink, L., \& Abrahamse, W. (2005). Factors influencing the acceptability of energy policies: A test of VBN theory. Journal of Environmental Psychology, 25(4), 415-425.

Stern, P. (2005). Understanding Individuals' Environmentally Significant Behaviour. Environmental Law Reporter, 35, 10785-10790.

Stern, P. (2006). Stern Review: The Economics of Climate Change. from www.hm-treasury.gov.uk/sternreview.

Stern, P., Dietz, T., Abel, T., Guagnano, G., \& Kalof, L. (1999). A Vaue-BeliefNorm Theory of Support for Social Movements: The case of Environmentalism. Human Ecology Review, 6(2).

Stern, P. C. (2000). Towards a coherent theory of environmentally significant behaviour Journal of Social Issues, 56, 407 - 424.

Stokes, M., Rylatt, M., \& Lomas, K. (2004). A simple model of domestic lighting demand. Energy and Buildings, 36(2), 103-116.

Stroombergen, A., Tait, A., Patterson, K., \& Renwick, J. (2006). The relationship between New Zealand's climate, energy, and the economy to 2025. New Zealand Journal of Social Sciences Online, 1, 139-160.

Swan, L. G., Ugursal, V. I., \& Beausoleil-Morrison, I. (2010). Occupant related household energy consumption in Canada: Estimation using a bottomup neural-network technique. Energy and Buildings, In Press, Corrected Proof.

Swedish Energy Agency (2006). Discussion paper on Market Transformation Strategy: Compact Fluorescents in Residential Lighting Discussion Paper.

Television New Zealand (2009). Insulation, clean heating more available

Thaler, R., \& Sunstein, C. (2008). Nudge: Improving decisions about health, wealth and happiness. London: Penguin Books Ltd.

The Ministry of Environment (Denmark) (2007). Denmark (The Ministry of Environment): Decoupling. Paper presented at the Asia Europe Meeting April 24 - 26, 2007.

The Nielsen Company (2009). High Speed Internet Sends Aussies To Online Radio, TV. Nielsenwire,

The Nielsen Company (2009). More than half of the homes in US have three or more TVs Nielsenwire

The Nielsen Company (2009). Three Screen Report: Media Consumption and Multi-tasking Continue to Increase Across TV, Internet and Mobile.

Retrieved from http://it.nielsen.com/site/documents/A2M2 3Screens 1Q09 FINAL.pdf

The Nielsen Company (2009). Viewing of Online Video Streams Up 26\% in October. Nielsenwire,

Tommerup, H., \& Svendsen, S. (2006). Energy savings in Danish residential building stock. Energy and Buildings, 38(6), 618-626.

Tonn, B., \& Eisenberg, J. (2007). The aging US population and residential energy demand. Energy Policy, 35(1), 743-745.

T'Serclaes, P. (2007). Financing Energy Efficient Homes: Existing policy responses to financial barriers. IEA Information Paper, 
Tukker, A., Poliakov, E., Heijungs, R., Hawkins, T., Neuwahl, F., RuedaCantuche, J. M., et al. (2009). Towards a global multi-regional environmentally extended input-output database. Ecological Economics, 68(7), 1928-1937.

Turiel, I., Atkinson, B., Boghosian, S., Chan, P., Jennings, J., Lutz, J., et al. (1997). Advanced technologies for residential appliance and lighting market transformation. Energy and Buildings, 26(3), 241-252.

UMR Research (2006). Electrical and Electronic Equipment Survey January 2006.

Unander, F., Ettestøl, I., Ting, M., \& Schipper, L. (2004). Residential energy use: an international perspective on long-term trends in Denmark, Norway and Sweden. Energy Policy, 32(12), 1395-1404.

United Nations (2009). Millenium Development Goals Retrieved 21 September, 2009, from http://www.undp.org/mdg/basics.shtml

Urbikain, M. K., \& Sala, J. M. (2009). Analysis of different models to estimate energy savings related to windows in residential buildings. [Article]. Energy and Buildings, 41(6), 687-695.

US Environmental Protection Agency (Unknown). Change the World, Start with Energy Star. Retrieved from http://www.energystar.gov/ia/products/event_toolkit/EventToolkit_Chec kUpGuide.pdf

Vaage, K. (2000). Heating technology and energy use: A discrete/continuous choice approach to Norwegian household energy demand. Energy Economics, 22(6), 649-666.

van den Bergh, J. C. J. M. (2008). Environmental regulation of households: An empirical review of economic and psychological factors. Ecological Economics, 66, 559-574.

Varman, M., Mahlia, T., \& Masjuki, H. (2006). Communication Method for calculating annual energy efficiency improvement of TV sets. Energy Policy, 34, 2429-2432.

Verbeek, P., \& Slob, A. (Eds.). (2006). User Behaviour and Technology Development.

Vine, E. (2008). Strategies and policies for improving energy efficiency programs: Closing the loop between evaluation and implementation. Energy Policy, 36, 3872-3881.

Vringer, K., Aalbers, T., \& Blok, K. (2007). Household energy requirement and value patterns. Energy Policy, 35(1), 553-566.

Vujcich, H. (2008). Valuing Warm Homes - Exploring New Zealanders' Home Heating Choices. Victoria University of Wellington, Wellington.

Waide, P. (2006). Light's Labour's Lost. Paris: International Energy Agency.

Waide, P., Lebot, B., \& Hinnells, M. (1997). Appliance energy standards in Europe. Energy and Buildings, 26(1), 45-67.

Wall, R., \& Crosbie, T. (2009). Potential for reducing electricity demand for lighting in households: An exploratory socio-technical study. Energy Policy, 37, 1021-1031.

Wang, Y., Tannian, F., \& Solano, P. (1985). A Residential Energy Market Model: An Econometric Analysis. Journal of Regional Science, 25(2).

Webb, A. R. (2006). Considerations for lighting in the built environment: Nonvisual effects of light. Energy and Buildings, 38(7), 721-727.

Widén, J., Lundh, M., Vassileva, I., Dahlquist, E., Ellegård, K., \& Wäckelgård, 
E. (2009). Constructing load profiles for household electricity and hot water from time-use data - Modelling approach and validation. Energy and Buildings, 41, 753-768.

Wikdahl, C. (1991). Sweden: Nuclear power policy and public opinion, IAEA Bulletin. Stocksund.

Wilhite, H., Nakagami, H., Masuda, T., Yamaga, Y., \& Haneda, H. (1996). A cross-cultural analysis of household energy use behaviour in Japan and Norway. Energy Policy, 24(9), 795-803.

Willis, R. M., Stewart, R. A., Panuwatwanich, K., Jones, S., \& Kyriakides, A. (2010). Alarming visual display monitors affecting shower end use water and energy conservation in Australian residential households. Resources, Conservation and Recycling, 54(12), 1117-1127.

Wilson, C., \& Dowlatabadi, H. (2007). Models of Decision Making and Residential Energy Use. The Annual Review of Environment and Resources, 32, 169 - 203.

Winton Sustainable Research Strategies (2008). Non-directive Consumer Group Discussion on Purchasing Major Household Appliances with Reference to TVs and ICT. Chatswood: Department of the Environment, Water, Heritage and the Arts.

Wood, G., \& Newborough, M. (2003). Dynamic energy-consumption indicators for domestic appliances: environment, behaviour and design. Energy and Buildings, 35, 821-841.

Woods, J. (2008). What people do when they say they are conserving electricity Energy Policy, 36, 1945-1956.

World Health Organisation (1987). Health impact of low indoor temperatures.

World Nuclear Association (2009). Nuclear Power in the World Today Retrieved September 15, 2009, from http://www.worldnuclear.org/info/inf01.html\#

Wright, A. (2008). What is the relationship between built form and energy use in dwellings? Energy Policy, 36, 4544-4547.

Xu, M., Hu, Z., Wu, J., \& Zhou, Y. (2008). A hybrid society model for stimulating residential electricity consumption. Electrical Power and Energy Systems, 30, 569-574.

Yale University, \& Columbia University (2008). Environmental Performance Index 2008 Retrieved 15 September, 2009, from http://epi.yale.edu/Home

Yohanis, Y. G., Mondol, J. D., Wright, A., \& Norton, B. (2008). Real-life energy use in the UK: How occupancy and dwelling characteristics affect domestic electricity use. Energy and Buildings, 40(6), 1053-1059.

Young, D. (2008). When do energy-efficient appliances generate energy savings? Some evidence from Canada. Energy Policy, 36(1), 34-46. 